


\title{
A T-DAB field trial using a low-mast infrastructure
}

\author{
Roel Schiphorst \\ Signals and Systems Group (SaS) \\ Department of Electrical Engineering, \\ Mathematics and Computer Science (EEMCS) \\ University of Twente
}

November 2006 
Cover: Top section of a C2000 mast with T-DAB band III antennas and microwave dishes. OW. Toerink

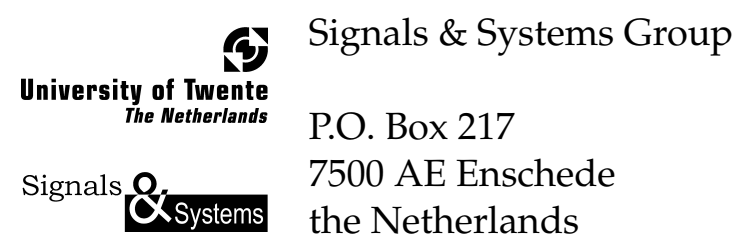

Typesetting: $\mathrm{HT}_{\mathrm{E}} \mathrm{X} 2 \mathrm{e}$

(C) Signals \& Systems Group, Enschede, 2006

No part of this publication may be reproduced by print, photocopy or any other means without the permission of the copyright owner.

ISBN: 90-365-2424-5

version: 1.0 


\section{Samenvatting}

De Universiteit Twente heeft van oktober 2004 tot en met juli 2006 een technische T-DAB pilot uitgevoerd in opdracht van het Ministerie van Economische Zaken. Voor dit project is er in Amsterdam een laagvermogen T-DAB netwerk gebouwd op lage opstelpunten voor zowel band III (kanaal 12B) als de L-band (kanaal LH).

In dit project is aangetoond dat een laagvermogen netwerk bestaande uit lage opstelpunten kan functioneren in een naburig kanaal van een hoogvermogen hoge opstelpunten netwerk. Een gap filler kan de stoorcontouren in het servicegebied van het hoogvermogen hoge opstelpunten netwerk effectief neutralizeren. Andere mogelijke oplossingen zoals een smallere verticale openingshoek van het antenne systeem zijn niet onderzocht. Het minimale vermogen van de gap filler moet $24 \mathrm{~dB}$ lager zijn dan het uitgangsvermogen van het lage opstelpunten netwerk.

Indien er geen gap filler of andere oplossing wordt gebruikt, is er een stoorcontour met een gemiddelde straal van $1 \mathrm{~km}$ waar geen ontvangst mogelijk is van het hoogvermogen hoge opstelpunten netwerk. De stoorcontour rondom een hoogvermogen hoge opstelpunt is niet onderzocht, maar het is aannemelijk dat deze contour vele malen groter is dan de gemeten contour rondom een opstelpunt van het pilot netwerk. Het T-DAB pilot netwerk is gemonteerd op masten van het C2000 TETRA netwerk. De storing van het T-DAB signaal op het TETRA communicatiesysteem is onderzocht door de C2000 organisatie.

Om binnenshuisontvangst te verkrijgen in $95 \%$ van de gebouwen, 
blijkt uit de binnenshuismetingen dat voor band III het verlies $21.9 \mathrm{~dB}$ bedraagt en voor de L-band $25.8 \mathrm{~dB}$. Om deze binnenshuisontvangst te realiseren moet de veldsterkte buitenshuis voor band III minimaal 67.9 $\mathrm{dB} \mu \mathrm{V} / \mathrm{m}$ zijn en voor de L-band $81.9 \mathrm{~dB} \mu \mathrm{V} / \mathrm{m}$ voor $50 \%$ van de locaties en $50 \%$ van de tijd bij een antenne op $1.5 \mathrm{~m}$ hoogte. Deze waarde kan gebruikt worden in coverage planning software.

Zowel het bestaande T-DAB netwerk van de Publieke Omroep alsmede het pilot netwerk (band III en L-band) bieden geen goede binnenshuisdekking. Indien het uitgangsvermogen op ieder opstelpunt wordt verhoogd met $10 \mathrm{~dB}$, dan zullen beide band III netwerken een goede binnenshuisdekking bieden. Natuurlijk is het plaatsen van meer zenderopstelpunten ook een mogelijkheid. Voor de L-band zijn zowel meer opstelpunten als meer uitgangsvermogen nodig om een goede binnenshuisontvangst in Amsterdam te bereiken.

Echter, de huidige internationale afspraken zijn gebaseerd op ontvangst buitenshuis en tijdens de RRC06 conferentie is besloten dat het interferentieniveau aan de buitengrens met $3 \mathrm{~dB}$ en in sommige gevallen tot $6 \mathrm{~dB}$ mag toenemen om ontvangst binnenshuis te realiseren. Daardoor zullen beide netwerktopologieën, om te voldoen aan de RRC06 normen, meer opstelpunten moeten gebruiken voor een goede binnenshuisdekking.

Daarnaast is ook de prestatie van consumenten T-DAB ontvangers geëvalueerd volgens de EN 50248 norm. Voor een keukenradio met een sprietantenne en uitgaande van een stedelijk kanaalmodel, is de typisch haalbare gevoeligheid $39 \mathrm{~dB} \mu \mathrm{V} / \mathrm{m}$ voor band III (wat $4 \mathrm{~dB}$ hoger is dan de minimale gevoeligheid die gespecificeerd is in de Wiesbaden overeenkomst); voor de L-band is dit $51 \mathrm{~dB} \mu \mathrm{V} / \mathrm{m}$ (5 $\mathrm{dB}$ hoger). De mediane consumenten T-DAB ontvanger bereikt deze typisch haalbare gevoeligheid. Echter voor de L-band is de gevoeligheid van de mediane consumenten $\mathrm{T}$-DAB ontvanger $6.5 \mathrm{~dB}$ minder dan de typisch haalbare L-band gevoeligheid. 


\section{Abstract}

Between October 2004 and July 2006, the University of Twente carried out a technical T-DAB field trial in Amsterdam which was commissioned by the Dutch Ministry of Economic Affairs. For this trial, a low-power low-mast T-DAB pilot network was constructed both for band III (channel 12B) and the L-band (channel LH).

This field trial provided evidence that a low-power low-mast network topology can coexist with a high-mast high-power network in an adjacent channel. Using gap fillers, the holes in the service area of the high-mast high-power network can be neutralized effectively. Other possible solutions such as a smaller vertical opening angle of the antenna system were not investigated. The minimum power level of the gap fillers should be $24 \mathrm{~dB}$ below the output power of the low-mast infrastructure.

If no gap fillers or other solution is used, there exists an interference area with a radius of $1 \mathrm{~km}$ on average, where there is no reception of the high-mast high-power network. The interference area around a high-power mast was not investigated, but it is expected that this interference area will be significantly larger. The T-DAB pilot network was mounted on masts of the C2000 TETRA network. The interference of the T-DAB signal on the TETRA system was investigated by the C2000 organization.

For indoor coverage in $95 \%$ of the buildings, the indoor penetration loss measurements revealed that the loss for band III is $21.9 \mathrm{~dB}$ and for L-band $25.8 \mathrm{~dB}$. For indoor coverage, the outdoor field strength has to be $67.9 \mathrm{~dB} \mu \mathrm{V} / \mathrm{m}$ for band III and $81.9 \mathrm{~dB} \mu \mathrm{V} / \mathrm{m}$ for L-band for $50 \%$ of the 
locations and $50 \%$ of the time at an antenna height of $1.5 \mathrm{~m}$. This value can be used in coverage planning software.

Both the existing T-DAB network of the Publieke Omroep and the pilot network (band III and L-band) do not provide good indoor coverage in Amsterdam. If output power is increased by $10 \mathrm{~dB}$ at every transmission site, both band III networks will provide good indoor coverage. Of course, an alternative is to use more transmitter locations. For the L-band more transmitters as well as more output power are required for good indoor reception in Amsterdam.

However, current internati-onal regulations are based on outdoor coverage and it was decided at the RRC06 conference that the interference level at the Dutch border may increase by $3 \mathrm{~dB}$ and it in particular cases by $6 \mathrm{~dB}$ to achieve indoor coverage. So, both the high-mast and low-mast topologies require more transmitter locations to obtain indoor coverage and to be in line with the RRC06 agreement.

In addition, the performance of T-DAB consumer receivers was evaluated according to the EN 50248 norm. For a kitchen radio, assuming an urban channel model and a passive whipe antenna, the typically achievable sensitivity will be $39 \mathrm{~dB} \mu \mathrm{V} / \mathrm{m}$ for band III (which is $4 \mathrm{~dB}$ higher than the minimum sensitivity specified in the Wiesbaden agreement); for the L-band this is $51 \mathrm{~dB} \mu \mathrm{V} / \mathrm{m}$ ( $5 \mathrm{~dB}$ higher). The median T-DAB consumer receiver achieves the typically achievable band III sensitivity. However, for the L-band, the sensitivity of the median T-DAB consumer receiver is $6.5 \mathrm{~dB}$ less than the typically achievable L-band sensitivity. 


\section{Preface}

Many people have contributed in some way to the realization of this report. First of all, I thank Andries Aarden. He wrote most of the Matlab code that converts the raw $\log$ files of the measurement equipment into the figures shown in this report. Moreover, during the hectic coverage and indoor measurement campaign, he organized and processed the gigabytes of data that were measured every day.

My appreciation also goes to Jordy Potman, who set up and performed the consumer T-DAB receiver experiments, Niels Moseley for the specification of the measurement vehicle and for writing software both for the coverage and indoor setup, and Henny Kuipers and Geert-Jan Laanstra for the construction of the indoor unit and measurement vehicle and for performing the antenna roundness measurements on the turntable. My acknowledgements also go to Harm Cronie for implementing the COST 207 channel models , Klaas Hofstra for testing the L-band receivers, Marnix Heskamp for writing the first version of the Matlab scripts, Anneke van Essen-Rekers for taking care of most of the administrative work and Fokke Hoeksema for the interesting discussions about this project.

I am also grateful to Arnaud Paagman and Klaas Tutelaers for carrying out the coverage measurements with the measurement vehicle, sometimes at impossible times. My appreciation also goes to Carlo Splint, Leon Broeren, Tijmen Hommes, Michiel van den Heuvel, Mathijs Kreeft, Steffen Smit, Marcel Danen and Arnaud Paagman for doing the indoor measurement campaign in a 7-day per week scheme.

I thank Corinne Hamming of the ANP (Netherlands national news 
agency) for the photo reports which we broadcasted in our pilot network. I also appreciate the hospitality of Herbert Visser for allowing the university to do the first indoor measurement trial in his house and for the music content of his radio station, $100 \% \mathrm{NL}$, which we used in the field trial. I am also grateful to the Dutch manufacturers and importers of T-DAB consumer radios for providing the university with T-DAB receivers; Sander Tinnemans of Music Matters, Henk de Boer of Blaupunkt, Taco Potze of i.Tech, Henk Graat of Freesat, Jan Best of Trinloc and Gert-Jan Duijn of Rebox.

My appreciation also goes to the members of the Technical Advisory Group (TBG), Toon Strijbosch of the Ministry of Economic Affairs, Fernand Pors of the Radiocommunications Agency Netherlands, Henk Milius of Broadcast Partners, Willem Toerink of db Europe, Willem van Ooijen of Nozema, Hans Bakhuizen of the Publieke Omroep, Ruud Vader of DigiRadio and Remko Welling of the C2000 organization for their fruitful comments during the TBG meetings. I also want to thank Louis Pierpont of Radiocommunications Agency for his support during the project.

In this field trial, the C2000 organization played an important role at different aspects. I acknowledge the support of the C2000 Engineering Bureau Amsterdam for enabling the university to carry out the coverage experiments. Moreover, I am grateful to Theo de Bont and Remko Welling for the interesting discussions and comments about the indoor and coverage measurements.

I am indebted to Willem Toerink for his ideas and the effort that he put into this field trial. Finally, I want to thank Kees Slump for his ideas and comments but and for solving the non-technical challenges in this project.

Roel Schiphorst

Enschede, the Netherlands

November 2006 


\section{Contents}

Samenvatting

Abstract iii

Preface v v

Contents vii

1 Introduction 1

1.1 Research questions . . . . . . . . . . . . . . . . . . . . 1

1.2 Outline . . . . . . . . . . . . . . . . . . . . 4

2 Coverage measurements 5

2.1 Introduction $\ldots \ldots \ldots \ldots \ldots \ldots \ldots$

2.2 Measurement setup . . . . . . . . . . . . . . . 6

2.2 .1 Measurement vehicle . . . . . . . . . . . . . . . . 6

2.2 .2 Pilot network Amsterdam . . . . . . . . . . . . . . . 9

2.2.3 Distribution of the Ensemble Transport Interface

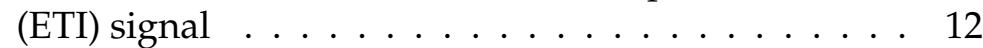

2.2 .4 Pilot ensembles . . . . . . . . . . . . . . . . . . 13

2.3 Calibration . . . . . . . . . . . . . . . . . . . . 14

2.3 .1 Antenna factor . . . . . . . . . . . . . . . . . 15

2.3 .2 Antenna diagram measurement . . . . . . . . . . 17

2.3.3 Difference between $2.65 \mathrm{~m}$ and $1.5 \mathrm{~m}$ antenna height 17 
2.4 Band III results $\ldots \ldots \ldots \ldots \ldots$

2.4 .1 Self interference . . . . . . . . . . . . . . . . 22

2.4 .2 Adjacent channel interference. . . . . . . . . . . . . 22

2.4 .3 Co-channel interference . . . . . . . . . . . . . . . . 24

2.4 .4 Service area . . . . . . . . . . . . . . . . . . . . . . . . . 29

2.4 .5 Redundancy . . . . . . . . . . . . . . . . . . . . . . 31

2.4 .6 Protection levels . . . . . . . . . . . . . . . . . . . . . . 31

2.4 .7 SFN network gain . . . . . . . . . . . . . 34

2.5 L-band results $\ldots \ldots \ldots \ldots \ldots$. . . . . . . . . . . . 38

2.5 .1 Self interference . . . . . . . . . . . . . . . . . 38

2.5 .2 Co-channel interference . . . . . . . . . . . . . . 38

2.5 .3 Service area . . . . . . . . . . . . . . . . . . 40

2.5 .4 Redundancy . . . . . . . . . . . . . . . . . . 43

2.5 .5 Protection levels . . . . . . . . . . . . . . . . . . . 45

2.5 .6 SFN network gain . . . . . . . . . . . . 51

3 Indoor measurements 55

3.1 Introduction . . . . . . . . . . . . . . . . . 55

3.2 Measurement setup . . . . . . . . . . . . . . . 56

3.2 .1 Method . . . . . . . . . . . . . . . . . . . . . 58

3.2.2 Calibration . . . . . . . . . . . . . . . 61

3.3 Results . . . . . . . . . . . . . . . . . . . . . 61

$3.3 .1 \quad$ Example of an indoor measurement . . . . . . . . . 61

3.3 .2 Indoor penetration loss $\ldots \ldots \ldots 66$

\begin{tabular}{lll}
\hline & Consumer receivers & 75
\end{tabular}

4.1 Introduction . . . . . . . . . . . . . . . . . . 75

4.2 Consumer receivers . . . . . . . . . . . . . . . 76

$4.2 .1 \quad$ Audio quality . . . . . . . . . . . . . . . . 77

4.3 Bodyloss measurements . . . . . . . . . . . . . . 78

$4.3 .1 \quad$ Literature . . . . . . . . . . . . . . . . . . . . 78

$4.3 .2 \quad$ Experimental results $\ldots \ldots \ldots$. . . . . . . . . . . . 79

4.3 .3 Discussion . . . . . . . . . . . . . . . . . . . . . . . . 82

4.4 Measurement setup . . . . . . . . . . . . . . . . . 82 
$4.4 .1 \quad$ Setup . . . . . . . . . . . . . . . . . . . . . 82

4.4 .2 Calibration . . . . . . . . . . . . . . . . . . . 84

4.5 Band III results $\ldots \ldots \ldots$

4.5.1 Performance of RadioScape RS-T1000b DAB monitor 84

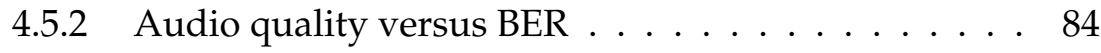

4.5 .3 Antenna factor measurements . . . . . . . . . . . 92

4.5 .4 Sensitivity experiment . . . . . . . . . . . . . . 93

4.5.5 Adjacent channel interference experiment. . . . . . . . 95

4.5.6 Non-adjacent channel interference experiment . . . . 98

4.5 .7 In-band interference experiment $\ldots . . \ldots . . .103$

4.6 L-band results . . . . . . . . . . . . . . . . . . . 107

4.6.1 Performance of RadioScape RS-T1000b DAB monitor 107

4.6 .2 Sensitivity experiment $\ldots \ldots \ldots \ldots$

$4.6 .3 \quad$ In-band interference experiment . . . . . . . . . . . 113

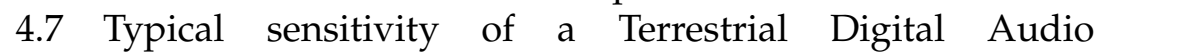

Broadcasting (T-DAB) consumer receiver . . . . . . . . 116

4.7 .1 Typical sensitivity . . . . . . . . . . . . . . . . . . . . 119

$\begin{array}{lll}5 & \text { Summary } & 123\end{array}$

\begin{tabular}{ll}
\hline References & 135
\end{tabular}

\begin{tabular}{ll}
\hline Acronyms & 141
\end{tabular} 



\section{Chapter 1}

\section{Introduction}

In February 2004, the Publieke Omroep started T-DAB broadcasts with traditional radio programs in band III. The Dutch Ministry of Economic Affairs intends to hand out also the licenses for commercial multiplex operators (both band III and L-band). This was the start of the technical T-DAB pilot, and the results of this field trial are presented in this report.

In general, there are three topologies for a T-DAB network: the traditional high-power high-mast network, a low-power low-mast network, and a combination of the two. In this report, the first two network topologies are evaluated and the field strength requirements for indoor coverage are deduced. Besides audio services, the T-DAB standard has evolved into a real multimedia standard including audio, video and data services. Of course, the level of these multimedia services depends also on the T-DAB network topology used.

\subsection{Research questions}

The Dutch Ministry of Economic affairs provided us with the following questions [1]:

- Can a T-DAB network consisting of low-power transmitters with 
Chapter 1. Introduction

antennas mounted at relatively low positions (i.e. the pilot network) co-exist with the current T-DAB network consisting of high-power transmitters mounted at relatively high positions (i.e. Publieke Omroep network)?

- What is the performance of consumer T-DAB receivers currently on the market compared to the reference Wiesbaden receiver?

- What is the indoor penetration loss for band III and the L-band?

- Which network architecture can provide indoor coverage in line with the current Wiesbaden agreement [2]?

Besides these questions, also a number of technical research issues were provided [1] that are summarized below. A number of questions regarding the performance of the Digital Audio Broadcasting (DAB) transmitting system are addressed in an internal document of the C2000 organization. For that reason they are not listed here. Each question is followed by a reference to the appropriate section where the question is answered.

1. Which combinations of T-DAB transmitter and network configurations are possible?

Evaluate these networks on the following aspects:

(a) What is the self-interference of the two networks? (Sections 2.4.1 and 2.5.1)

(b) What is the co-channel interference of the two networks? (Sections 2.4.3 and 2.5.2

(c) What is the adjacent channel interference between the pilot network (channel 12B) and the Publieke Omroep network (channel 12C)? (Section 2.4.2)

(d) What is the ratio of the interference levels at different distances up to $200 \mathrm{~km}$ between high and low positions network topologies? (Sections 2.4.3 and 2.5.2) 
(e) What is the effect of downtilt in combination with smaller vertical opening angles of the antenna on the service area and the different interference levels of both networks? (Not answered in this report.)

(f) What is the influence of shifting the time synchronization on the service area? (Sections 2.4.1 and 2.5.1)

(g) What are the delays of microwave links, line links, internet or satellite connections? And how does this affect the performance of the system? (Section 2.2.3)

(h) How redundant and vulnerable are the networks? (Sections 2.4.5 and 2.5.4)

(i) What is the Inter-Symbol Interference (ISI) in the following area: water, urban and rural areas, with and without temperature inversion? (Section 2.4.3 and Section 2.5.2)

(j) Does flat fading occur, and will it affect the service area? (Sections 2.4.7 and 2.5.6)

(k) What are the optimal protection levels? (Sections 2.4.6 and 2.5.5)

(l) What is the service area? (Sections 2.4.3, 2.4.4, 2.5.2 and 2.5.3)

(m) What is the interference area? (Sections 2.4.3 and 2.5.2)

(n) What is the co-channel re-use distance? (Sections 2.4.3 and 2.5.2)

(o) What is the indoor penetration loss? (Chapter 3)

(p) What is the Single Frequency Network SFN gain? (Sections 2.4.7 and 2.5.6)

2. Which combinations of T-DAB transmitter and network configurations are possible to achieve portable indoor coverage in line with the requirements of the Wiesbaden agreement [2]? (Chapter 5) 
3. What is the performance of a median T-DAB receiver with respect to the sensitivity and adjacent and non-adjacent interferer performance? (Chapter 4)

4. What is the bodyloss of a personal T-DAB receiver? (Section 4.3)

5. How does the performance of the median receiver affect the service and interference area of the T-DAB networks? (Chapter 5)

\subsection{Outline}

This report contains five chapters which cover the following subjects:

Chapter 1 . This introductory chapter.

Chapter 2. This describes experiments carried out with the measurement vehicle in Amsterdam to evaluate the performance of the different network topologies.

Chapter 3 Besides coverage, also the indoor penetration loss of 50 objects has been measured. The results of these measurements are presented in this chapter.

Chapter 4 This chapter describes the $\mathrm{DAB}$ receiver characteristics for consumer equipment intended for terrestrial (and cable) reception, operating in band III and L-band.

Chapter 5 The final chapter summarizes the principal findings of this report. 


\section{Chapter 2}

\section{Coverage measurements}

\subsection{Introduction}

This chapter describes experiments carried out with the measurement vehicle in Amsterdam to evaluate the performance of the pilot network (channel 12B) and the existing network of the Publieke Omroep (channel 12C). In addition, an L-band pilot network has been investigated.

In this report, we assume that the reader is familiar with the properties of a wireless channel. A good general introduction about the wireless channel can be found in [3]. In the past, several T-DAB coverage measurements have been conducted both for band III and the L-band. Most measurements were performed in the first half of the 1990s: for band III, in the UK by the $B B C$ [4, 5, 6], in Finland [7] by the Finnish Broadcasting Company (Yleisradio Oy) and in Bavaria (Germany) [8] by the Bayerischer Rundfunk. A field trial in the L-band has been performed in Canada [9] by the Communications Research Centre. The main focus of these measurement campaigns was to match the received data with simulation models. In this report the focus is on different network topologies, but the results are also compared with the ITU propagation curves ITU-R P.1546-1 [10].

The outline of this chapter is as follows. First, the technical details of the measurement vehicle and pilot network are described. Next, the 


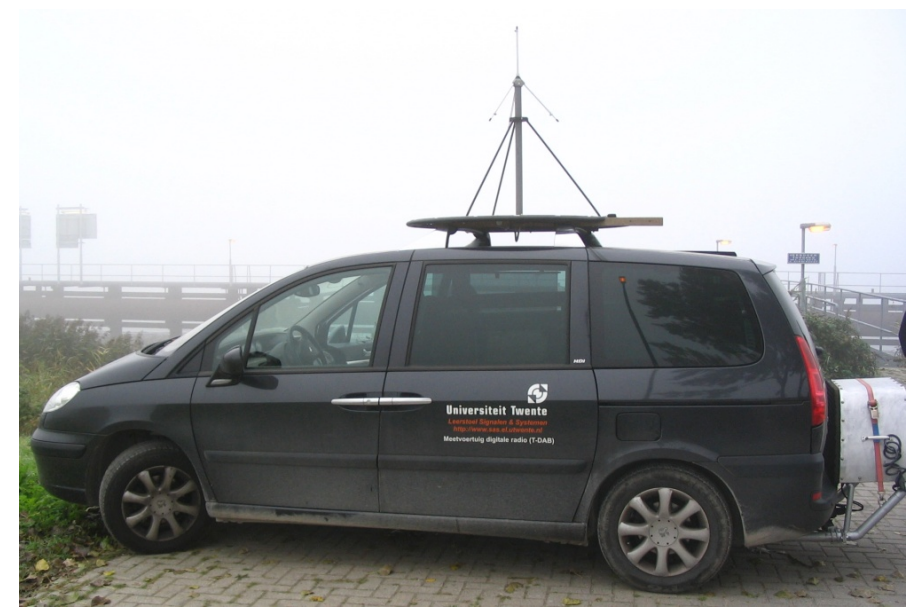

Figure 2.1: Photograph of the measurement vehicle

calibration of the measurement vehicle is discussed. Finally, the results of the experiments are given.

\subsection{Measurement setup}

\subsubsection{Measurement vehicle}

Figure 2.1 shows a photograph of the measurement vehicle, a Peugeot 807, with the band III antenna. Mounting the Radio Frequency (RF) antenna directly on the roof would have resulted in an antenna pattern with a variation of more than $\pm 1 \mathrm{~dB}$. For that reason, a small mast was constructed on the roof of the vehicle. More information about the antenna diagram can be found in Section 2.3.2.

Figure 2.2 depicts the block diagram for the L-band of the measurement equipment inside the vehicle. For field strength measurements we used the Rhode \& Schwarz ESPI, and for qualitative analysis of the DAB signal, we installed two RadioScape RS-T1000b 


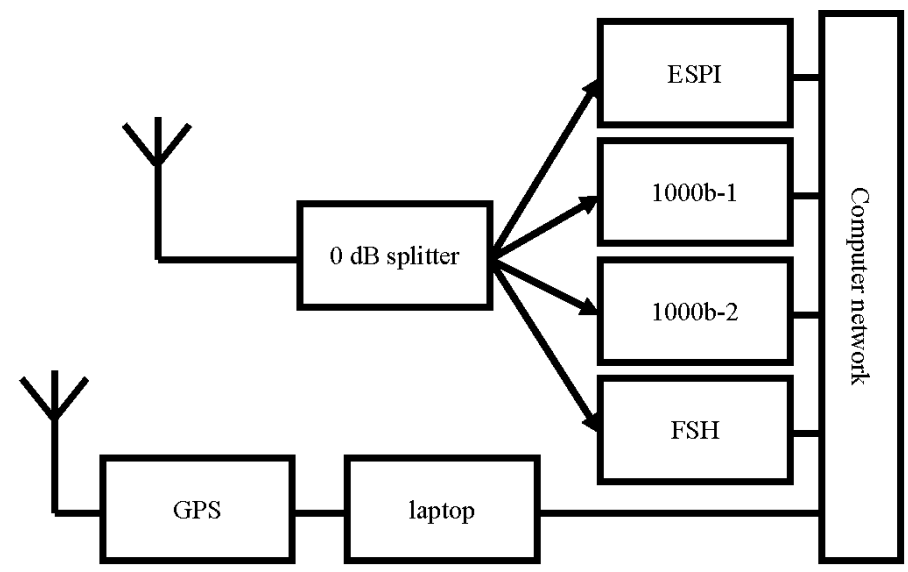

Figure 2.2: Block diagram of the measurement vehicle (L-band configuration)

DAB monitors. The two monitors allow monitoring two subchannels simultaneously, for example with different protection levels. In addition, a Rhode $\mathcal{E}$ Schwarz FSH spectrum analyzer was used to monitor a $10-\mathrm{MHz}$-wide spectrum around the selected multiplex.

Both the ESPI and DAB monitors are connected to the receiving antenna with a $0-\mathrm{dB}$ active splitter. For the band III measurements, an extra ESPI and RS-T1000b monitor was installed to monitor and measure the field strength of the Publieke Omroep multiplex. To log the Global Positioning System (GPS) locations and speed, a Garmin Street pilot 2650 GPS receiver with dead reckoning was connected to a laptop. The laptop is the control center where all equipment can be monitored.

The analog front-end for band III contains a Sirio GPA $\frac{1}{4} \lambda$ ground plane antenna (for the band III measurements) with a 0-dB active splitter which consisted of a BKV 165 amplifier with Merrimac PDM-40-250 splitters and RG $58 \mathrm{RF}$ cable. In addition, we adjusted the gain of the active splitter to compensate for the cable loss.

For the L-band, the European Antennas VOA4-1500/054 antenna was 
Chapter 2. Coverage measurements

used with an ETL active 4-way 0-dB splitter (DIV 04 L1 A-2322 S). Aircell $7 \mathrm{RF}$ cable was selected for the L-band measurements. Also for this band, the cable loss was measured and the field strength values adjusted to correct for this loss $(1.6 \mathrm{~dB})$.

\section{Measurement method}

The measured field strength depends both on time and place. The European Conference of Postal and Telecommunications Adminstrations (CEPT) recommendation Field strength measurements along a route with geographical coordinate registrations was used [11] to estimate the local average mean of the field strength. This is based on the Lee method [12] that prescribes that the field strength measurements should be averaged over $40 \lambda$ to obtain the local mean. To obtain a 1-dB confidence interval, 50 samples have to be measured which also determines the maximum speed of the vehicle.

As existing software could only sample the field strength every 2 seconds, the university developed its own software to speed up to measurements of ESPIs. This software runs on the laptop and configures the ESPIs to the selected channel and a bandwidth of $1.5 \mathrm{MHz}$ with an integration time of $96 \mathrm{~ms}$ (the duration of a DAB frame). The software supports approximately 10 measurements per second. The maximum speed of the vehicle is therefore $40 \mathrm{~km} / \mathrm{h}$. For convenience, we chose a maximum speed of $50 \mathrm{~km} / \mathrm{h}$, which results in a slightly higher confidence interval.

The software also controls and reads out the FSH and GPS receiver. The $\mathrm{DAB}$ monitors are configured by remote desktop. Each monitor logs several parameters, which include time, Bit Error Rate (BER) before and after Forward Error Correction (FEC), Signal-to-Noise Ratio (SNR), null symbol, constellation diagram and Channel Impulse Response (CIR). All $\log$ files are combined offline and processed in Matlab [13]. The GPS log file is the master log file, and the system time in each log file is used to combine all files. The result is a large matrix containing: time, location, field strength, BER values, etc. For example, if the field strength is plotted, 


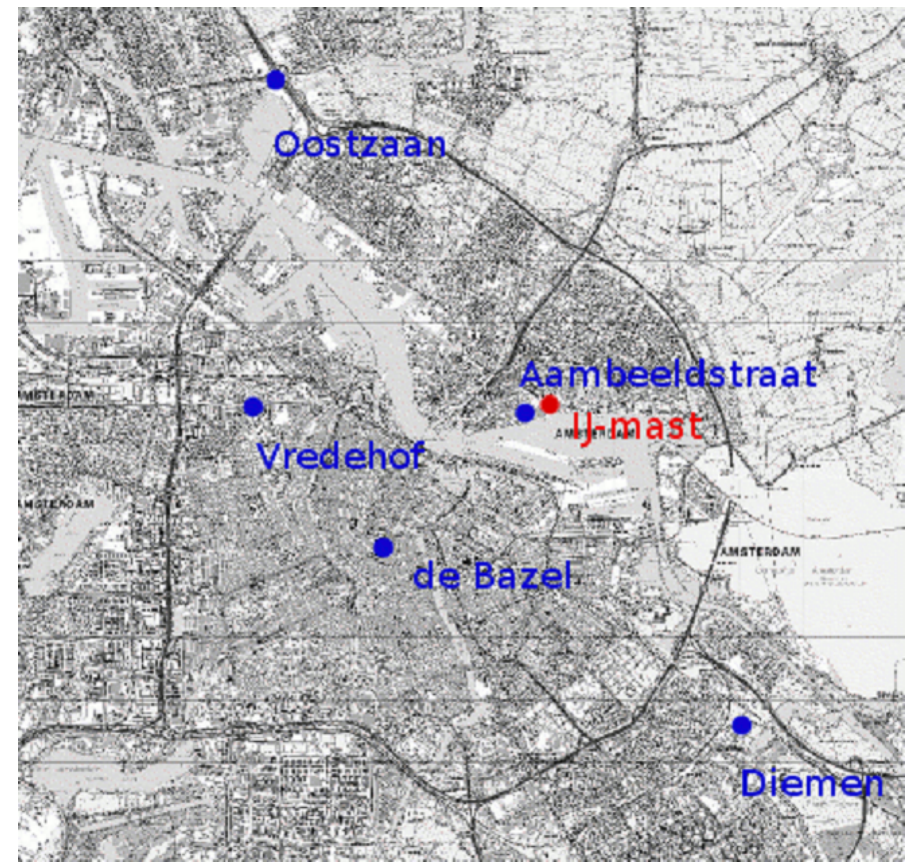

Figure 2.3: Transmitter locations

the values are average per 50 meter.

\subsubsection{Pilot network Amsterdam}

To test both a low mast and high mast infrastructure, a pilot network was built in Amsterdam, which is in the service area of the Publieke Omroep. The Publieke Omroep uses a high mast infrastructure, and one of their transmitters (IJ-mast) is located in Amsterdam. The IJ-mast radiates its main power in the south-east direction with $2 \mathrm{~kW}$ Effective Radiated Power (ERP).

The pilot network consists of four low-mast band III transmitters (Oostzaan, Vredehof, Diemen and Aambeeldstraat) and five L-band 


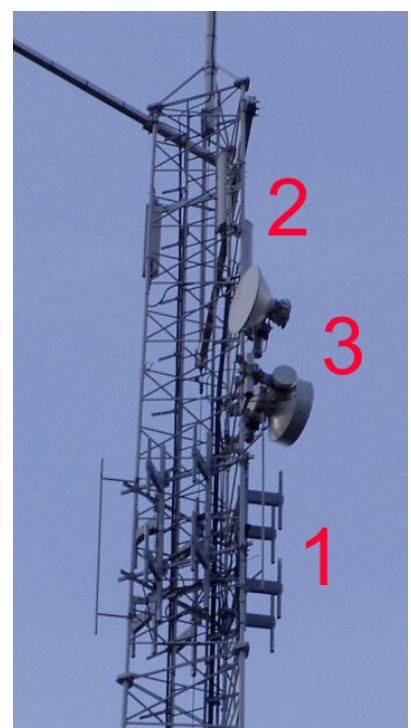

Figure 2.4: Photograph of the top section of the mast where the DAB transmit antennas are mounted: 1 = band III antenna, 2 = L-band antenna and $3=$ microwave dishes. Other installed equipment is property of the C2000 organization. (Photograph taken from http://www.radio.nl/ fmtv.) 


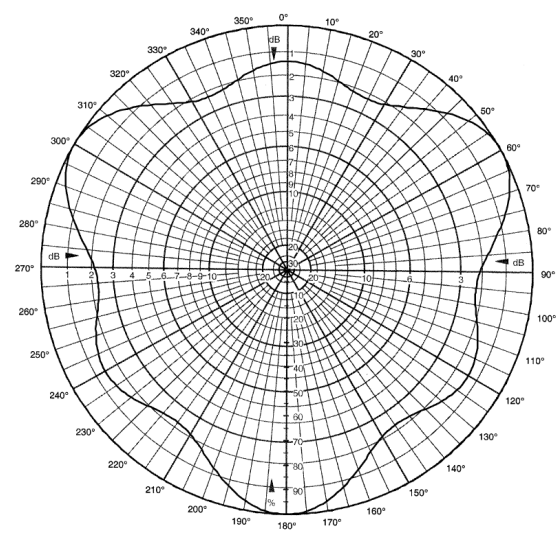

(a) band III

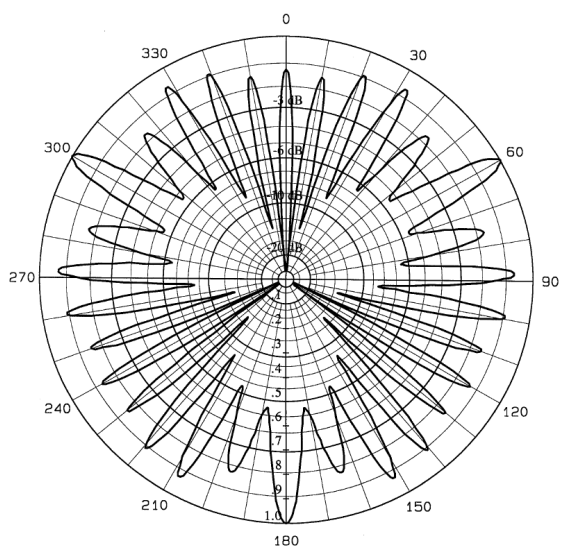

(b) L-band

Figure 2.5: Antenna diagram of the transmit antennas [14]

transmitters (Oostzaan, Vredehof, Diemen, de Bazel and Aambeeldstraat). Figure 2.3 presents a map of Amsterdam with the locations of the transmitters. Each transmitter has an omnidirectional antenna with 200 W ERI for each channel. The antennas are mounted at a height of 42 meters. Figure 2.4 shows a photograph of the top section of the mast and Figure 2.5 depicts the antenna diagram of the antennas used.

A list of Transmitter Identification Information (TII) codes used can be found in Table 2.1.

A block diagram of each transmitter location is given in Figure 2.6 . Basically, each site contains two Plisch SDA 730 transmitters (12B and LH) [15]. Siemens microwave link equipment is used for distribution of the ETI signals. The two ETI signals are generated by two RadioScape broadcast systems. In addition, each location (except Aambeeldstraat and de Bazel) have a gap filler at channel $12 \mathrm{C}$ and a band III combiner in order to assess whether a gap filler can suppress the interference area around the $12 \mathrm{~B}$ pilot

\footnotetext{
${ }^{1}$ This output value (cable losses and antenna gain are included) has been verified by the Radiocommunications Agency Netherlands.
} 
Chapter 2. Coverage measurements

\begin{tabular}{c|c|c} 
Transmitter site & Main ID & Sub ID \\
\hline Pilot network & & \\
Aambeeldstraat & 1 & 1 \\
Diemen & 2 & 2 \\
Vredehof & 3 & 3 \\
de Bazel & 8 & 8 \\
Oostzaan & 5 & 5 \\
PO network (12C) & & \\
IJ-mast & 1 & 9 \\
Haarlem & 1 & 6
\end{tabular}

Table 2.1: TII codes

transmitters. For a more detailed description of the block diagram, see [14].

\subsubsection{Distribution of the ETI signal}

The ETI signal has to be distributed from the multiplex system to the transmitters. In principle, different networks can be used including microwave, line, internet or satellite link. The maximal allowable delay of the ETI signal between multiplex system and transmitter is about 1 second. This value also depends on the installed equipment. In the pilot network, a microwave connection has been used which has a delay much smaller than 1 second. Another option is to use a satellite link which has a delay of approximately $320 \mathrm{~ms}$ [16] including processing delay time. An internet line connection can also be used, although the delay varies in time and depends on both the load in the network and the location of the multiplex system and transmitters. In [17], the maximum delay between two random locations is $360 \mathrm{~ms}$. An internet line connection may thus be used, but it will not have the reliability which is required for a broadcast system. 


\subsubsection{Pilot ensembles}

For our coverage and indoor measurements we used Pseudo Random Bit Sequence (PRBS) data channels at different protection levels. In combination with the RadioScape RS-T1000b this allows both the registration of the BER after FEC and an estimate of the BER before FEC. Besides data channels, also video and audio subchannels were broadcasted. The multiplex in band III was transmitted in mode I and the L-band multiplex in mode IV. Both mode II and mode IV are suitable for the L-band, but the latter allows a larger distance between transmitters [18].

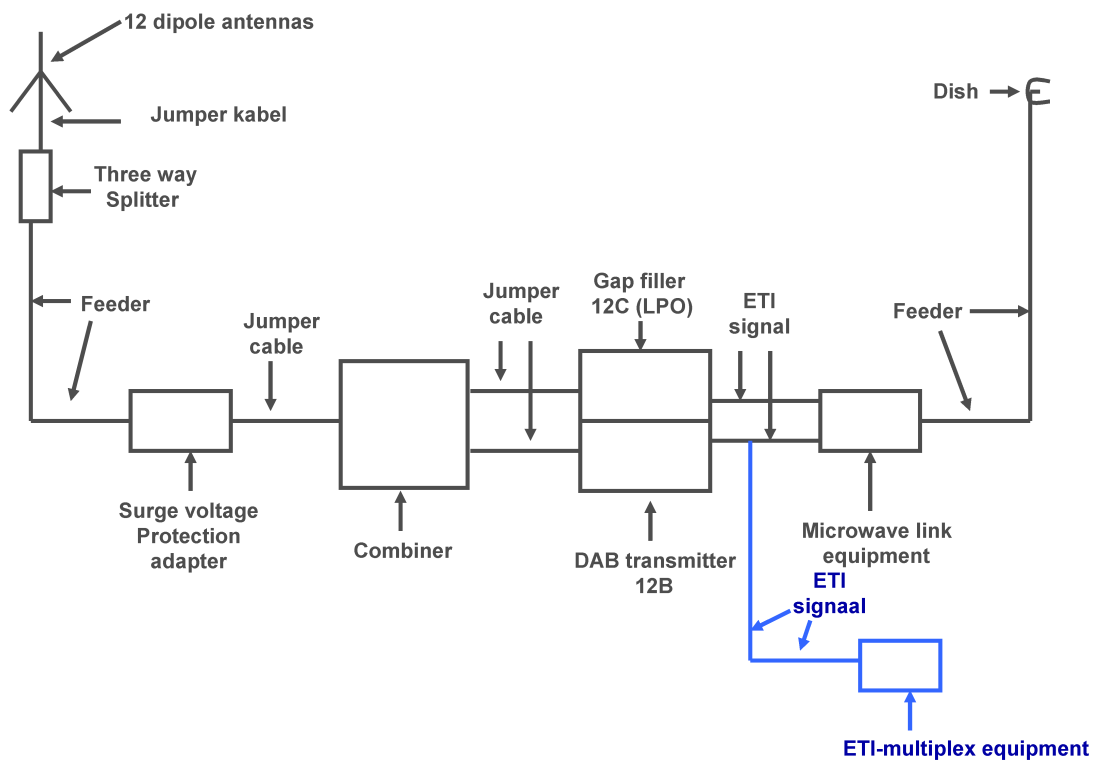

(a) band III

Figure 2.6: Block diagram of a transmitter site. The blue blocks are only at the Aambeeldstraat location. 


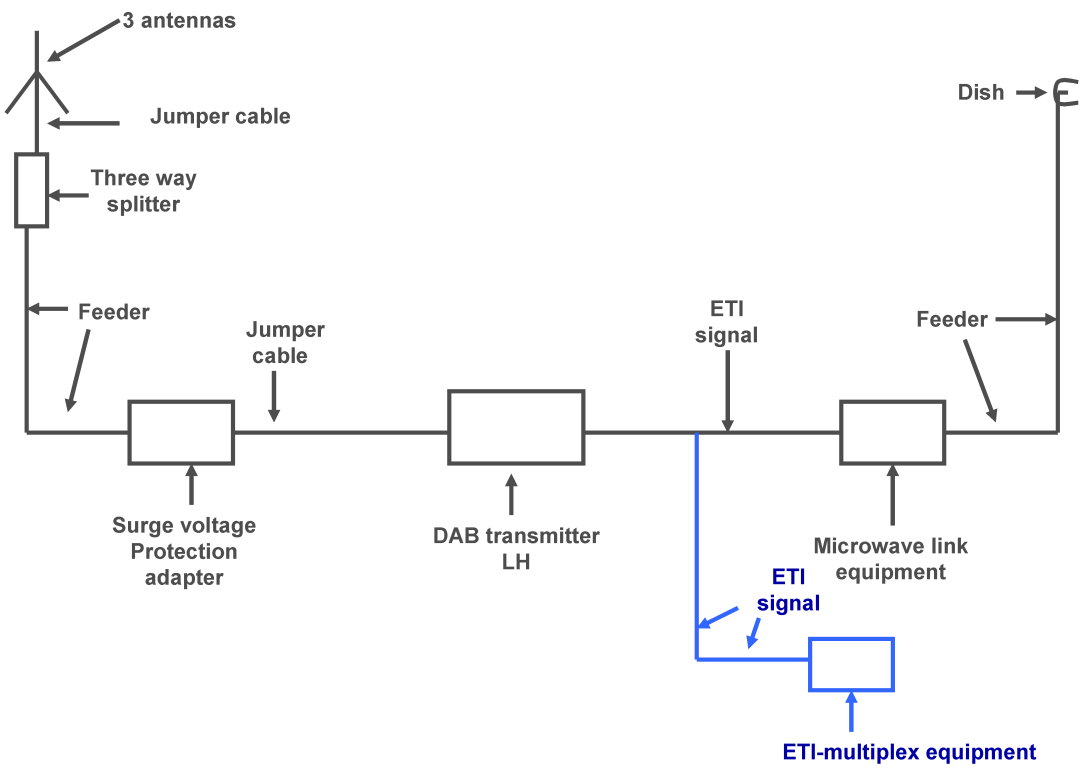

(b) L-band

Figure 2.6: Block diagram of a transmitter site. The blue blocks are only at the Aambeeldstraat location. (cont)

\subsection{Calibration}

Before a measurement setup (here the measurement vehicle) can be used for field strength measurements, it has to be calibrated. Two calibrations are needed: antenna factor and antenna diagram measurement.

The antenna factor is the ratio between the electric field strength and the output voltage or power of an antenna. As the Rhode $\mathcal{E}$ Schwarz ESPI can only measure the received power we need the antenna factor of both the band III and L-band antennas for conversion to the electric field strength.

The antenna diagram, on the other hand, determines among other 


\subsection{Calibration}

factors (e.g. measurement accuracy of the ESPI) how accurately the field strength can be measured.

\subsubsection{Antenna factor}

To determine the antenna factor we used the Standard Site Method (SSM) [19, 20, 21]. This method requires an open field site of 7 by 14 meters; no obstacles are allowed within 20 meters of this area. The ground plane can be metallic or earth. For purpose of convenience we chose to use the earth as ground plane. An advantage of this method is that it does not require calibrated antennas. Instead it needs three uncalibrated antennas.

The SSM method determines the antenna factors for horizontal polarization. This has a number of advantages including relatively insensitive to site variations. It also yields free-space antenna factors even though the reflecting ground plane will not create a free-space environment during calibration. In this project, only the antenna factor for vertical polarization is important. Antenna factors for vertical polarization are determined in a similar way by rotating the antennas 90 degrees.

Figure 2.7 depicts the measurement setup. The SSM method has an uncertainty of $\pm 1 \mathrm{~dB}$ for frequencies below $800 \mathrm{MHz}$ [20].

\section{Method}

The method requires three measurements using the setup of Figure 2.7

- Measurement 1: Antennas 1 and 2

- Measurement 2: Antennas 1 and 3

- Measurement 3: Antennas 2 and 3

In each measurement, the height of the second antenna is varied until the maximum field strength is achieved. The difference between this value and a direct connection between the cable is defined as $A_{x}$.

The antenna factors can be derived using the following equations: 


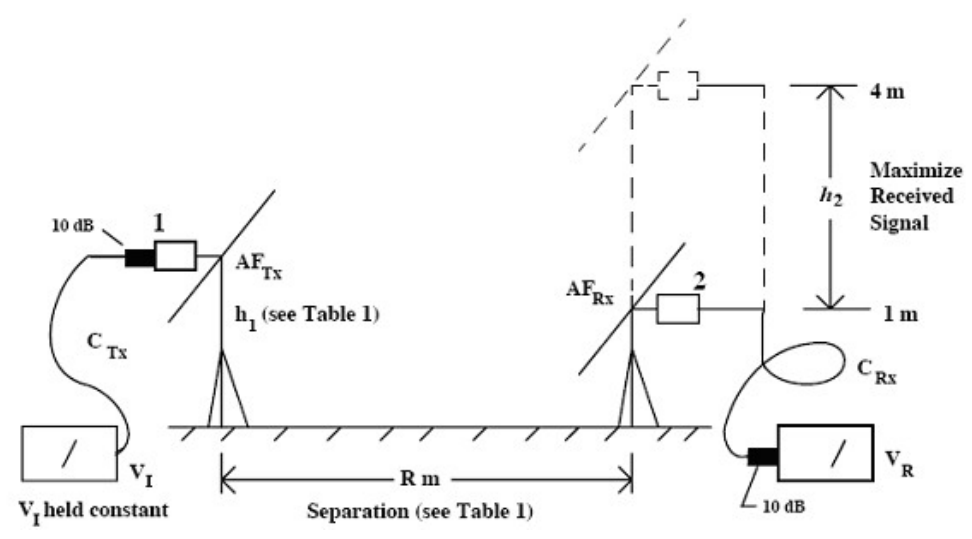

Figure 2.7: Measurement setup of the Standard Site Method [20]

$$
\begin{aligned}
& A F_{1}=10 \log _{10}\left(f_{M}\right)-24.46+1 / 2\left[E_{D}^{\max }+A 1+A 2-A 3\right] \\
& A F_{2}=10 \log _{10}\left(f_{M}\right)-24.46+1 / 2\left[E_{D}^{\max }+A 1-A 2+A 3\right] \\
& A F_{3}=10 \log _{10}\left(f_{M}\right)-24.46+1 / 2\left[E_{D}^{\max }-A 1+A 2+A 3\right]
\end{aligned}
$$

with $E_{D}^{\max }$ equal to $2.0 \mathrm{~dB}$ and $f_{M}$ the selected frequency in $\mathrm{MHz}$ i.e. 225.648 Mhz or 1464.944 MHz.

\section{Results}

From the measurement results we derived an antenna factor of $15.7 \mathrm{~dB}$ for the band III antenna (12B) and an antenna factor of $31.7 \mathrm{~dB}$ for the L-band antenna (LH). Experiments with a calibrated antenna (of Agentschap Telecom) for band III resulted in a similar antenna factor $( \pm 1$ $\mathrm{dB})$.

The theoretical antenna factor for a dipole is defined as:

$$
A F=20 \log _{10}\left(f_{M}\right)-31.8
$$




\subsection{Calibration}

with $f_{M}$ the selected frequency in $\mathrm{MHz}$. The theoretical antenna factors for band III (12B) and the L-band are $15.3 \mathrm{~dB}$ and $31.5 \mathrm{~dB}$, respectively. The measured values are slightly higher, which is probably due to implementation imperfections.

In addition, we measured the cable losses for both bands and included the loss in the field strength conversion.

\subsubsection{Antenna diagram measurement}

To measure the antenna diagram we used an SSM site where a turntable slowly rotates the measurement vehicle. The setup is depicted in Figure 2.8 .

\section{Method}

To determine the antenna diagram, a low power DAB transmitter broadcasts a DAB signal. In the far field $(>10 \mathrm{~m})$, the measurement vehicle is slowly $\left.\right|^{2}$ rotated on a turntable. In the vehicle, a laptop registers the field strength picked up by the antenna under test and the angle of the turntable over ten revolutions. The antenna diagram is determined by averaging these 10 revolutions.

Figure 2.9 shows the antenna diagram for band III, and Figure 2.10 shows it for the L-band. It can be seen that the field strength can be determined for band III with an accuracy of $\pm 1.2 \mathrm{~dB}$ and for the L-band with $\pm 0.9 \mathrm{~dB}$. In an urban environment, this value will be lower due to the reception of multiple paths. As the ESPI has a smaller accuracy of $\pm 1.5 \mathrm{~dB}$, the accuracy of the ESPI will determine the accuracy of the field strength measurements.

\subsubsection{Difference between $2.65 \mathrm{~m}$ and $1.5 \mathrm{~m}$ antenna height}

The measurement vehicle measures the field strength at $2.65 \mathrm{~m}$, whereas international standards use an antenna height of $1.5 \mathrm{~m}$ [2, 22]. For

\footnotetext{
${ }^{2}$ Slowly means 1 revolution per minute.
} 


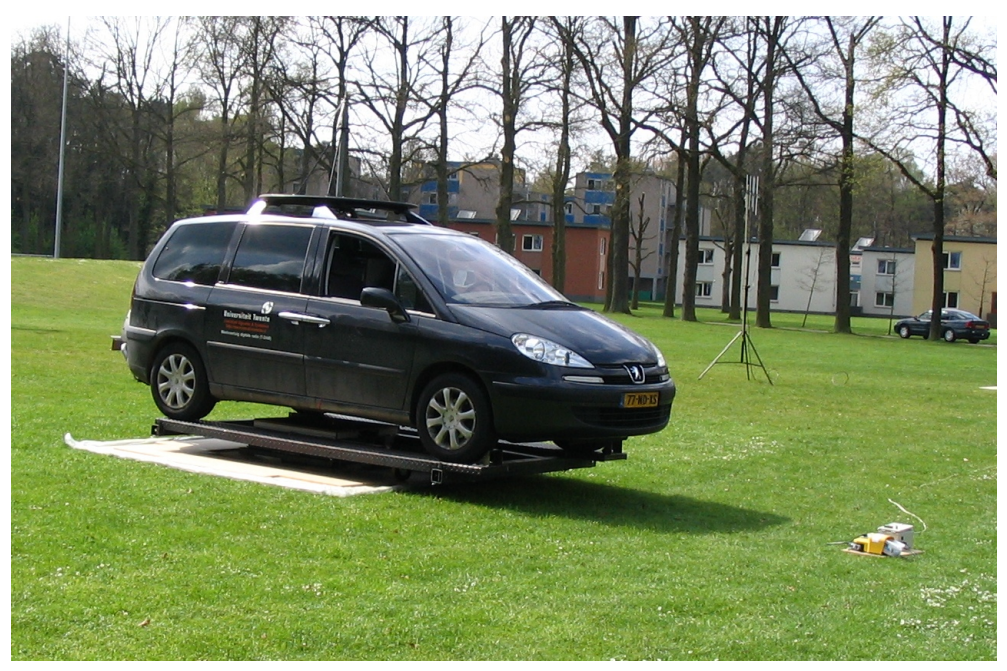

Figure 2.8: Measurement setup for antenna diagram measurements where the measurement vehicle is rotated on a turntable

conversion to a field strength at an antenna height of $10 \mathrm{~m}$ which has the same coverage as an antenna at $1.5 \mathrm{~m}$, these standards use a conversion factor of $10 \mathrm{~dB}$. For the measurement vehicle this means that the field strength at $2.65 \mathrm{~m}$ is $(2.65-1.5) \cdot 10 /(10-1.5)=1.4 \mathrm{~dB}$ higher than at $1.5 \mathrm{~m}$.

To verify these results we measured the field strength at 8 outdoor locations in Amsterdam at antenna heights of $1.5 \mathrm{~m}$ and $2.65 \mathrm{~m}$. For these measurements the antennas were mounted on two masts of the appropriate length. The outdoor locations are depicted in Figure 2.11, and the results are listed in Table 2.2. The measured values are within $1 \mathrm{~dB}$ of the theoretical value of $1.4 \mathrm{~dB}$. Differences are assumed to be caused by different antenna heights and different transmitter antennas. The coverage field strengths measured were corrected for this difference and show the field strength at an antenna height of $1.5 \mathrm{~m}$.

In addition, the standard deviation of the received signal $\sigma_{\text {time }}$ and the standard deviation of the means of all measurement points $\sigma_{\text {place }}$ was 


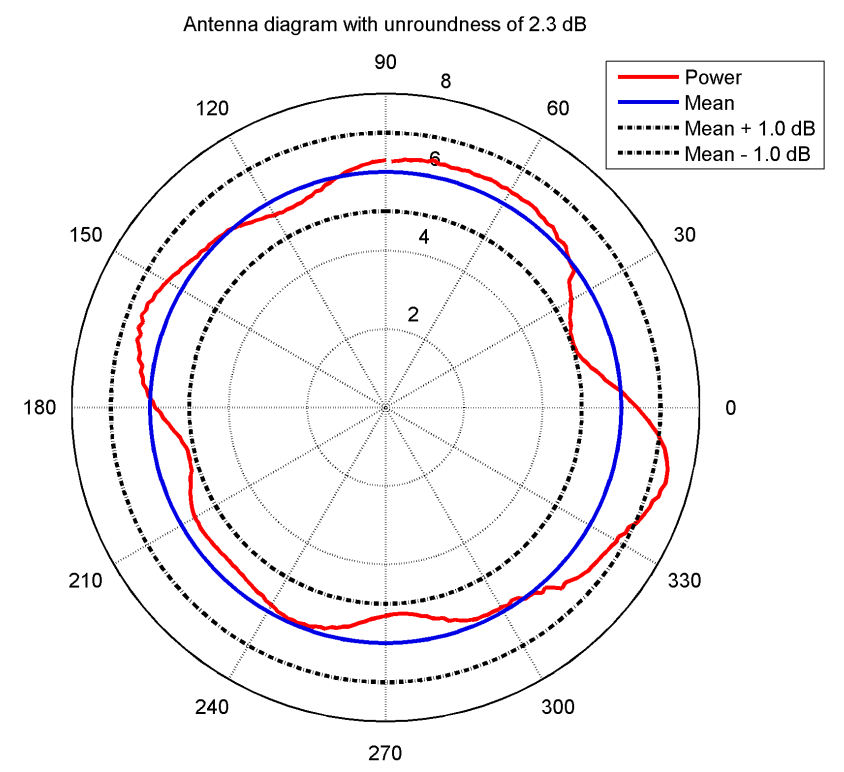

Figure 2.9: Antenna diagram of the measurement vehicle antenna (band III, 12B)

\begin{tabular}{l|cc} 
Channel & difference & \\
& $\mu$ & $\sigma$ \\
\hline band III 12B & $2.0 \mathrm{~dB}$ & $0.3 \mathrm{~dB}$ \\
band III 12C & $2.5 \mathrm{~dB}$ & $0.3 \mathrm{~dB}$ \\
L-band LH & $0.7 \mathrm{~dB}$ & $0.3 \mathrm{~dB}$
\end{tabular}

Table 2.2: Antenna height: difference between antenna heigth at 2.65 and $1.5 \mathrm{~m}$ 


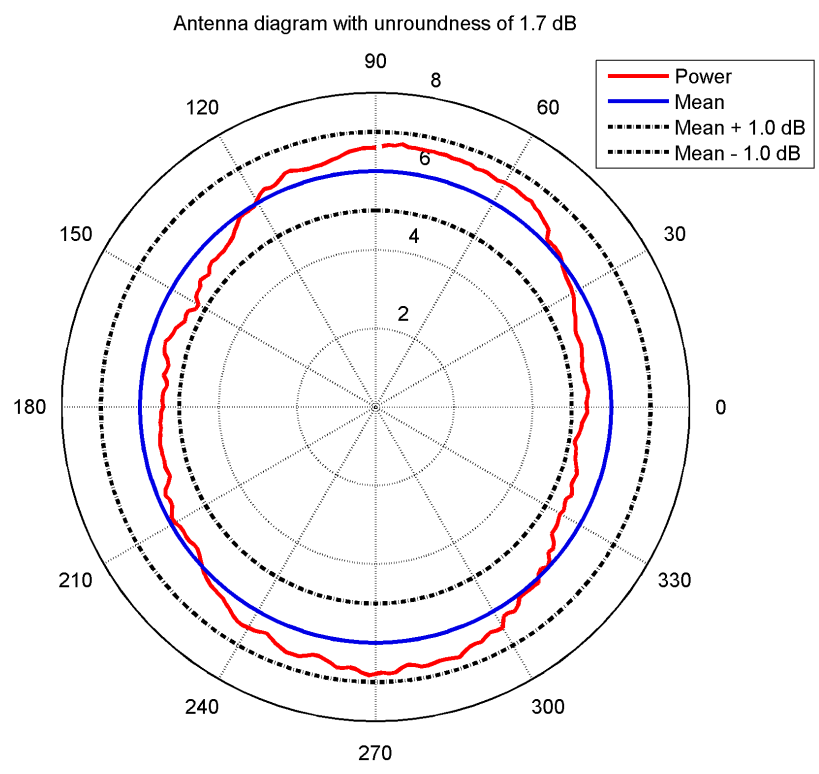

Figure 2.10: Antenna diagram of the measurement vehicle antenna (L-band, LH) 


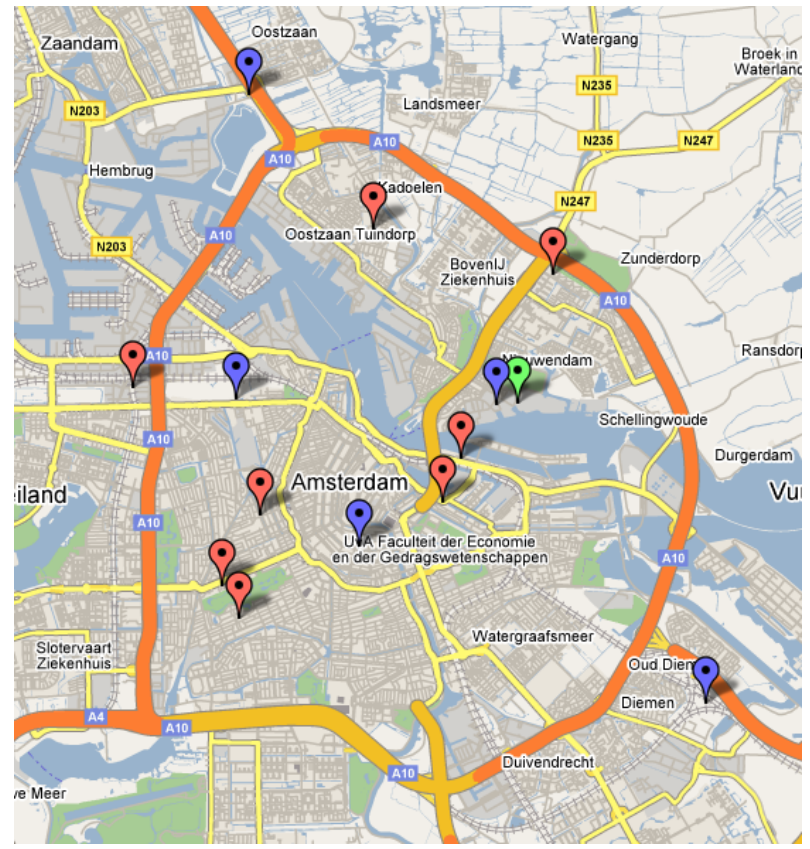

Figure 2.11: Outdoor locations (legend: red $=$ outdoor locations, blue= transmitters pilot network, green $=$ transmitters Publieke Omroep) CGoogle Maps 
Chapter 2. Coverage measurements

\begin{tabular}{l|cc} 
Channel & $\sigma_{\text {place }}$ & $\sigma_{\text {time }}$ \\
\hline band III 12B & $2.8 \mathrm{~dB}$ & $0.4 \mathrm{~dB}$ \\
band III 12C & $3.2 \mathrm{~dB}$ & $0.4 \mathrm{~dB}$ \\
L-band LH & $2.2 \mathrm{~dB}$ & $0.7 \mathrm{~dB}$
\end{tabular}

Table 2.3: Standard deviation of the received signal $\sigma_{\text {time }}$ and the standard deviation of the means of all measurement points $\sigma_{\text {place }}$ for the outdoor measurement points

calculated for these 16 outdoor points. The results are listed in Table 2.3 . To calculate these values, the Statistics toolbox of Matlab was used. The histogram of $\sigma_{\text {time }}$ tends to be a Gamma distribution [23] (Figure 2.12), and $\sigma_{\text {place }}$ histogram tends to be a (log-) normal distribution.

\subsection{Band III results}

\subsubsection{Self interference}

Self-interference in the network will occur if the maximum distance between the transmitters is too large. For mode I, this maximum distance is $74 \mathrm{~km}$ [18]. In both our pilot network and in the network of the Publieke Omroep this does not occur.

\subsubsection{Adjacent channel interference}

Adjacent channel interference occurs if the field strength of a neigbouring channel is much larger than the selected channel. According to the EN 50248 norm [24], a maximum difference of $30 \mathrm{~dB}$ is allowed for adjacent channels and $40 \mathrm{~dB}$ for non-adjacent channels.

In this field trial, we have determined how large the field strength difference between two adjacent channels is when two different network topologies are used. Especially around the pilot transmitters there is an interference area where the strong signal of channel 12B will prevent reception of the multiplex at $12 \mathrm{C}$. With our measurement vehicle, we 


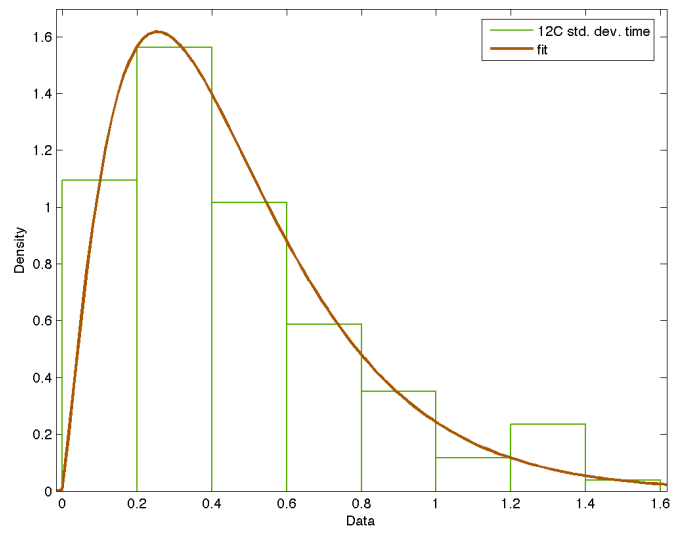

Figure 2.12: Histogram of the standard deviation in time of the outdoor measurement points (channel 12C)

measured this difference. One of the solutions to suppress the interference areas is to use a gap filler at channel $12 \mathrm{C}$ at the pilot transmitter sites. A gap filler power level of $880 \mathrm{~mW}$ and $2 \mathrm{~W}$ was evaluated. In addition, we measured the adjacent and non-adjacent performance of consumer receivers (Sections 4.5.5 and 4.5.6).

Figure 2.13 shows the difference in field strength between channel $12 \mathrm{~B}$ and $12 \mathrm{C}$ versus the distance from a transmitter location of the pilot network where the speed of the measurement vehicle is below $50 \mathrm{~km} / \mathrm{h}$. As the Diemen location is near the highway, several measurement points are invalid due to the excessive speed. All results are averaged (solid lines) per 50-meter, or the $99 \%$ limit in this segment is shown (dashed lines). The $99 \%$ limit indicates that $99 \%$ of all measurements in the segment are below this value.

The red line is the Wiesbaden requirement, the black lines apply when no gap filler was used, blue when a gap filler of $880 \mathrm{~mW}$ was used and green when the power of the gap fillers is $2 \mathrm{~W}$. The Aambeeldstraat transmitter site does not require a gap filler due to the vicinity of the 
Chapter 2. Coverage measurements

IJ-mast.

When no gap fillers are used, the holes in the service area of the Publieke Omroep are a circle with a radius of $\pm 800 \mathrm{~m}$ for the Diemen transmitter site, $\pm 1000 \mathrm{~m}$ for Vredehof, and $\pm 1650 \mathrm{~m}$ for Oostzaan. As the field strength of the Publieke Omroep is the lowest near Oostzaan, the hole in the service is the largest there. A gap filler of $880 \mathrm{~mW}$ per pilot site will be enough to neutralize the holes in the service area of the Publieke Omroep. The interference area around a high-power mast was not investigated, but it is expected that this interference area will be significantly larger.

\subsubsection{Co-channel interference}

Figure 2.14 depicts the measured field strength for a route around the IJsselmee $]^{3}$. Figure 2.15 shows the same information in a field strength versus distance plot. As the propagation conditions vary from day to day, these figure give only an indication of the co-channel interference.

\section{Re-use distance}

The ITU has derived a relation between distance and (predicted) field strength in [25] and [10]. Figure 2.15 depicts the relation between measured field strength and distance. In addition, four extra lines are plotted in Figure 2.15, a free space red line, which gives the field strength for a free space environment; the itu-p1546-1 green line, which gives the predicted field strength using Recommendation ITU-P1546-1 [10] for land paths; a purple line for sea paths; and a dotted red line which indicates the sensitivity of the measurement equipment.

From Figure 2.15, it can be concluded that the predicted field strength using Recommendation ITU-P1546-1 for land paths is a good estimate of the received field strength.

In the Wiesbaden agreement [2], the service area for outdoor coverage is defined as the area where the field strength is greater than $48 \mathrm{~dB} \mu \mathrm{V} / \mathrm{m}$

\footnotetext{
${ }^{3} \mathrm{~A}$ former sea which was separated from the North Sea
} 


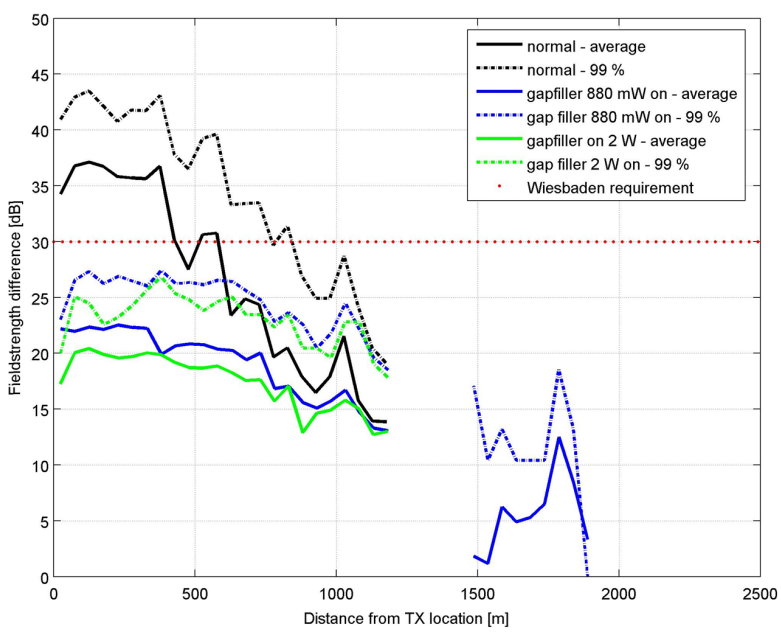

(a) Diemen

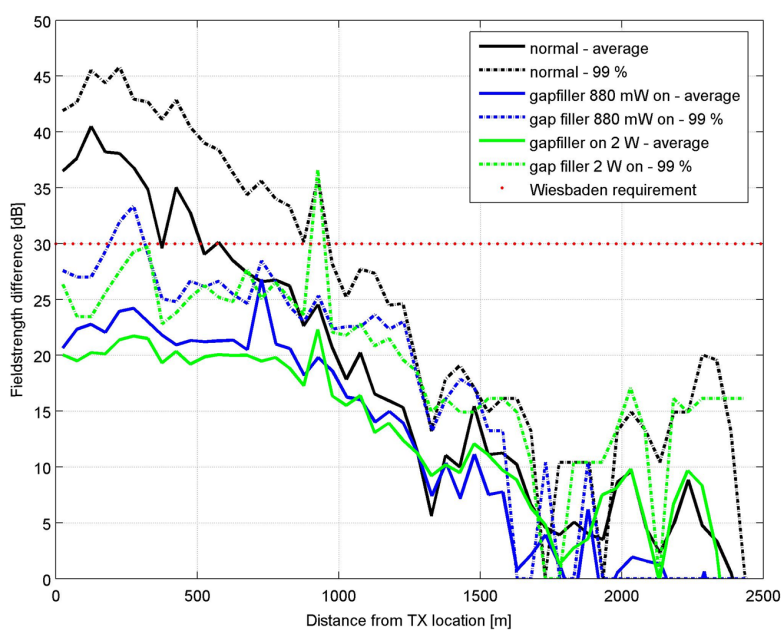

(b) Vredehof

Figure 2.13: Field strength difference (12B-12C) versus distance from a transmitter location 


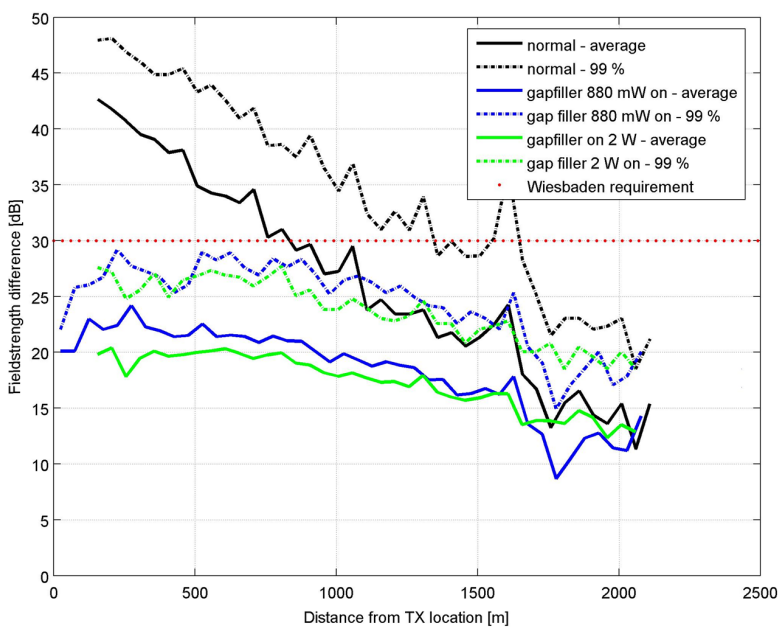

(c) Oostzaan

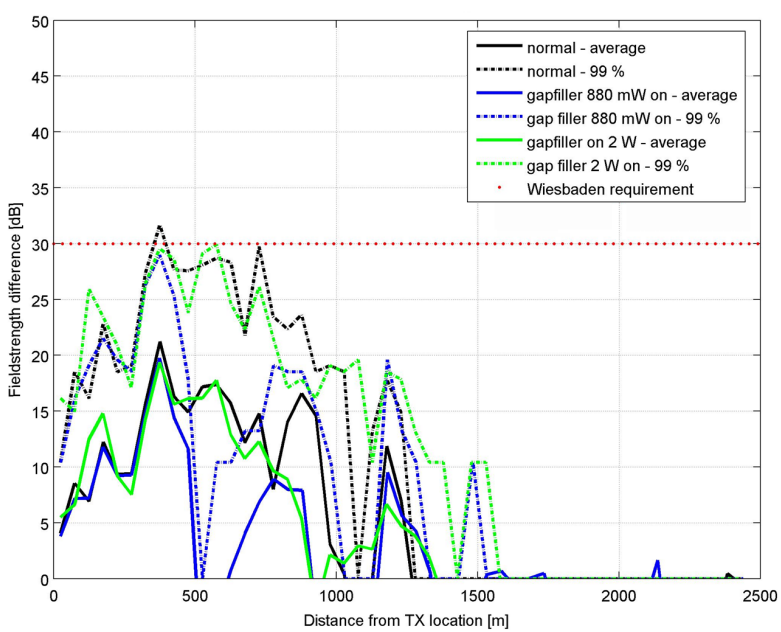

(d) Aambeeldstraat

Figure 2.13: Field strength difference (12B-12C) versus distance from a transmitter location (cont) 


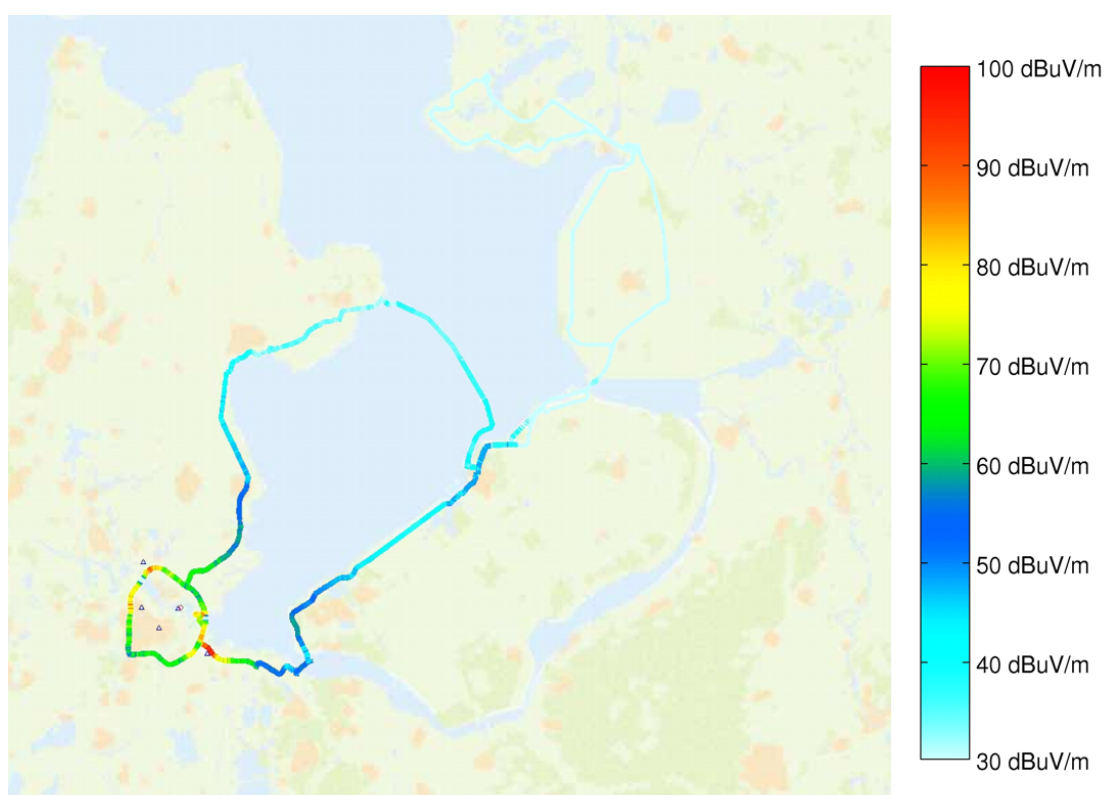

Figure 2.14: Field strength of channel $12 \mathrm{~B}$ at a large distance of the pilot network 


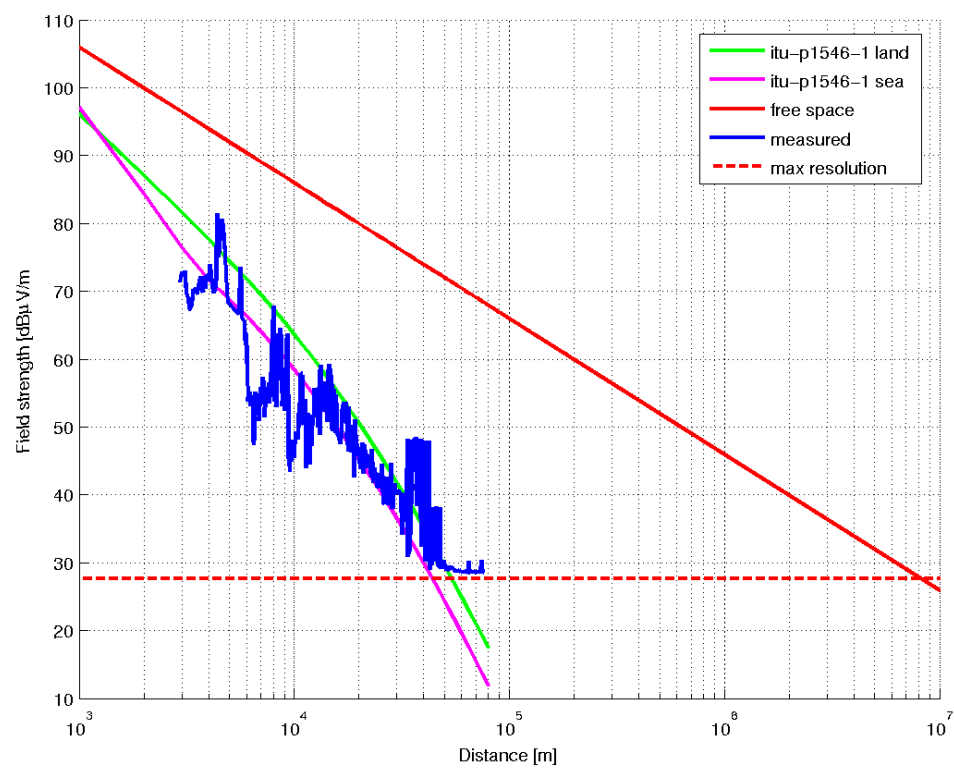

Figure 2.15: Field strength versus distance plot for channel 12B

(50\% place, $50 \%$ time at a $1.5 \mathrm{~m}$ antenna height). The area of interference area from other T-DAB networks is defined as the area where the field strength is between $23 \mathrm{~dB} \mu \mathrm{V} / \mathrm{m}$ and $48 \mathrm{~dB} \mu \mathrm{V} / \mathrm{m}$. However, the Wiesbaden agreement assumes that the transmitters have a $12 \mathrm{~dB}$ power reduction at the boundary of the service area. In the pilot network the antennas are omnidirectional so that there is no $12 \mathrm{~dB}$ power reduction. If $12 \mathrm{~dB}$ power reduction would have been applied, the interference area would be between $35 \mathrm{~dB} \mu \mathrm{V} / \mathrm{m}$ and $48 \mathrm{~dB} \mu \mathrm{V} / \mathrm{m}$. Figure 2.15 reveals that the re-use distance in this case is about $50 \mathrm{~km}$. 


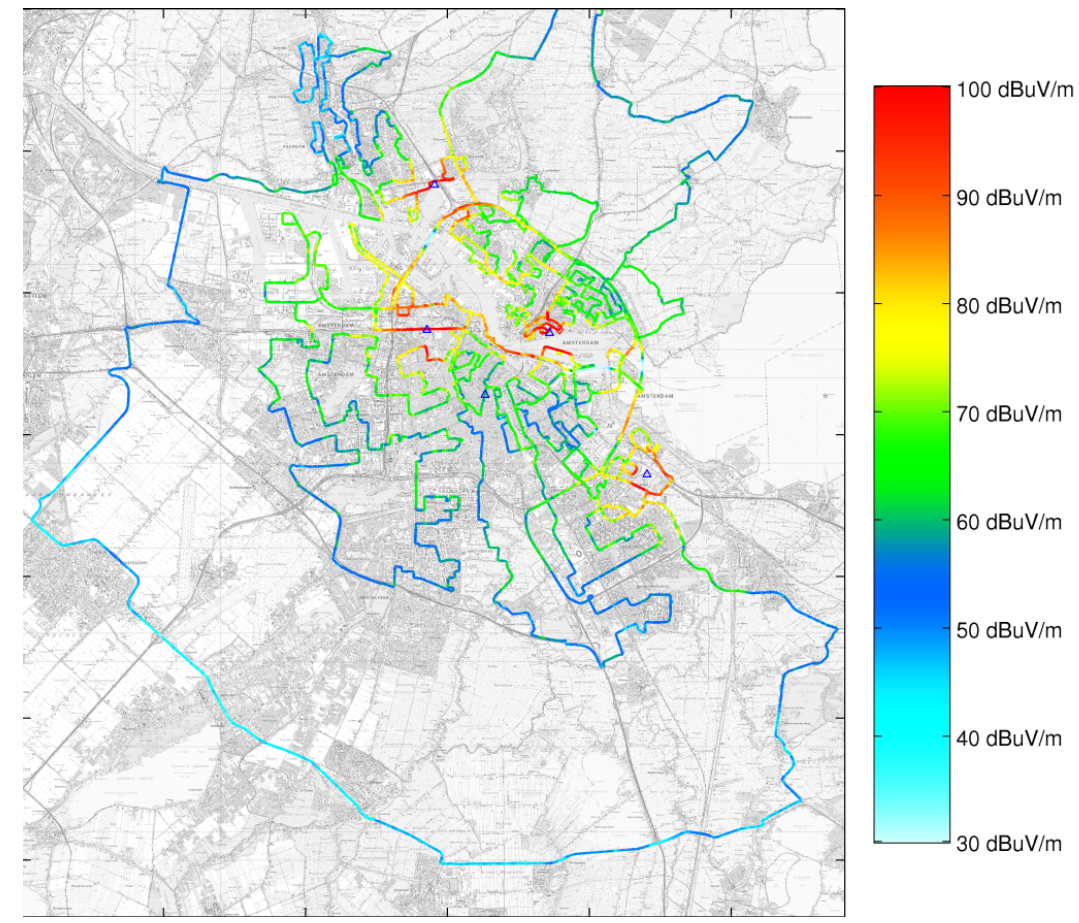

Figure 2.16: The field strength of channel 12B for multiple measurement routes

\subsubsection{Service area}

In Figure 2.16, the field strength of channel 12B for multiple measurement routes has been plotted. Figure 2.17 depicts this for channel 12C. In the Wiesbaden agreement [2], the service area for outdoor coverage is defined as the area where the field strength is greater than $45 \mathrm{~dB} \mu \mathrm{V} / \mathrm{m}$.

Both networks give good outdoor coverage in Amsterdam. Of course, the pilot network for a commercial service would also include transmitter sites in the south of Amsterdam. 


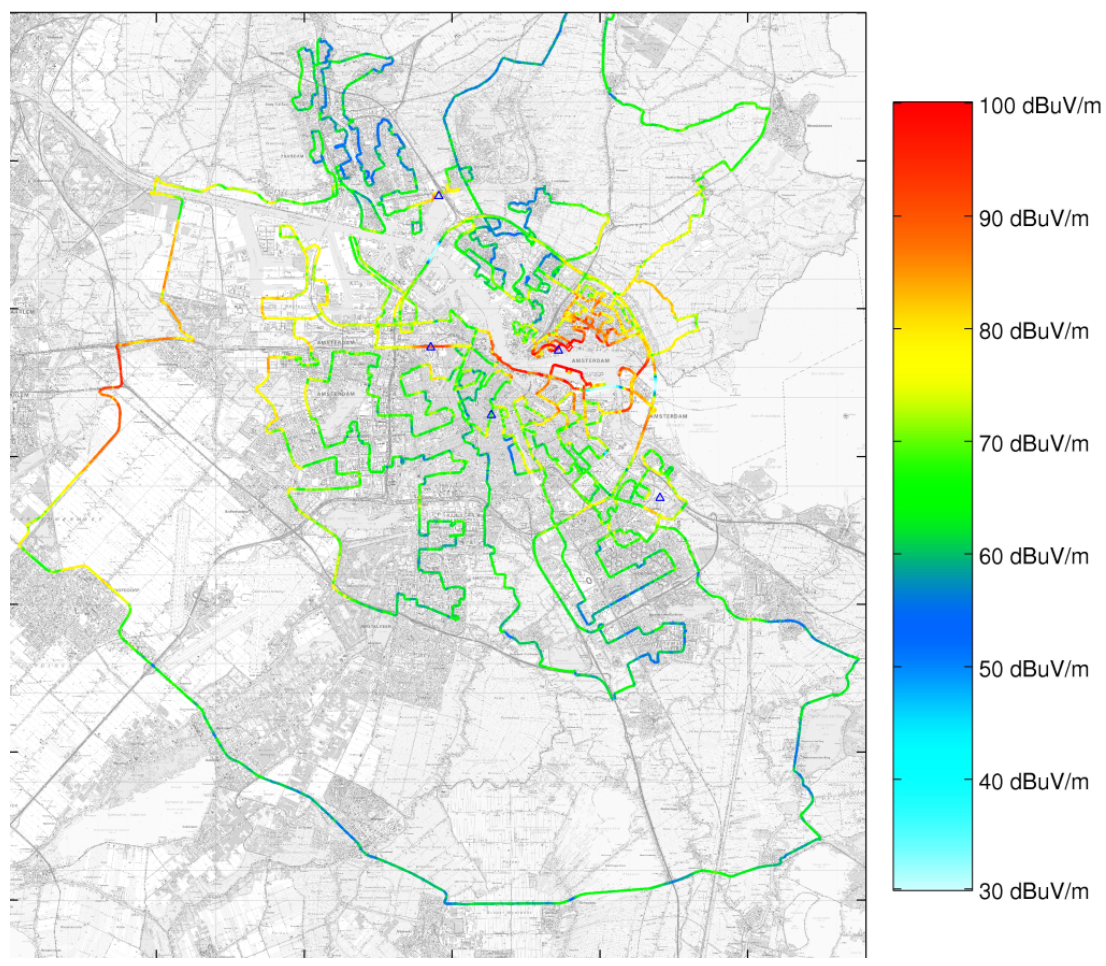

Figure 2.17: The field strength of channel $12 \mathrm{C}$ for multiple measurement routes 


\subsubsection{Redundancy}

Figure 2.18 depicts the field strength of the channel 12B network when location Aambeeldstraat is switched off. Figure 2.19 shows the accompanying BER after FEC plot. A black color indicates that at this point no BER values have been logged, in other words the receiver could not synchronize to the DAB multiplex.

Due to the strong field strength of channel $12 \mathrm{C}$, the field strength measurement equipment (ESPI) detects for the adjacent 12B channel a relatively strong non-existing field strength around location Aambeeldstraat.

It is clear from the figures than when a transmitter of the pilot network fails, only a small part of the coverage in Amsterdam is affected. Using a high power high mast infrastructure would have resulted in a larger hole in the service area.

\subsubsection{Protection levels}

In this field trial several protection levels were tested. For band III, protection level Unequal Error Protection (UEP) 3 and UEP 5 were evaluated. Figure 2.20 shows the BER after FEC performance for UEP 3 and Figure 2.21 shows this for UEP $\overline{5}$. A black color indicates that this point no BER values were logged, meaning that the receiver could not synchronize to the $\mathrm{DAB}$ multiplex. For error-free reception, the BER after FEC should be lower than $10^{-4}$ [24].

From these figures it is clear that only $\overline{\mathrm{UEP}} \beta$ is useable. From our L-band protection level measurements (Section 2.5.5), UEP4 seems to be a good trade off between performance and capacity. If protection level UEPt is used, the capacity of the multiplex is $1.336 \mathrm{Mbit} / \mathrm{s}$.

The maximum useable protection level obviously depends on the performance of the receiver, in our case the RadioScape RS-T1000b DAB monitor. Chapter 4 shows that this receiver has a good performance for band III. However, an interesting question arises, namely what is the theoretical maximum useable capacity? This capacity could be reached 


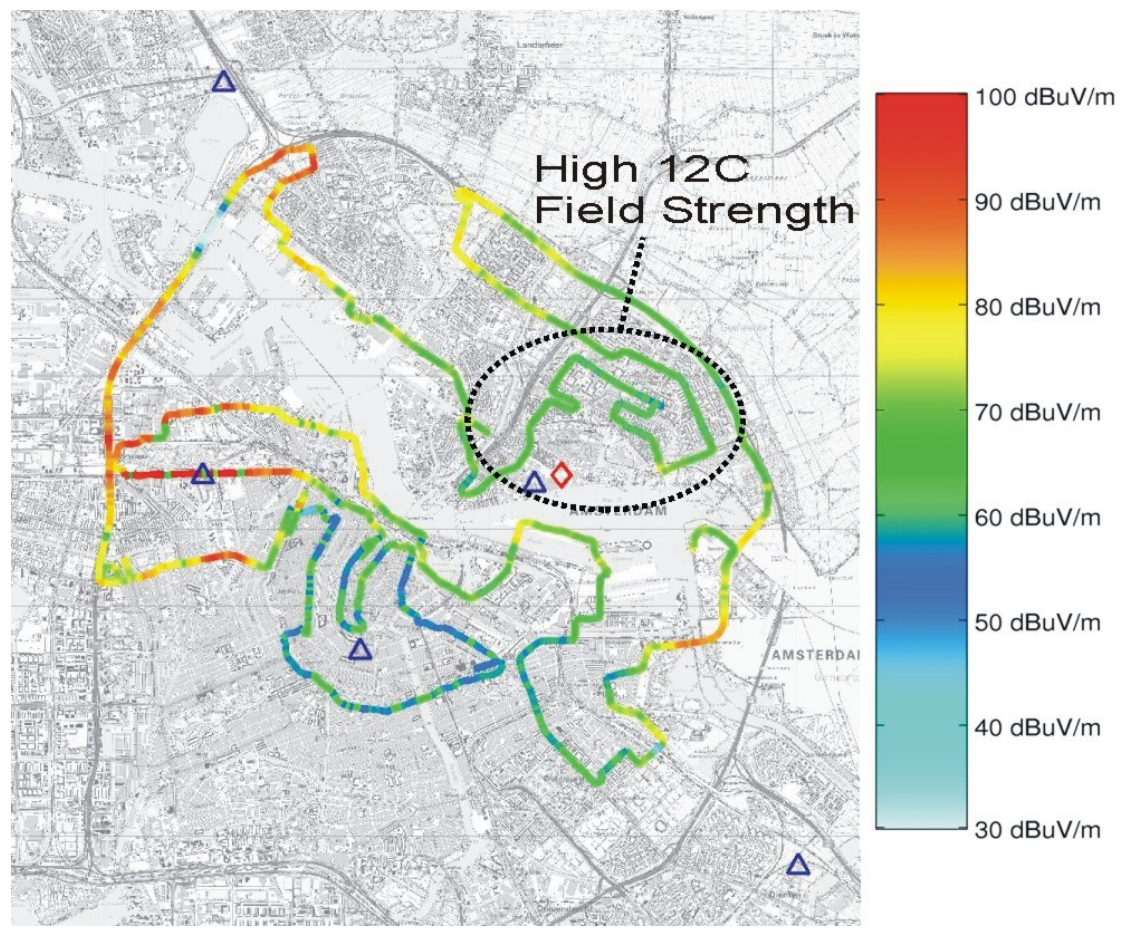

Figure 2.18: Field strength of channel 12B with transmitter site Aambeeldstraat switched off. 


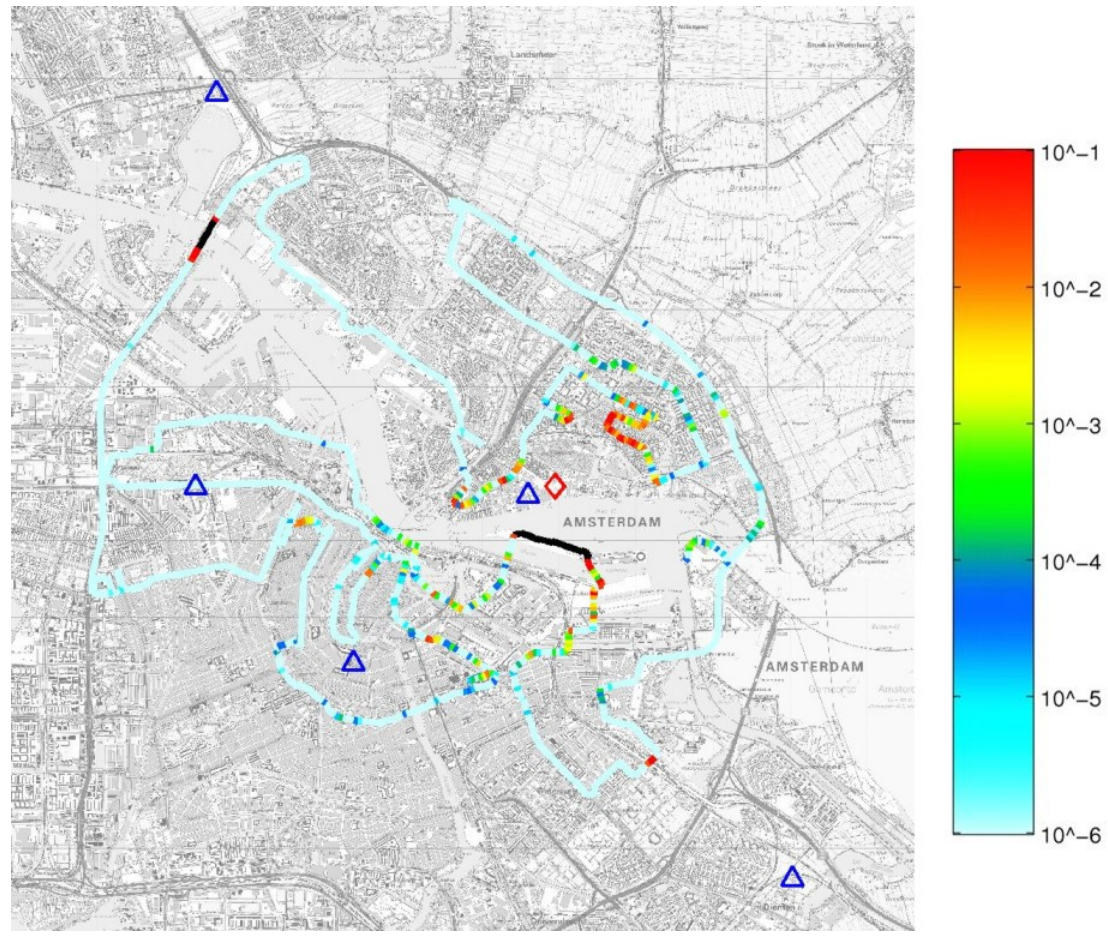

Figure 2.19: BER after FEC of channel 12B for protection level UEP3 with transmitter site Aambeeldstraat switched off. 


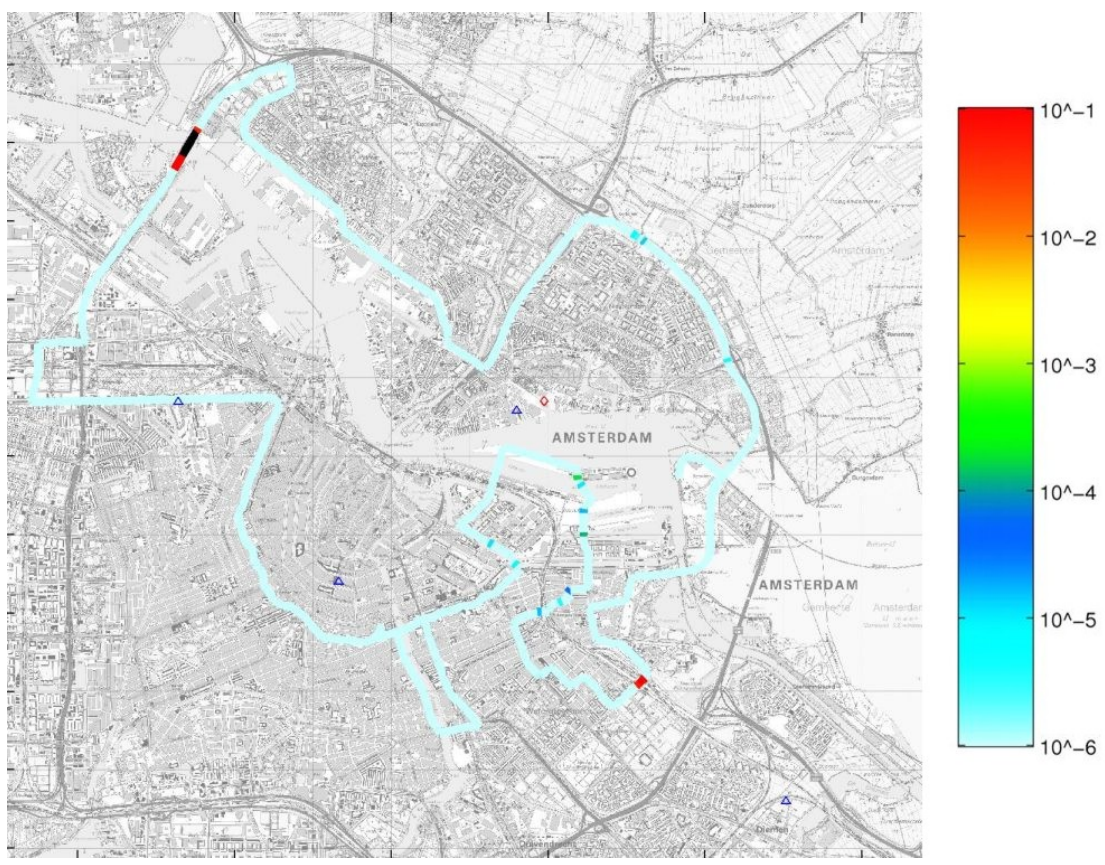

Figure 2.20: BER after FEC of channel 12B for protection level UEP3.

if the most advanced algorithms are implemented in the receiver. Further research is needed to answer this question.

\subsubsection{SFN network gain}

In Figure 2.16, the field strength of channel 12B for multiple measurement routes has been plotted. Figure 2.22 depicts the field strength of the network when a single transmitter is switched on. The difference between both figures can be considered as SFN gain. This gain can be up to $10 \mathrm{~dB}$. During the coverage measurements, no occurrences of flat fading were measured. 


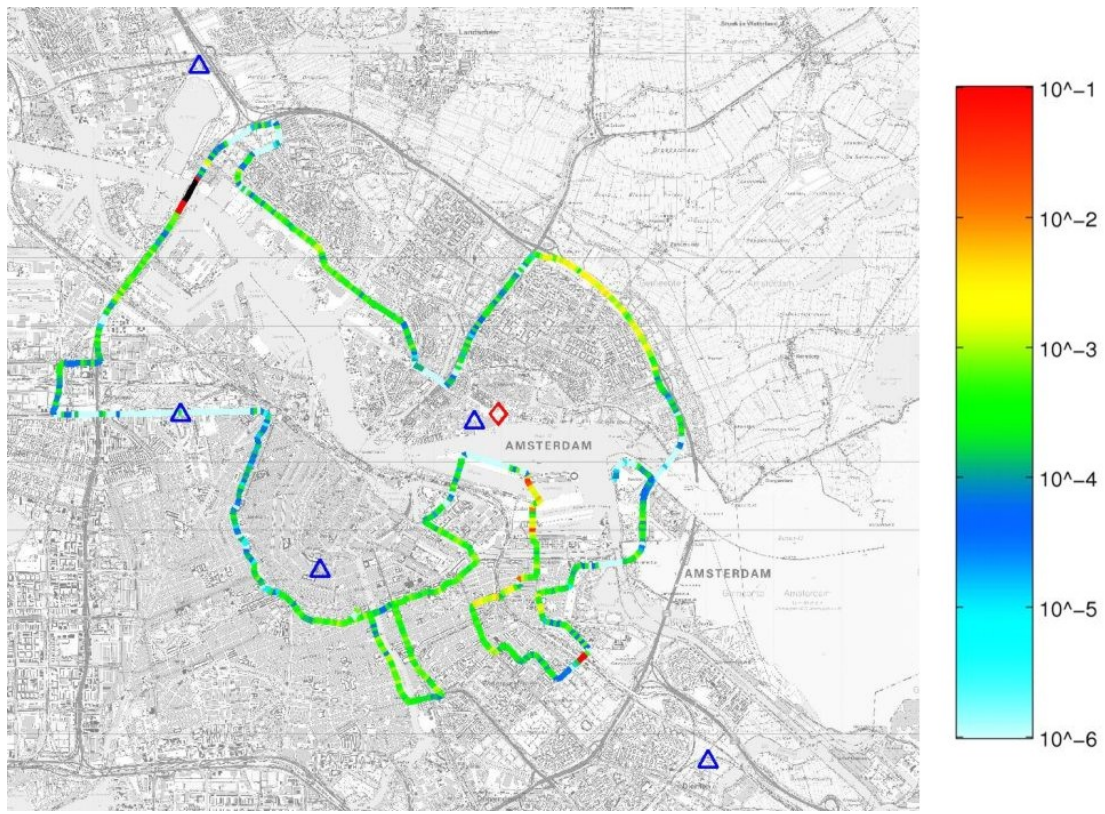

Figure 2.21: BER after FEC of channel 12B for protection level UEP5. 


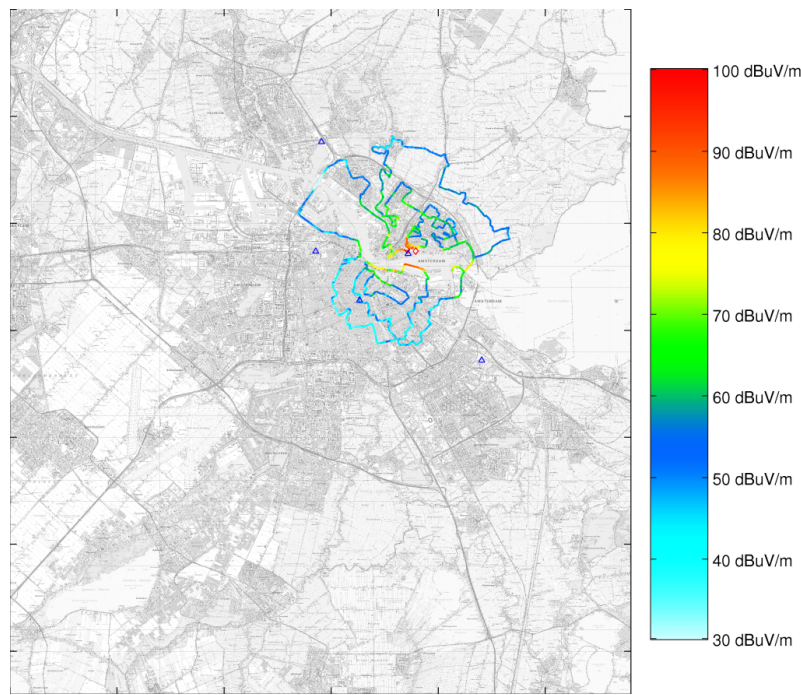

(a) Aambeeldstraat

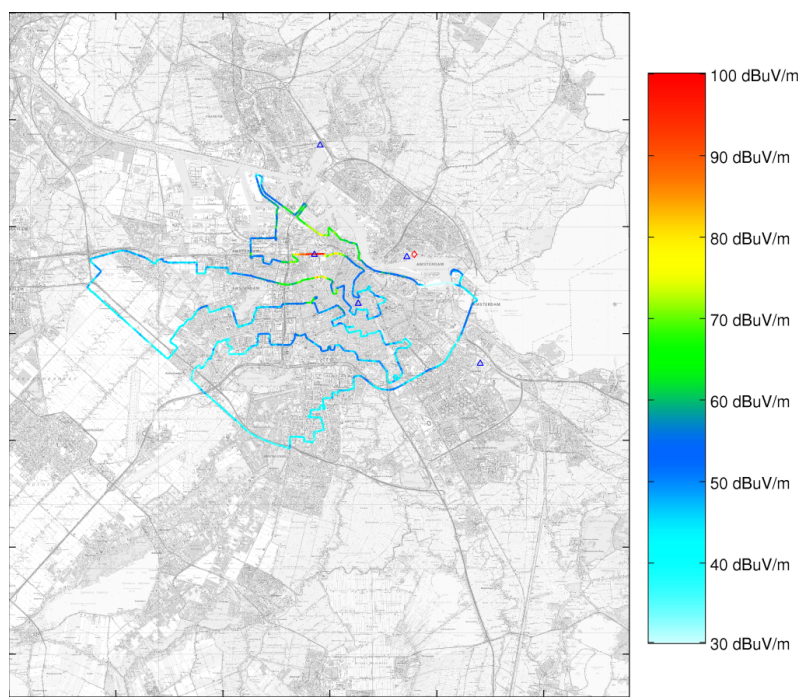

(b) Vredehof

Figure 2.22: The field strength of channel 12B when one transmitter is switched on at a time 


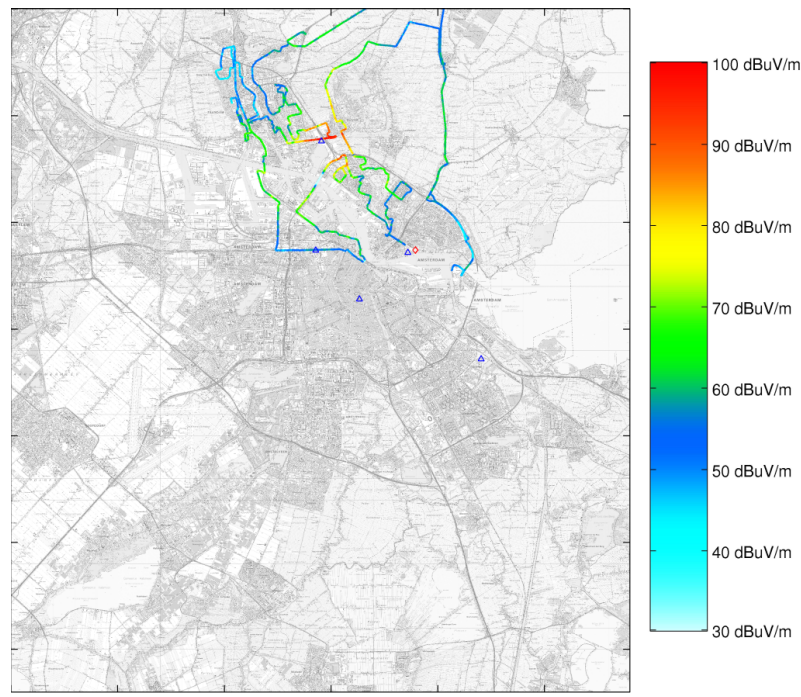

(c) Oostzaan

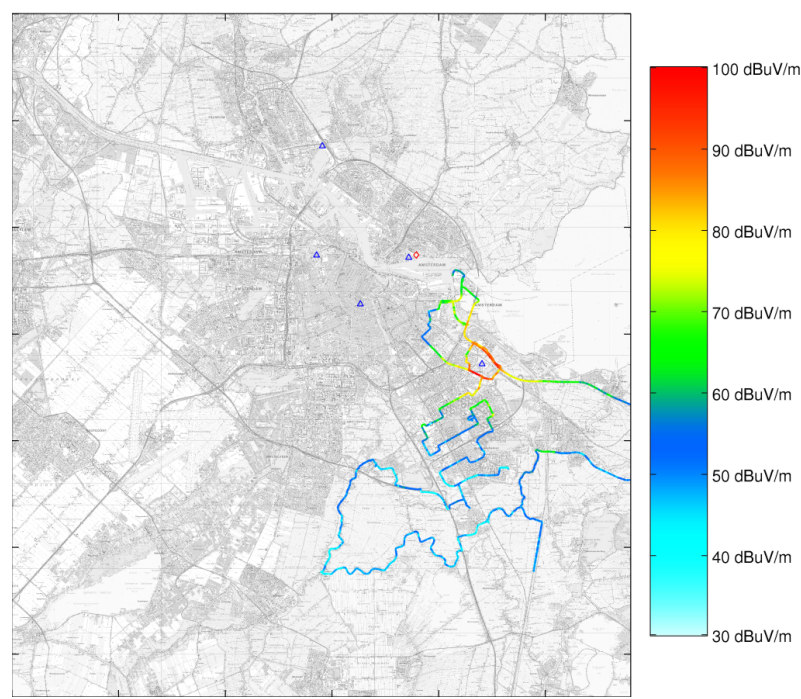

(d) Diemen

Figure 2.22: The field strength of channel $12 \mathrm{~B}$ when one transmitter is switched on at a time (cont) 


\section{$2.5 \quad$ L-band results}

\subsubsection{Self interference}

Self-interference in the network will occur if the maximum distance between the transmitters is too large. For mode IV, the maximum distance is $37 \mathrm{~km}$ and for mode II it is $18 \mathrm{~km}[18]$. In a field trial in Canada [26], a larger distance was found before self-interference occurred. However, the specific geographical area can play a role in this.

In our coverage measurements we did not experience self-interference in the network. The transmitter distance is also much smaller than $37 \mathrm{~km}$.

\subsubsection{Co-channel interference}

Figure 2.23 depicts the measured field strength for a route around the IJsselmeer. Figure 2.24 shows the same information in a field strength versus distance plot. As the propagation conditions vary from day to day, these figure give only an indication of the co-channel interference.

\section{Re-use distance}

The ITU derived a relation between distance and (predicted) field strength in [25] and [10]. Figure 2.24 depicts the relation between measured field strength and distance. In addition, three extra lines are plotted in Figure 2.24: a free space red line, which gives the field strength for a free space environment; the itu-p1546-1 green line, which gives the predicted field strength using Recommendation ITU-P1546-1 [10] for land paths; a purple line for sea paths; and a dotted red line which indicates the sensitivity of the measurement equipment.

On the measurement day, the signal of channel LH could be received on the opposite side of the IJsselmeer. Compared to our band III measurement (on a different measurement day), it seems that the LH signals propagate further than channel 12B. Moreover, the measured field strength curve is above the free space line, and there appears to be a large difference between this line and the ITU-P1546-1 curves. 

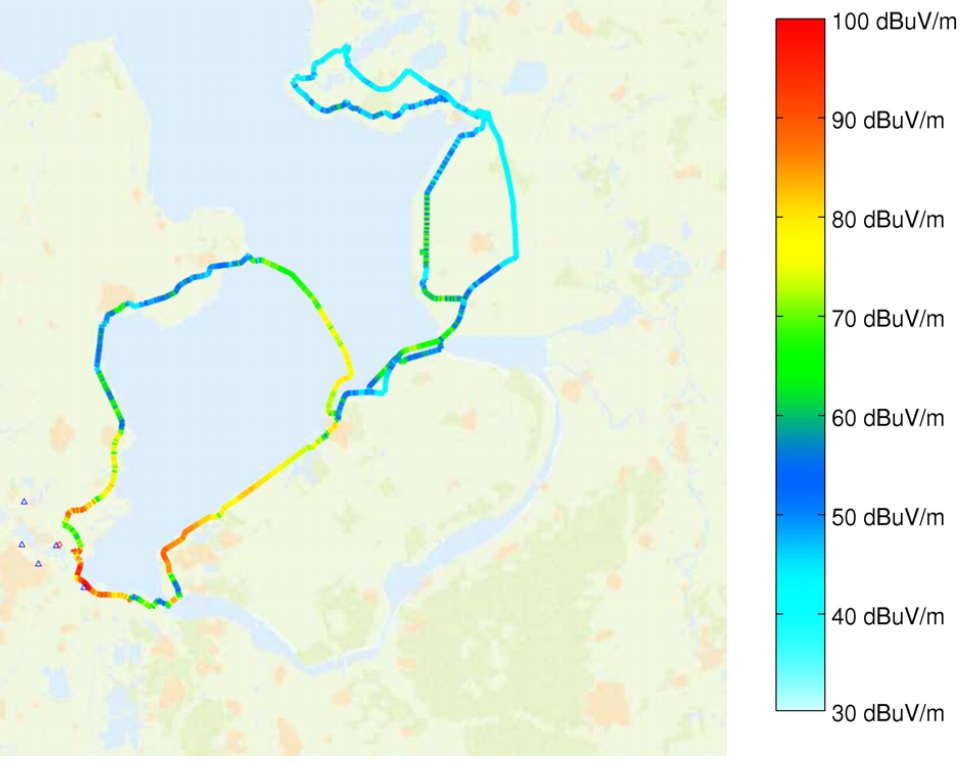

Figure 2.23: Field strength of channel LH at a large distance of the pilot network 
Chapter 2. Coverage measurements

A possible explanation for this is that the opening angle of the L-band antenna is narrower (12 degrees) compared to the band III antennas (32 degrees). The plotted free space line assumes that the field strength propagates in three directions meaning that the power is distributed on the surface of a sphere. When an antenna with a small opening angle is used, this condition does not hold. In addition, the IJsselmeer may affect the propagation conditions.

Moreover, in Figure 2.24 the local variations in measured field strength are larger than for the band III (Figure 2.15). This could be explained also by a small opening angle of the antennas. With a small opening angle, high objects will have greater impact on the received field strength. Moreover, there are large variations in the antenna diagram (Figure 2.5) of the L-band antenna, up to $20 \mathrm{~dB}$, which may also explain the large variations.

In the Maastricht agreement [22], the service area for outdoor coverage is defined as the area where the field strength exceeds $59 \mathrm{~dB} \mu \mathrm{V} / \mathrm{m}(50$ $\%$ place, $50 \%$ time at a $1.5 \mathrm{~m}$ antenna height). The area of interference to other T-DAB networks is defined as the area where the field strength is between $31 \mathrm{~dB} \mu \mathrm{V} / \mathrm{m}$ and $59 \mathrm{~dB} \mu \mathrm{V} / \mathrm{m}$. However, the Maastricht agreement assumes that the transmitters have a $12 \mathrm{~dB}$ power reduction at the boundaray of the service area. In the pilot network the antennas are omnidirectional so that there is no $12 \mathrm{~dB}$ power reduction. If $12 \mathrm{~dB}$ power reduction would have been applied, the interference area would be between $43 \mathrm{~dB} \mu \mathrm{V} / \mathrm{m}$ and $59 \mathrm{~dB} \mu \mathrm{V} / \mathrm{m}$. Figure 2.24 reveals that the re-use distance in this case is about $100 \mathrm{~km}$.

\subsubsection{Service area}

In Figure 2.25, the field strength of channel LH for multiple measurement routes has been plotted. In the Maastricht agreement [22], the service area for outdoor coverage is defined as the area where the field strength is greater than $59 \mathrm{~dB} \mu \mathrm{V} / \mathrm{m}$.

The L-band pilot network provides good outdoor coverage in Amsterdam. Of course, the pilot network for a commercial service would also include transmitter sites in the south of Amsterdam. 


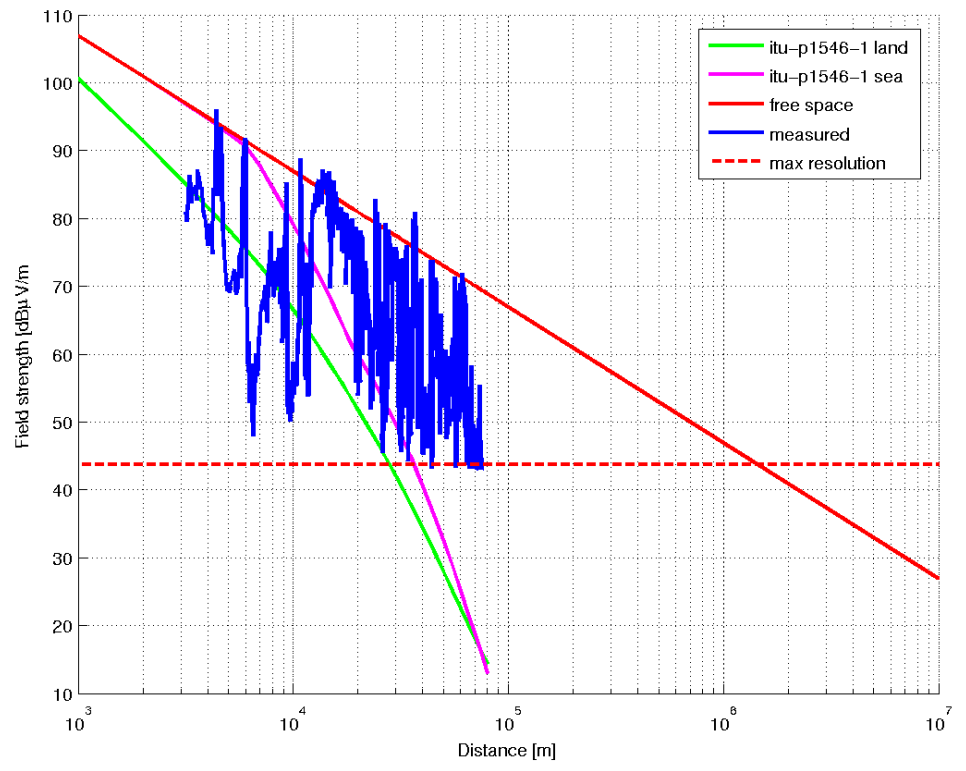

Figure 2.24: Field strength versus distance plot for channel LH 


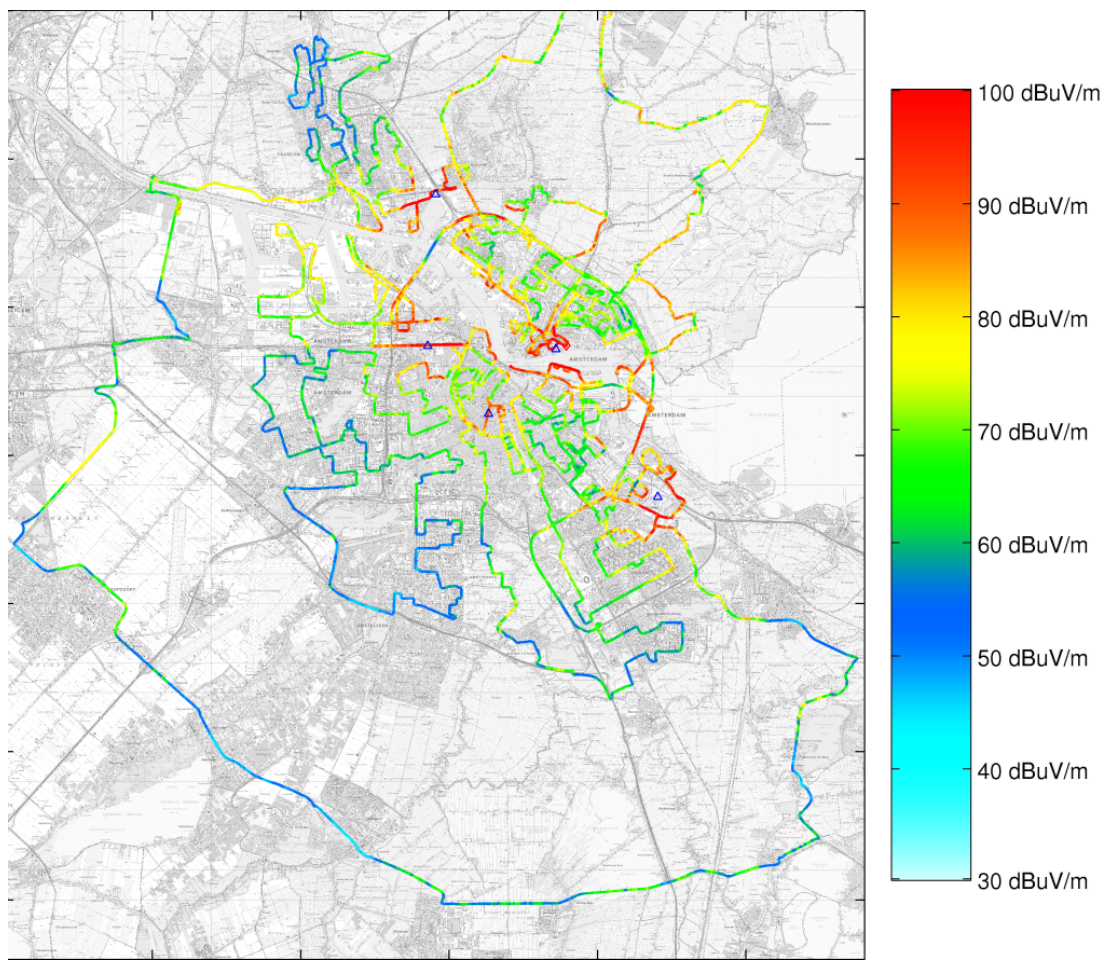

Figure 2.25: The field strength of channel LH for multiple measurement routes. 


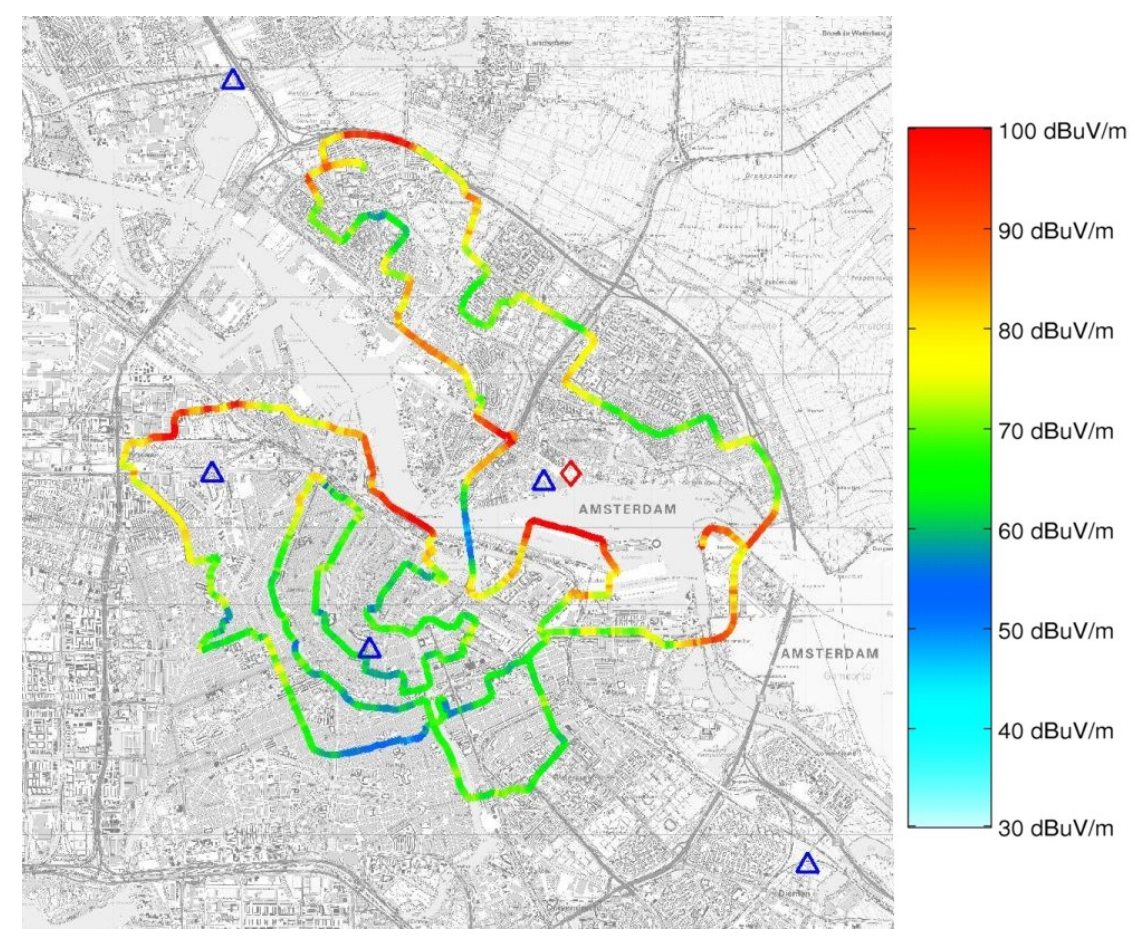

Figure 2.26: Field strength of channel LH with transmitter site de Bazel switched off.

\subsubsection{Redundancy}

Figure 2.26 depicts the field strength of the channel LH network when location de Bazel is switched off. Figure 2.27 shows the accompanying BER after FEC plot. The figures, make clear that when a pilot network transmitter fails, only a small part of the coverage in Amsterdam is affected. Using a high power high mast infrastructure would have resulted in a larger hole in the service area. 


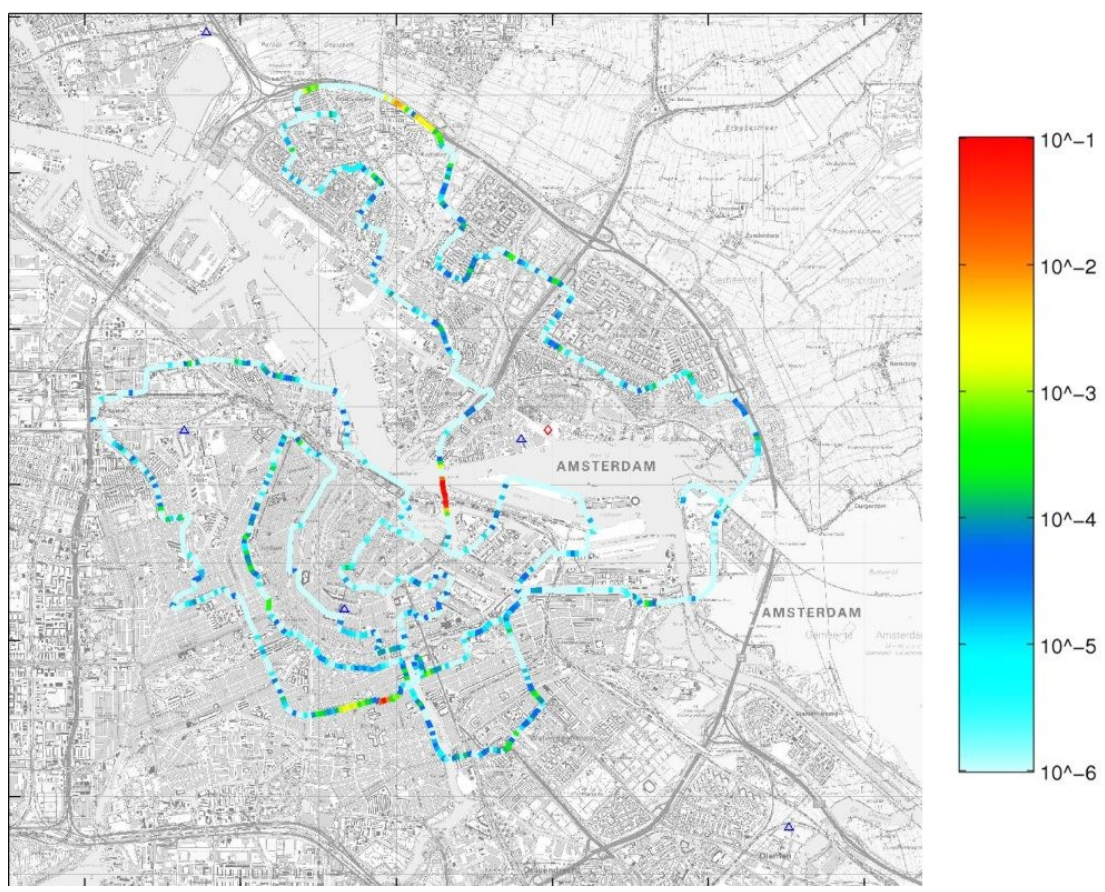

Figure 2.27: BER after FEC of channel LH for protection level UEP3 with transmitter site de Bazel switched off. 


\subsubsection{Protection levels}

In this field trial several protection levels were tested. For the L-band, protection level UEP 3 , UEPA 4 and UEP 5 were evaluated.

Figure 2.30 shows the BER after FEC performance for UEP $\beta$, Figure 2.31 shows this for UEP4 and Figure 2.32 for UEP $\overline{5}$. For error-free reception, the BER after FEC should be lower than $10^{-4}$ [24].

The L-band coverage measurements as well as the consumer receiver experiments revealed that the T-DAB receivers cannot decode the subchannel error-free for mode IV and a rural channel model in the L-band. Figure 2.29 depicts the BER for a UEP 3 subchannel, and Figure 2.29 shows the speed of the route. There is a clear relation between speed and BER if the speed is above $50 \mathrm{~km} / \mathrm{h}$ (i.e. $15 \mathrm{~m} / \mathrm{s}$ ) the BER is unacceptably high.

In an L-band field trial in Canada [9], the maximum speed for mode IV was found to be $80 \mathrm{~km} / \mathrm{h}$ and for mode II $180 \mathrm{~km} / \mathrm{h}$. As our measurements reveal a maximum speed of $50 \mathrm{~km} / \mathrm{h}$ for mode IV, it seems that there are implementation errors in the RadioScape T-1000b DAB monitor. Mode II should thus be used for the L-band (which limits the maximum distance of the transmitters to $18 \mathrm{~km}$ ). This mode can be received up to speeds of $180 \mathrm{~km} / \mathrm{h}$.

The areas with a high BER in Figures 2.30, 2.31 and 2.32 are due to the speed of the vehicle. From the figures it seems that protection level UEP4 is a good trade off between performance and capacity.

The maximum useable protection level obviously depends on the performance of the receiver, in our case the RadioScape RS-T1000b DAB monitor. In Chapter 4 it is shown that this receiver has very poor performance for the L-band (mode IV) and a rural channel model. For this reason, the results should be used with care.

An interesting question arises, namely what is the theoretical maximum useable capacity? This capacity could be reached if the most advanced algorithms are implemented in the receiver. Further research is needed to answer this question. 

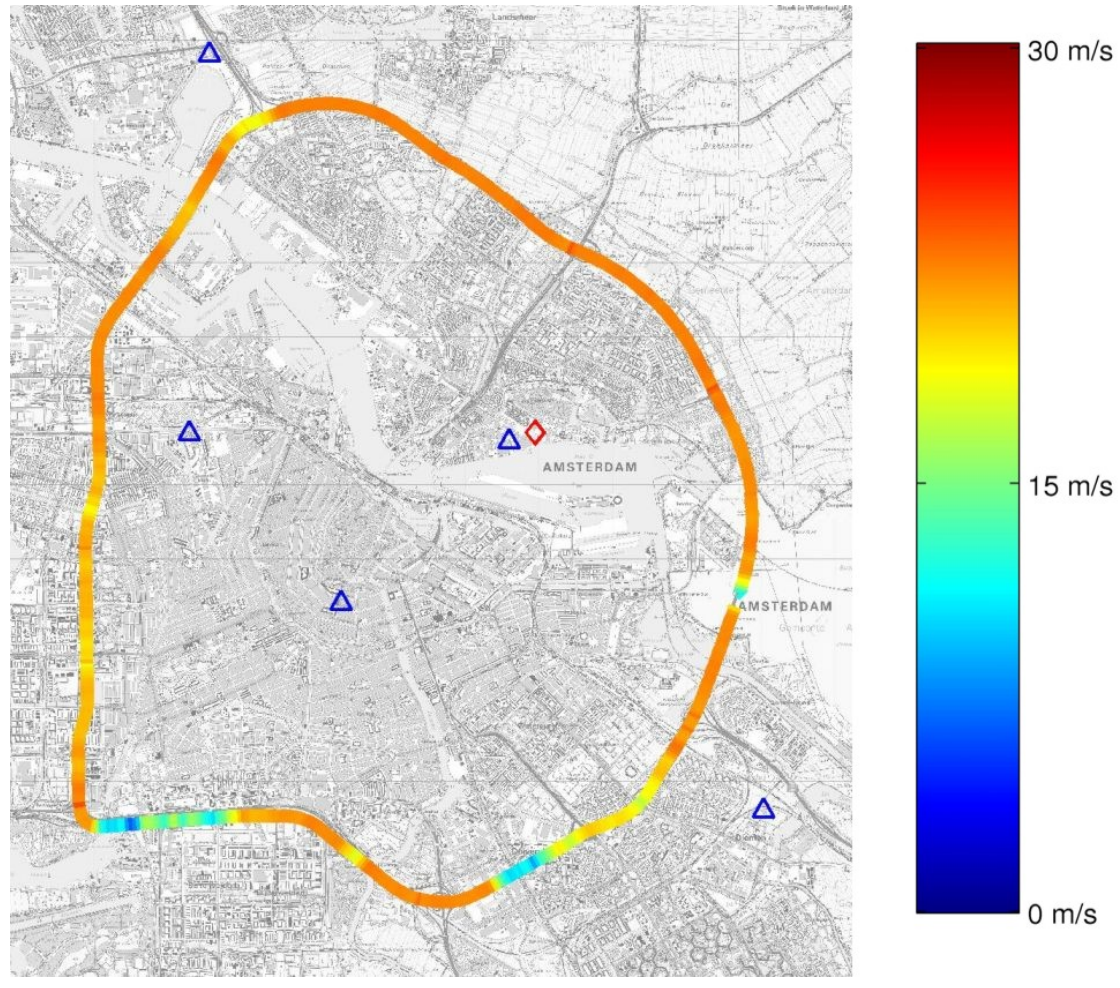

Figure 2.28: Speed of the measurement vehicle on the inner ring of Amsterdam 


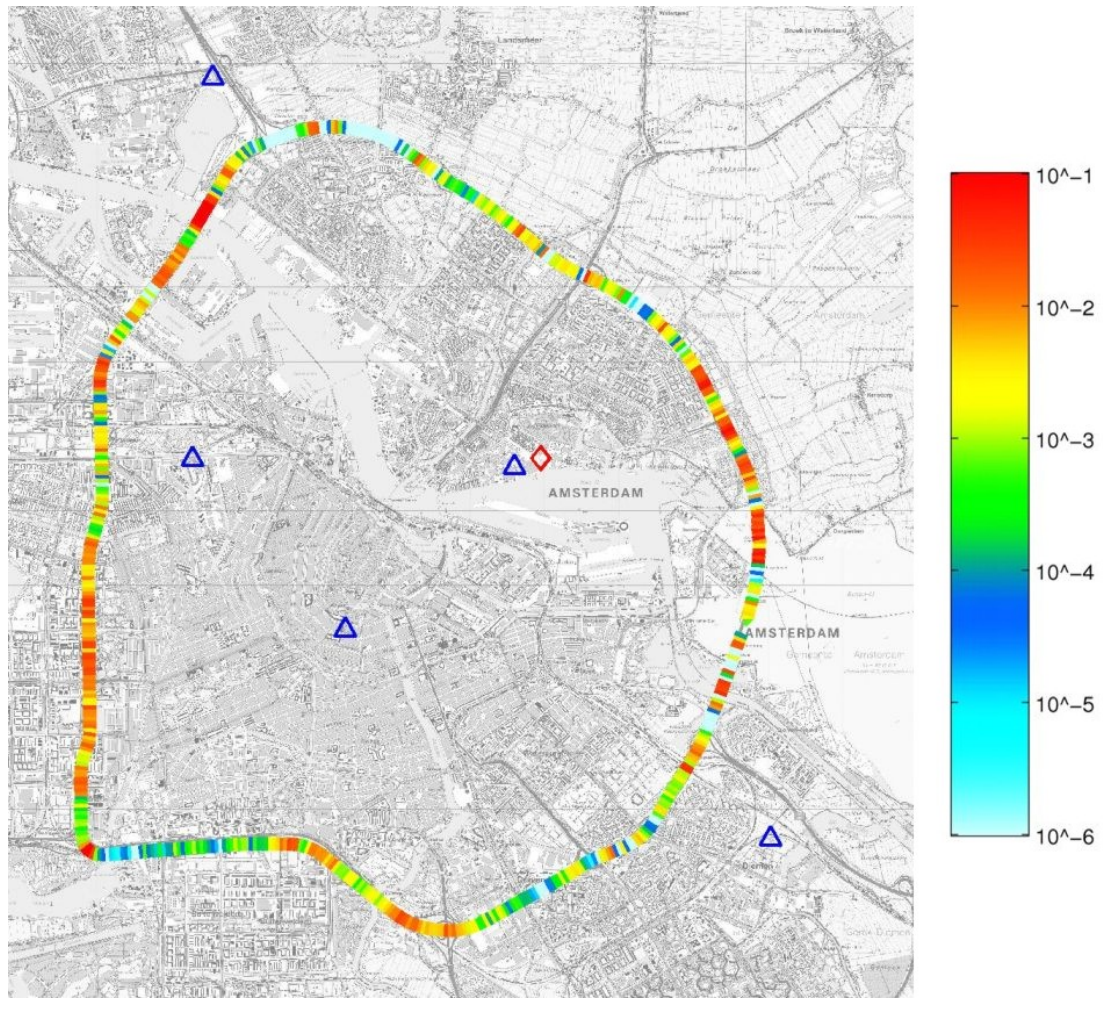

Figure 2.29: BER after FEC of channel LH for protection level UEP3 and mode IV on the inner ring of Amsterdam 


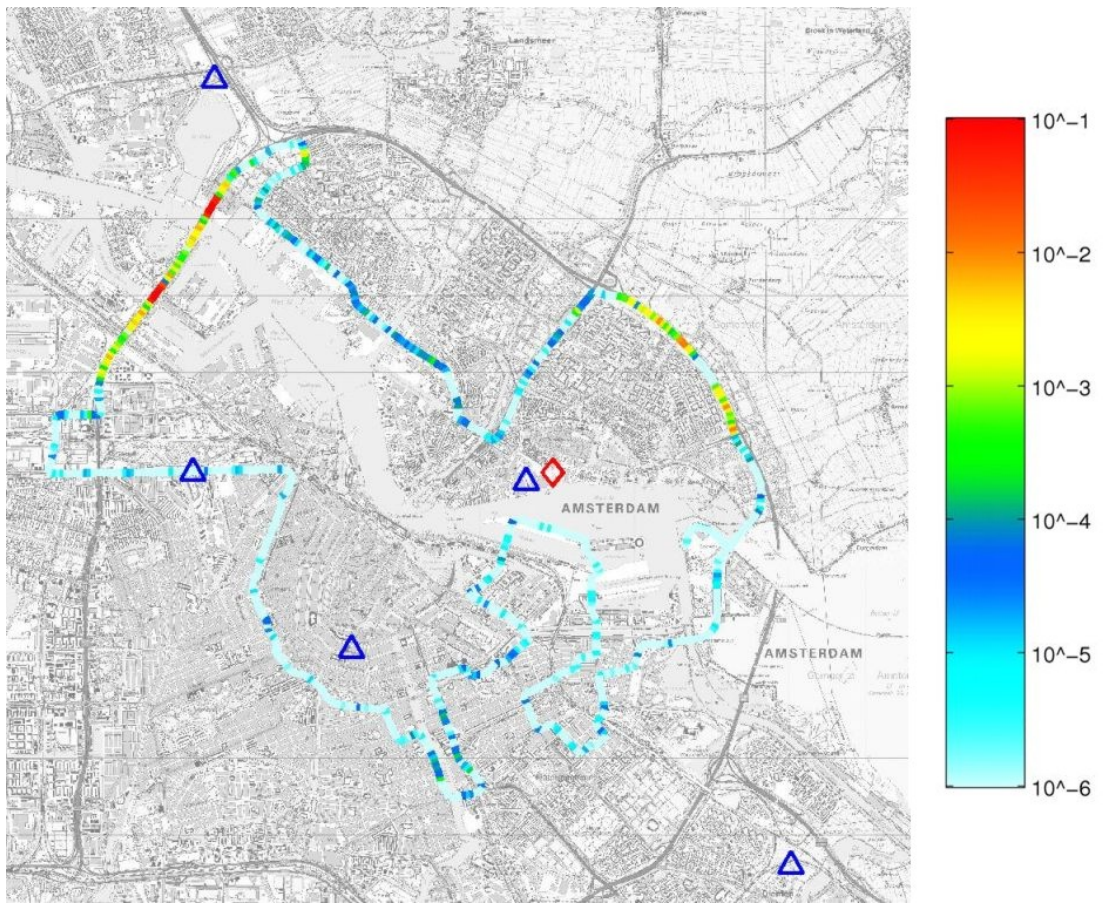

Figure 2.30: BER after FEC of channel LH for protection level UEP3 


\subsection{L-band results}

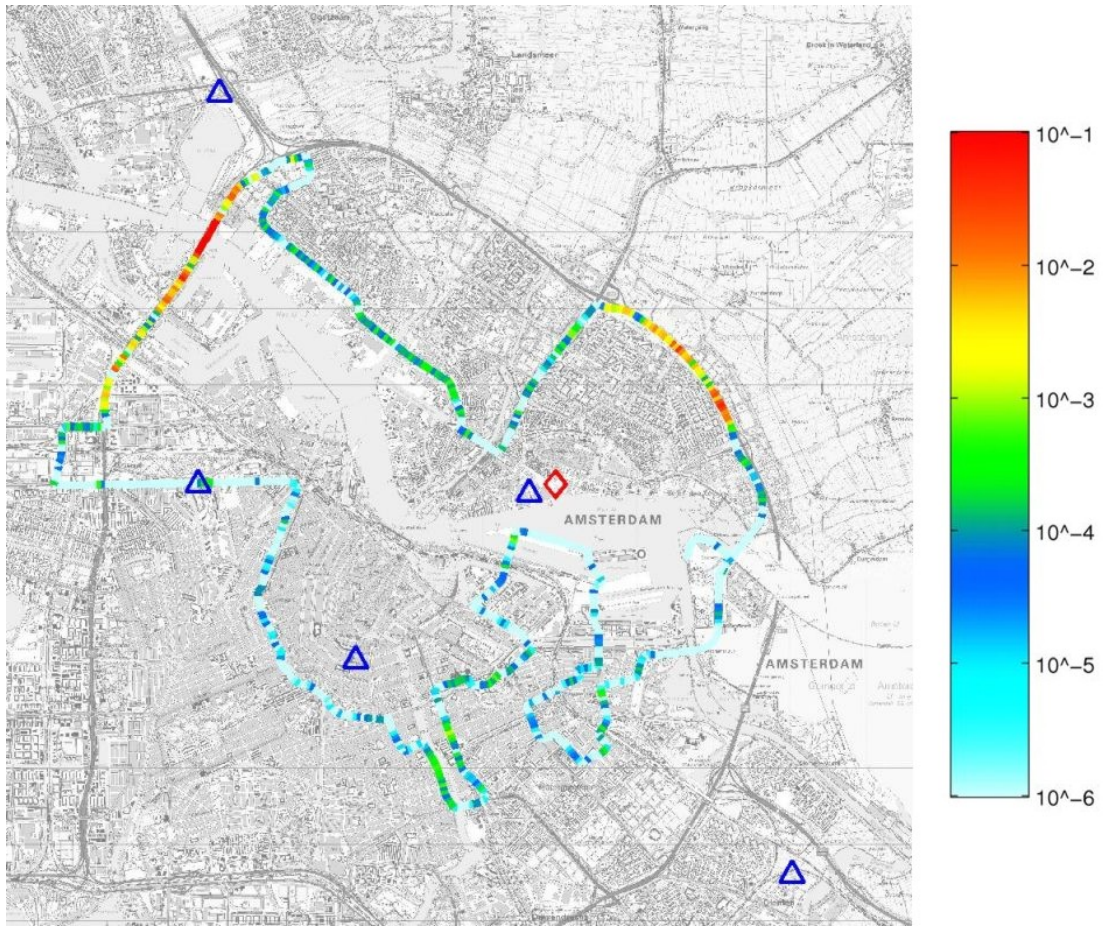

Figure 2.31: BER after FEC of channel LH for protection level UEP4 


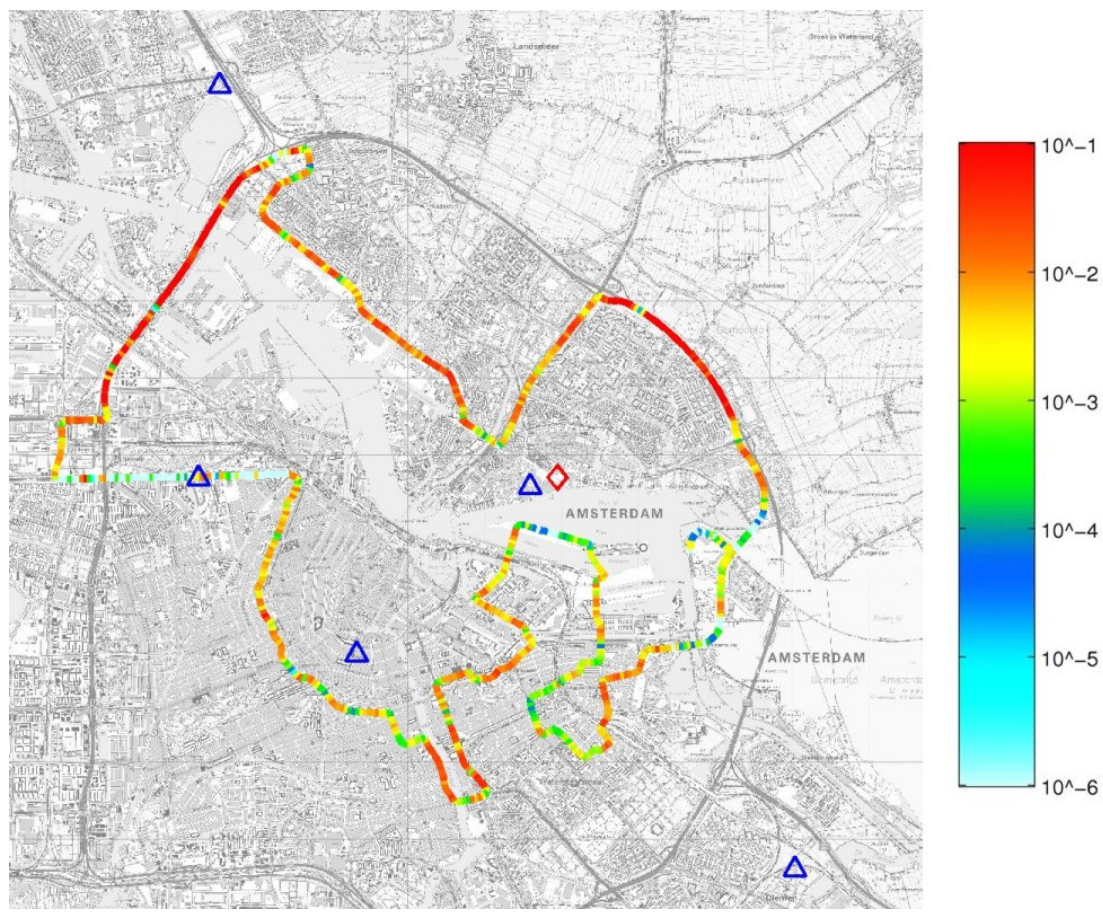

Figure 2.32: BER after FEC of channel LH for protection level UEP5 


\subsubsection{SFN network gain}

In Figure 2.25, the field strength of channel 12B for multiple measurement routes has been plotted. Figure 2.33 depicts the field strength of the network when a single transmitter is switched on. The difference between both figures can be considered as SFN gain. This gain can be up to $10 \mathrm{~dB}$. During the coverage measurements, no occurrences of flat fading were measured. 


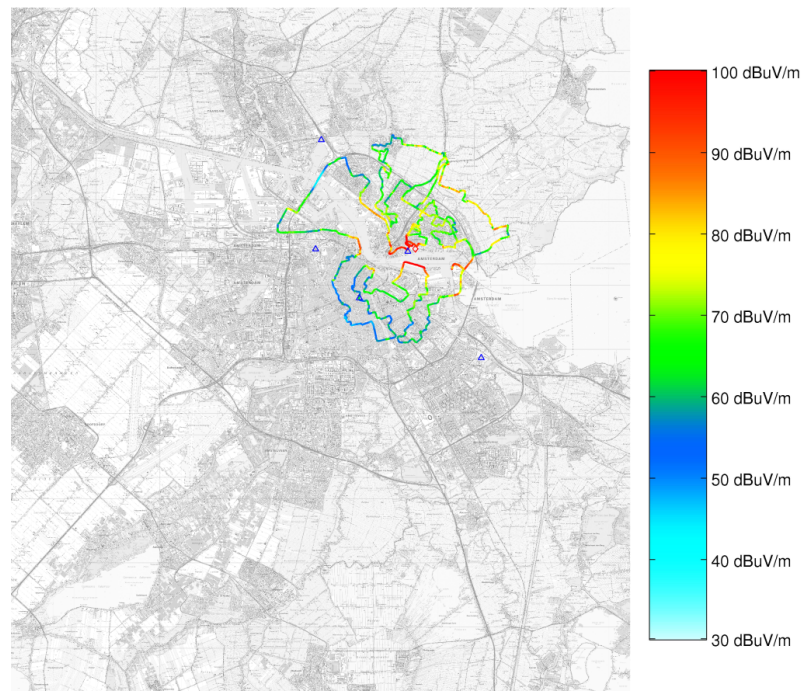

(a) Aambeeldstraat

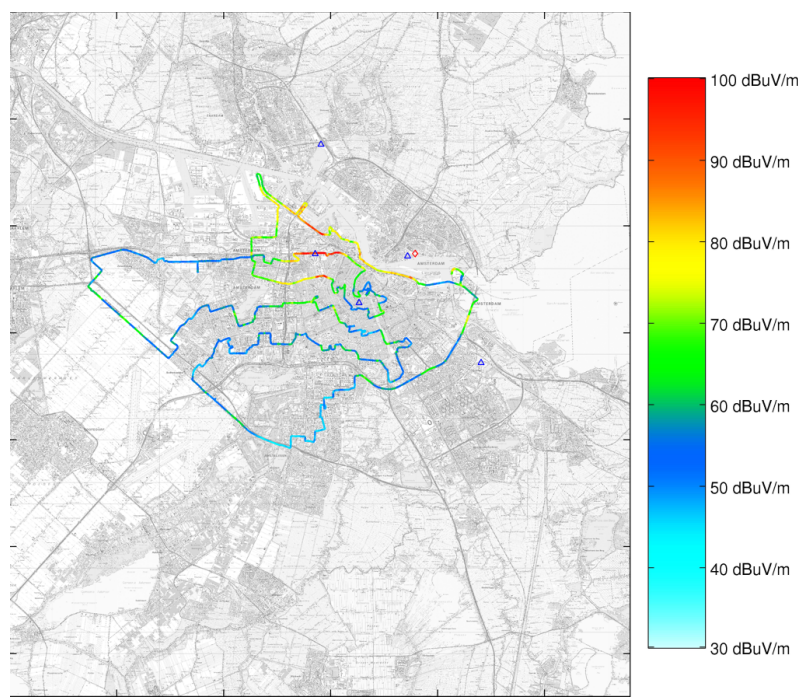

(b) Vredehof

Figure 2.33: Field strength of channel LH when one transmitter is switched on at a time 


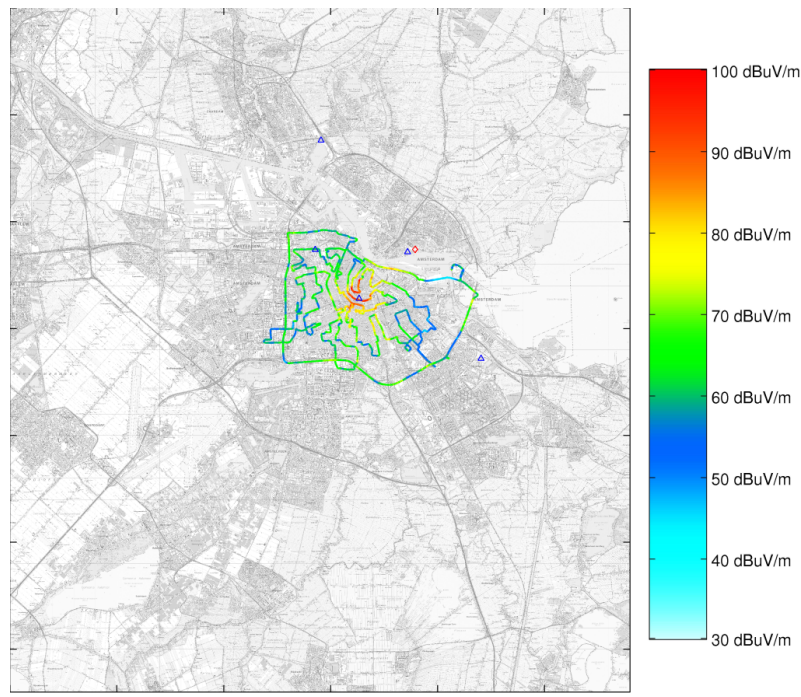

(c) de Bazel

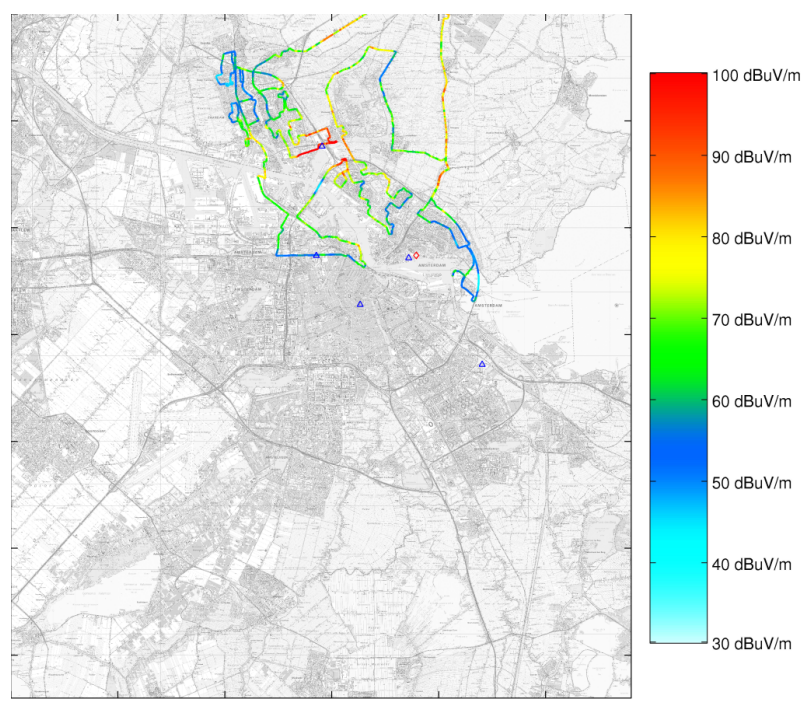

(d) Oostzaan

Figure 2.33: Field strength of channel LH when one transmitter is switched on at a time (cont) 


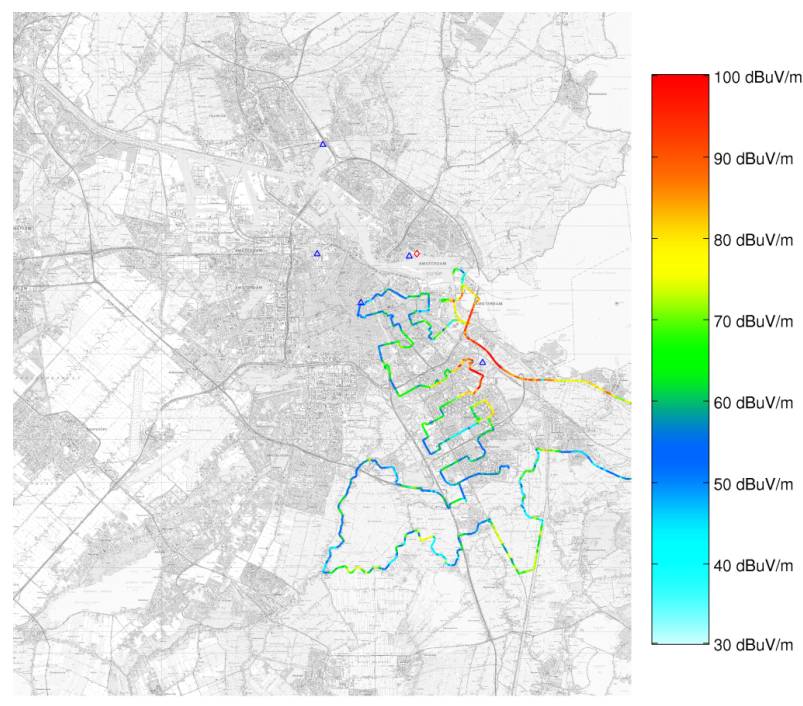

(e) Diemen

Figure 2.33: Field strength of channel LH when one transmitter is switched on at a time (cont) 


\section{Chapter 3}

\section{Indoor measurements}

\subsection{Introduction}

This chapter describes the results of the indoor measurements. The indoor radio environment is not constant in time and location. This is due to the movement of people and the large number of objects in buildings that can reflect or scatter the radio signal [27]. A general introduction about the indoor and outdoor wireless channel can be found in [3]. For reproducibility reasons, the influence of moving objects (e.g. people) and bodyloss (mobile devices carried on the body) are measured separately. The results of these bodyloss experiments are presented in Section 4.3 .

The distribution of field strength at a particular point tends to be log-normal distributed [19]. Variations are caused by time varying changes in the radio environment such as moving objects. In a static environment without moving objects, spatial field strength differences are much larger than in time. Moreover, in buildings, attenuation mainly depends on the distance from the outer wall (but is not linear as it also depends on the interior design) [28].

The received field strength depends on the antenna height of the receiver. At ground level the field strength is the lowest, as this level "sees" the most obstacles between the transmitter and receiver. For that reason, 
indoor coverage is most critical at ground level.

In the past, several other indoor measurements have been conducted. In the UK, the $B B C[4,5,6]$ has measured 39 objects for band III. In this research the median loss was $8 \mathrm{~dB}$ with a standard deviation of $4 \mathrm{~dB}$. Good indoor coverage is achieved, if $95 \%$ of the locations are covered. For the $\mathrm{BBC}$ research this means that the indoor loss for $95 \%$ of the locations is $14.4 \mathrm{~dB}$. Another research in the UK has been performed by the NTL [29]. This researched focussed mainly on large buildings, e.g. offices for band III. The indoor loss in this research was $20.0 \mathrm{~dB}$ for $95 \%$ of the locations. The L-band indoor penetration loss has been researched both in Germany and Canada. In Canada [9], the penetration loss was between 3 to $30 \mathrm{~dB}$, with a typical value of 15 to $20 \mathrm{~dB}$. In Dresden, Germany, a median indoor loss of about $10 \mathrm{~dB}$ has been measured [30]. Recently, the results have been published of a building indoor penetration loss survey in Sydney [31]. In this trial, the losses of both band III and the L-band were measured. This average loss for band III and the L-band for coverage in $95 \%$ of the locations were $18.8 \mathrm{~dB}$ and $22.4 \mathrm{~dB}$, respectively.

The outline of this chapter is as follows. First the measurement setup is described. Before the indoor measurements can be carried out, calibration of the indoor measuring setup has to take place, so this is discussed next. The last part of this chapter consists of the results of the indoor measurements.

\subsection{Measurement setup}

Figure 3.1 shows a photograph of the measurement indoor unit. The unit has been built into a custom-made flight case for easy transportation. The setup of the indoor unit is very similar to the measurement vehicle. Figure 3.2 depicts the block diagram. For field strength measurements we used the Rhode $\mathcal{E}$ Schwarz ESPI, and for qualitative analysis of the DAB signal a RadioScape RS-T1000b DAB monitor was installed. A $20 \mathrm{~m}$ long RF cable (Aircell 7) is connected to the equipment with on the other side the antenna with an RF amplifier to compensate for cable and insertion losses. 


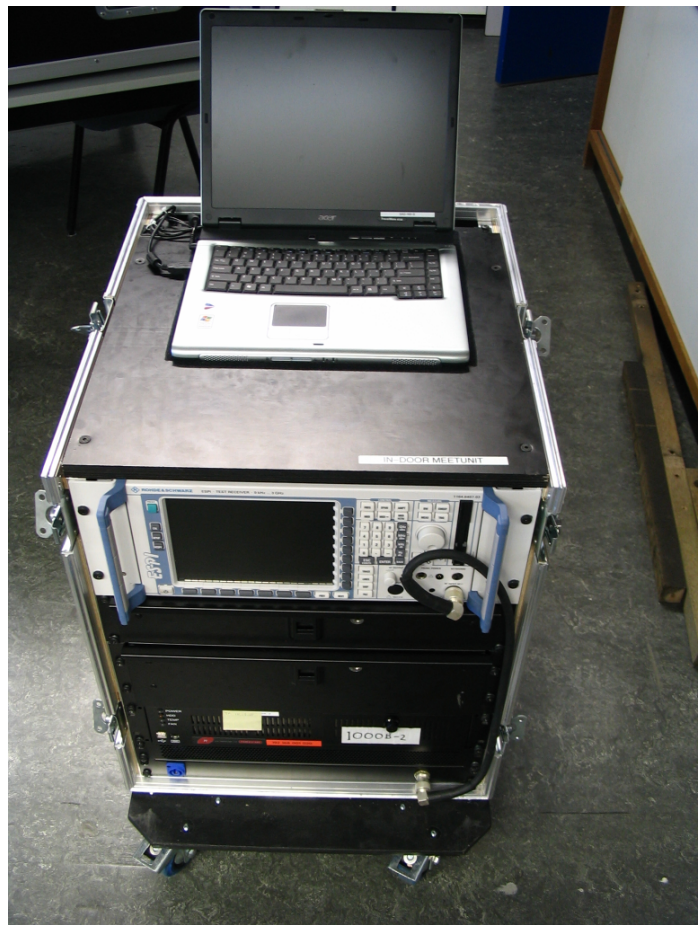

Figure 3.1: Photograph of the indoor unit

For the L-band the total loss is about $10 \mathrm{~dB}$ and for band III a similar value can be found due to the use of a passive splitter. The two RF switches ( $D B$ products 6SS1R31) allow selection of band III or L-band measurements.

For the band III, a custom-made dipole for channel 12 and Mini-Circuits (ZX60-3018G-S) amplifier was used with a passive 2-way splitter (Mini-Circuits (ZA2CS-500-15W-S)). For the L-band, the European Antennas VOA4-1500/054 antenna and a Mini-circuits (ZX60-2534M-S) amplifier was installed with an ETL active 2-way 0-dB splitter (DIV 04 L1 A-2322 S).

The indoor measurements are only relative measurements, so the only purpose of the amplifiers is to compensate for cable losses. Both antennas 


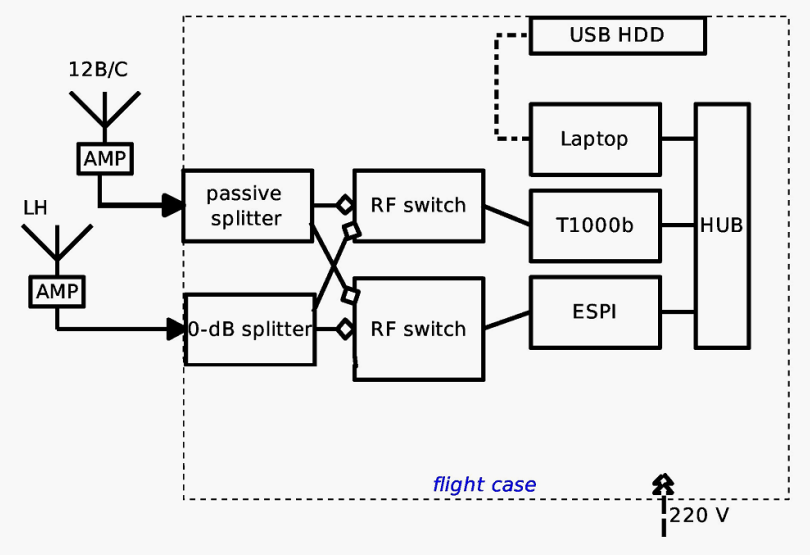

Figure 3.2: Block diagram of the indoor unit

are installed on a small mast with a height of $73 \mathrm{~cm}$ (i.e. table height). Figure 3.3 presents the measurement setup of both antennas.

\subsubsection{Method}

According to the indoor research conducteed in Dresden [30], the spatial variations of the field strength are much larger than the variations in time at one particular location. Moreover, the distribution of the field strength tends to be log-normal. The standard deviation of the spatial variations is $3.5 \mathrm{~dB}$, while for time a value of $0.8 \mathrm{~dB}$ [30] was found. Other trials in Spain [32], Germany [8] and the UK [4, 5, 6, 29] found a slightly higher standard deviation. The research in Germany [8] indicated also that an SFN network will lower this value compared to a single transmitter.

The basic indoor measurement setup is to measure $\mathrm{N}$ points inside a building and $\mathrm{M}$ points outside. There is a tradeoff between the number of points (and therefore also the measurement time of one object) and the accuracy of the measurement.

To validate that the received signal has an log-normal distribution, we 


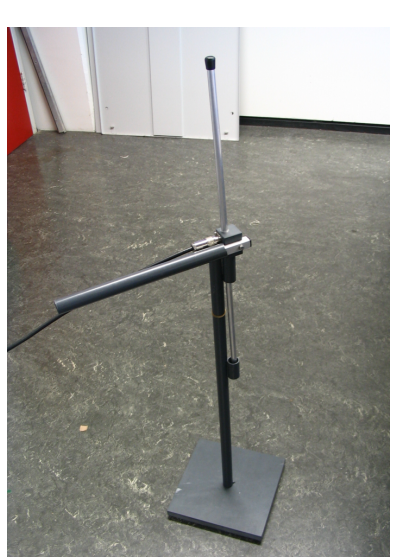

(a) band III

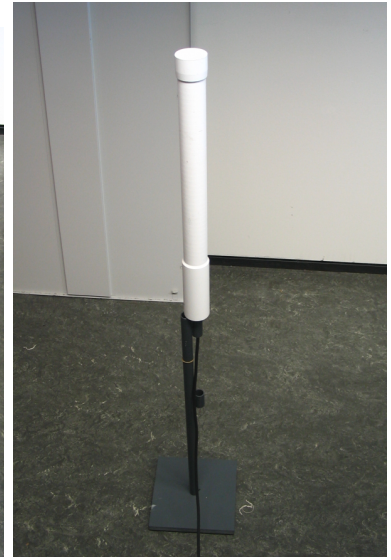

(b) L-band

Figure 3.3: Indoor antennas

performed an endurance measurement in Amsterdam. This involved the measurement of the received signal of the L-band network every $96 \mathrm{~ms}$ for about three days ${ }^{1}$. The histogram of the received signal is displayed in Figure 3.4. which indeed resembles a log-normal distribution.

In our research, we chose to measure for channel 12B, 12C and LH, 16 independent ${ }^{2}$ points indoor ( $5 \mathrm{~s}$ each) and 8 independent points outdoor (10 s each). With the values reported in Dresden [30], this results in an accuracy of indoor loss of $\pm 1.6 \mathrm{~dB}$ with a confidence interval of $85 \%$. An improvement of the accuracy to $\pm 0.8 \mathrm{~dB}$ would require 4 times more measurement points. The above scheme allowed us to perform an indoor measurement in 2 hours (typical time).

In the indoor unit, the laptop is the control center. The university has developed a program to configure the ESPI to the selected channel (12B, $12 \mathrm{C}$ or $\mathrm{LH}$ ) and a bandwidth of $1.5 \mathrm{MHz}$ with an integration time of $96 \mathrm{~ms}$

\footnotetext{
${ }^{1}$ The location was situated between the Aambeeldstraat and Vredehof transmitter.

${ }^{2}$ Measurement points can be considered to be independent if the distance to other points is at least $\frac{1}{2} \lambda$.
} 


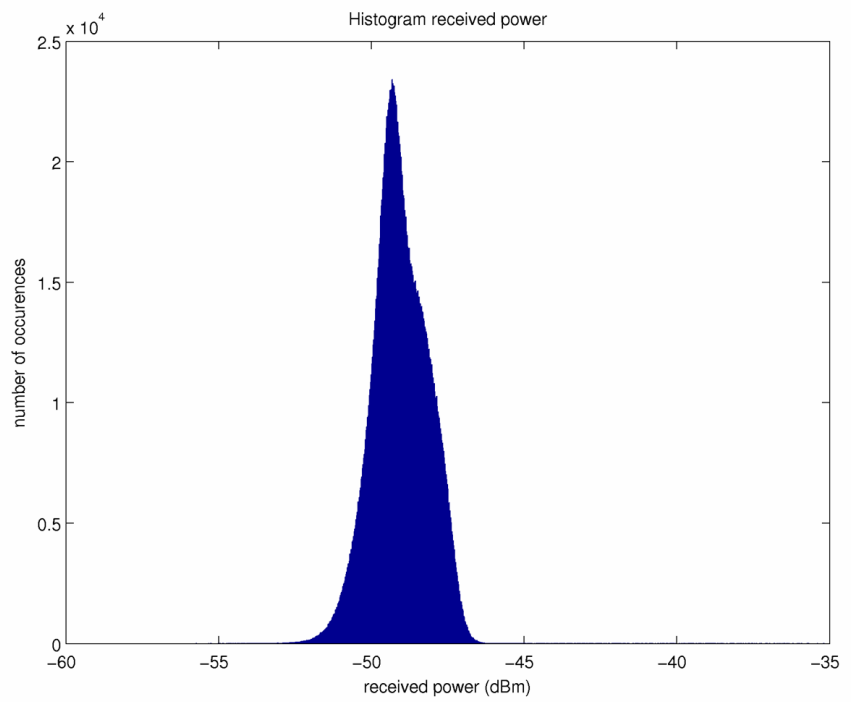

Figure 3.4: Histogram of received signal (3 days, channel LH) 


\subsection{Results}

(the duration of a DAB frame). Moreover, it selects the correct RF input of the RF switch.

In one measurement of 5 seconds, the ESPI is configured to measure 52 values. Simultaneously with these measurements, the DAB RS-T1000b monitor logs several parameters, which include time, BER before and after FEC, SNR null symbol, constellation diagram and CIR All log files are combined offline and processed in Matlab.

\subsubsection{Calibration}

The indoor measurements only focus on relative field strength (i.e. difference between outside and inside field strength). For that reason we only have to determine the antenna diagram of the antennas used.

\section{Antenna diagram measurement}

We determined the antenna diagram using the same procedure as in Section 2.3.2. For the purpose of these measurements, the antennas were mounted in a similar way as for the indoor measurements. The results are depicted in Figures 3.5 and 3.6 . For both antennas, the field strength can be determined with an accuracy of $\pm 1 \mathrm{~dB}$. As the ESPI has a smaller accuracy $( \pm 1.5 \mathrm{~dB})$, the accuracy of the ESPI will determine the accuracy of the indoor penetration loss measurements.

\subsection{Results}

This section presents the results of the indoor measurements. First, the results of one example indoor measurement are discussed. The second part describes the typical indoor loss for each channel.

\subsubsection{Example of an indoor measurement}

Figure 3.7 depicts the location of object where an indoor measurement has been conducted. It is located between the Vredehof, de Bazel and 


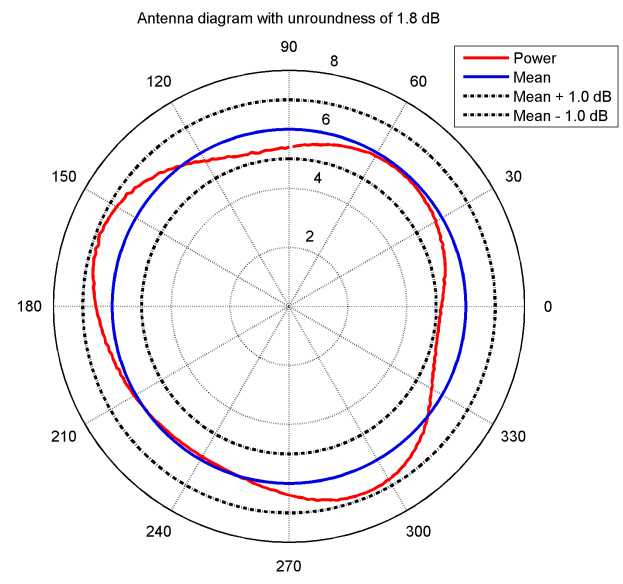

Figure 3.5: Antenna diagram of the indoor antenna (band III, 12B)

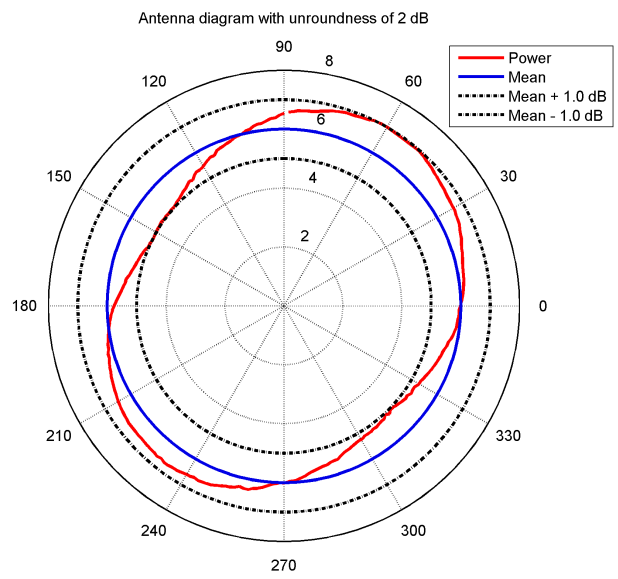

Figure 3.6: Antenna diagram of the indoor antenna (L-band, LH) 


\begin{tabular}{c|c|c|c|}
$\begin{array}{c}\text { point } \\
\text { no. }\end{array}$ & $\begin{array}{c}\text { mean of } \\
\text { loss [dB] }\end{array}$ & $\begin{array}{c}\text { std. dev. } \\
\text { loss [dB] }\end{array}$ & $\begin{array}{c}\text { TII } \\
\text { codes }\end{array}$ \\
\hline 1 & +5.2 & $1.5 \mathrm{e}+00$ & $3: 3(89)$ \\
2 & +3.1 & $9.7 \mathrm{e}-01$ & $3: 3(95)$ \\
3 & +4.3 & $2.6 \mathrm{e}-01$ & $3: 3(82)$ \\
4 & +6.1 & $1.4 \mathrm{e}-01$ & $3: 3(74)$ \\
5 & +5.4 & $5.9 \mathrm{e}-02$ & $1: 1(51) 3: 3(36)$ \\
6 & +0.2 & $7.3 \mathrm{e}-02$ & $3: 3(40)$ \\
7 & -2.4 & $7.4 \mathrm{e}-02$ & $3: 3(100)$ \\
8 & +0.5 & $3.7 \mathrm{e}+00$ & $3: 3(90)$ \\
9 & +1.5 & $1.8 \mathrm{e}-01$ & $3: 3(93)$ \\
10 & +1.6 & $1.1 \mathrm{e}-01$ & $3: 3(78)$ \\
11 & +4.4 & $3.7 \mathrm{e}+00$ & $1: 1(67)$ \\
12 & +4.4 & $5.9 \mathrm{e}-02$ & $1: 1(48) 3: 3(85)$ \\
13 & +2.2 & $5.1 \mathrm{e}-02$ & $1: 1(90) 3: 3(36)$ \\
14 & +9.7 & $9.9 \mathrm{e}-01$ & $1: 1(14) 3: 3(84)$ \\
15 & +2.3 & $1.0 \mathrm{e}-01$ & $1: 1(86)$ \\
16 & -4.0 & $4.0 \mathrm{e}-02$ & n.a.
\end{tabular}

Table 3.1: Results of sample indoor measurement for channel 12B

Aambeeldstraat transmitters. It is important to note that the results are unique for each object. So the results of this object cannot be extrapolated to other objects.

Figure 3.8 and Table 3.1 show the results for channel 12B. Both the Vredehof and Aambeeldstraat transmitter can be received at this location. See Section 2.2.2 for the meaning of the TII codes. The values after the TII code give the relative field strength compared to other transmitters. The indoor loss is $2.8 \mathrm{~dB}$.

Figure 3.9 and Table 3.2 reveal the results for channel 12C. For this network only the IJ-mast transmitter can be received. The loss is $4.5 \mathrm{~dB}$ which is slightly higher than the loss for the other band III network.

Figure 3.10 and Table 3.3 give the values for the L-band measurements. 


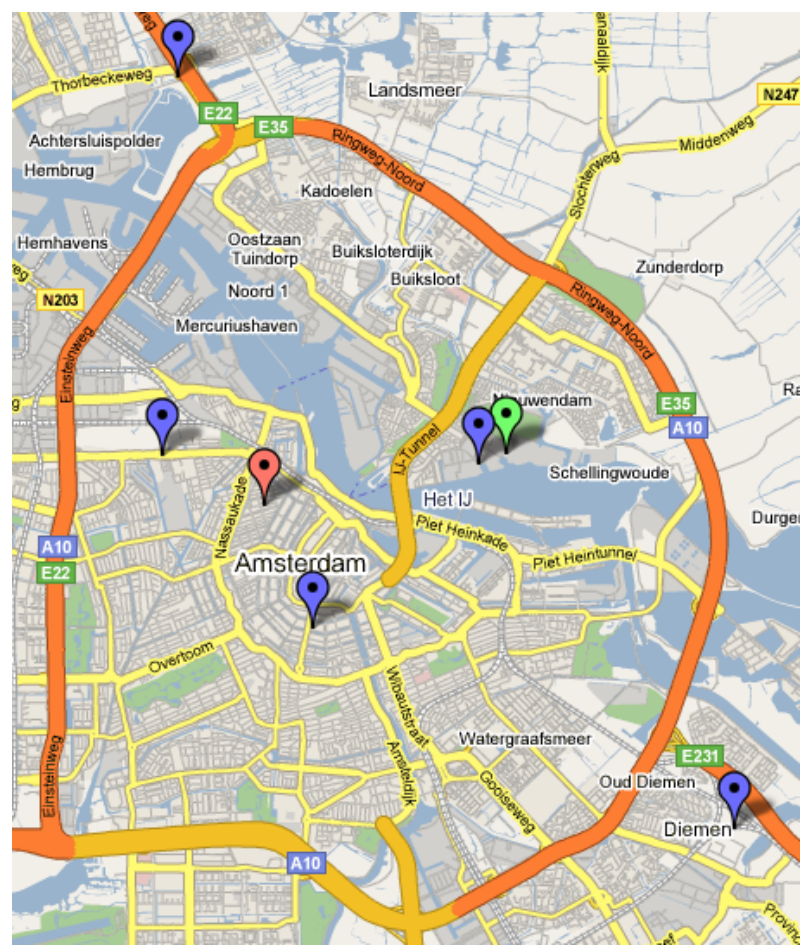

Figure 3.7: Location of the sample object (legend: red = indoor location, blue $=$ transmitters of pilot network, green $=$ transmitters of Publieke Omroep) (CGoogle Maps 


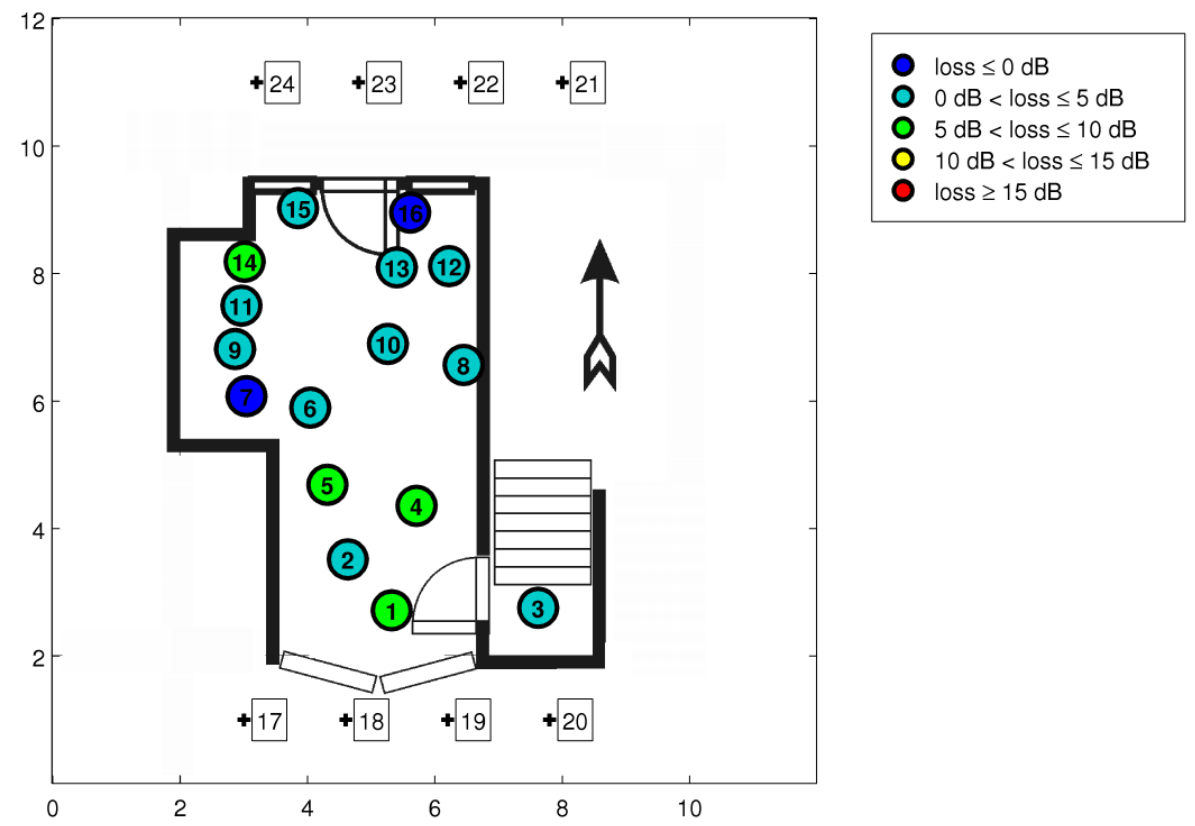

Figure 3.8: Results of sample indoor measurement for channel 12B 


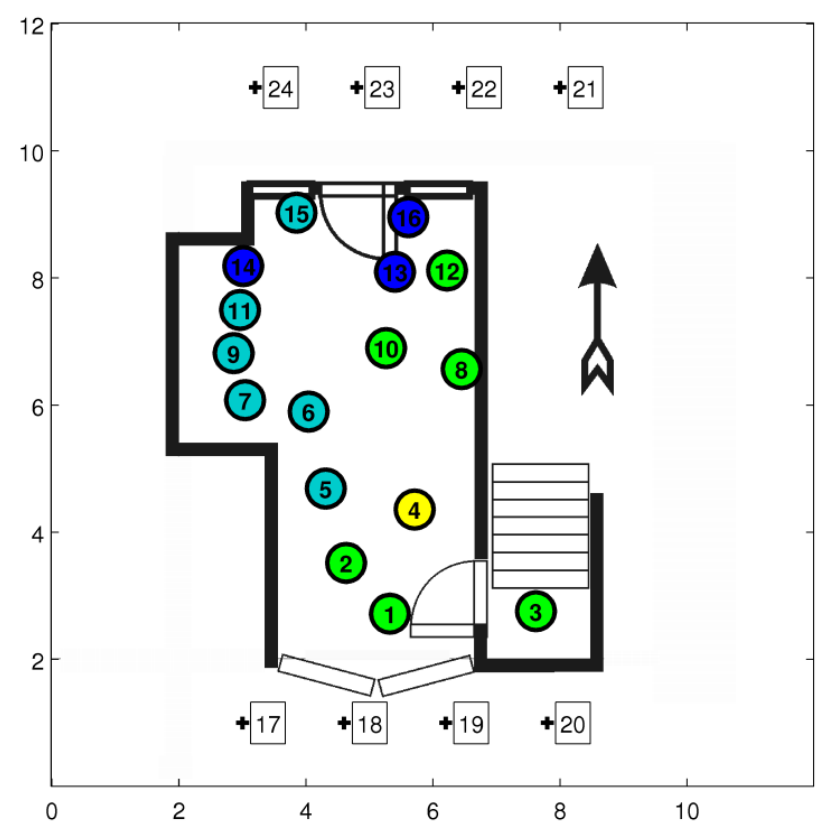

- loss $\leq 0 \mathrm{~dB}$

- $0 \mathrm{~dB}<$ loss $\leq 5 \mathrm{~dB}$

O $5 \mathrm{~dB}<$ loss $\leq 10 \mathrm{~dB}$

O $10 \mathrm{~dB}<$ loss $\leq 15 \mathrm{~dB}$

- loss $\geq 15 \mathrm{~dB}$

Figure 3.9: Results of sample indoor measurement for channel 12C

Interestingly, the de Bazel transmitter cannot be received at this location. Probably the signal from this transmitter site is blocked by high buildings. The loss for channel LH is $10.4 \mathrm{~dB}$.

\subsubsection{Indoor penetration loss}

The indoor penetration loss depends both on the construction materials used and on the location and surroundings of the object. For that reason we chose to measure many objects. During a 5-week measurement campaign, 49 objects were measured. The objects are mostly situated in an area where multiple transmitters can be received and where the outdoor field strength is high enough to allow an indoor measurement.

After the measurement campaign, we removed invalid indoor 


\begin{tabular}{c|c|c|c|}
$\begin{array}{c}\text { point } \\
\text { no. }\end{array}$ & $\begin{array}{c}\text { mean of } \\
\text { loss [dB] }\end{array}$ & $\begin{array}{c}\text { std. dev. } \\
\text { loss [dB] }\end{array}$ & $\begin{array}{c}\text { TII } \\
\text { codes }\end{array}$ \\
\hline 1 & +8.4 & $4.4 \mathrm{e}-01$ & $1: 9(82)$ \\
2 & +7.0 & $1.8 \mathrm{e}-01$ & $1: 9(83)$ \\
3 & +8.3 & $5.4 \mathrm{e}-01$ & $1: 9(88)$ \\
4 & +12.2 & $1.0 \mathrm{e}+00$ & $1: 9(56)$ \\
5 & +2.7 & $7.1 \mathrm{e}-02$ & $1: 9(69)$ \\
6 & +4.6 & $1.1 \mathrm{e}-01$ & $1: 9(47)$ \\
7 & +4.9 & $1.4 \mathrm{e}+00$ & $1: 9(62)$ \\
8 & +9.5 & $9.3 \mathrm{e}-01$ & $1: 9(58)$ \\
9 & +1.0 & $1.8 \mathrm{e}-01$ & $1: 9(69)$ \\
10 & +8.2 & $1.1 \mathrm{e}+00$ & $1: 9(53)$ \\
11 & +4.1 & $1.4 \mathrm{e}-01$ & $1: 9(70)$ \\
12 & +7.7 & $6.2 \mathrm{e}-01$ & $1: 9(64)$ \\
13 & -2.1 & $1.6 \mathrm{e}-01$ & $1: 9(100)$ \\
14 & -1.5 & $9.7 \mathrm{e}-02$ & $1: 9(71)$ \\
15 & +0.5 & $4.8 \mathrm{e}-01$ & $1: 9(87)$ \\
16 & -2.4 & $8.4 \mathrm{e}-02$ & $1: 9(92)$
\end{tabular}

Table 3.2: Results of sample indoor measurement for channel 12C 


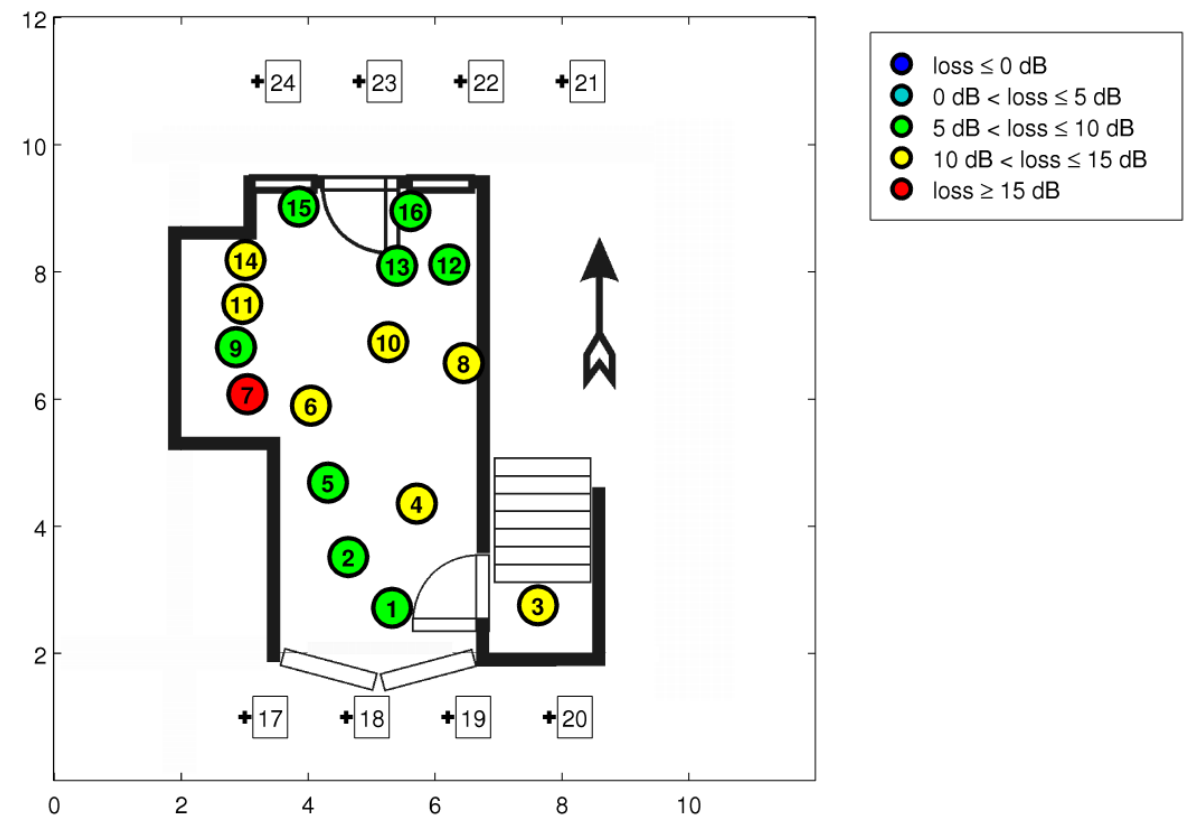

Figure 3.10: Results of sample indoor measurement for channel LH 


\begin{tabular}{c|c|c|c|}
$\begin{array}{c}\text { point } \\
\text { no. }\end{array}$ & $\begin{array}{c}\text { mean of } \\
\text { loss [dB] }\end{array}$ & $\begin{array}{c}\text { std. dev. } \\
\text { loss [dB] }\end{array}$ & $\begin{array}{c}\text { TII } \\
\text { codes }\end{array}$ \\
\hline 1 & +5.1 & $4.3 \mathrm{e}-01$ & $1: 1(37) 3: 3(40)$ \\
2 & +7.0 & $4.6 \mathrm{e}-01$ & $3: 3(37)$ \\
3 & +10.8 & $1.4 \mathrm{e}-01$ & $1: 1(25) 3: 3(33)$ \\
4 & +13.7 & $5.8 \mathrm{e}-01$ & $1: 1(19) 3: 3(4)$ \\
5 & +9.7 & $1.1 \mathrm{e}-01$ & $3: 3(11)$ \\
6 & +10.5 & $6.4 \mathrm{e}-01$ & $3: 3(23)$ \\
7 & +16.1 & $1.1 \mathrm{e}+00$ & $3: 3(13)$ \\
8 & +11.1 & $3.7 \mathrm{e}-01$ & $3: 3(38)$ \\
9 & +8.2 & $3.9 \mathrm{e}-01$ & $3: 3(35)$ \\
10 & +13.0 & $4.0 \mathrm{e}-01$ & $1: 1(12) 3: 3(27)$ \\
11 & +13.8 & $4.3 \mathrm{e}-01$ & $3: 3(28)$ \\
12 & +9.9 & $1.9 \mathrm{e}-01$ & $3: 3(31)$ \\
13 & +9.7 & $4.3 \mathrm{e}-01$ & $3: 3(37)$ \\
14 & +14.7 & $1.1 \mathrm{e}+00$ & $3: 3(31)$ \\
15 & +7.5 & $8.2 \mathrm{e}-01$ & $3: 3(45)$ \\
16 & +5.4 & $3.9 \mathrm{e}-01$ & $3: 3(38)$
\end{tabular}

Table 3.3: Results of sample indoor measurement for channel LH 


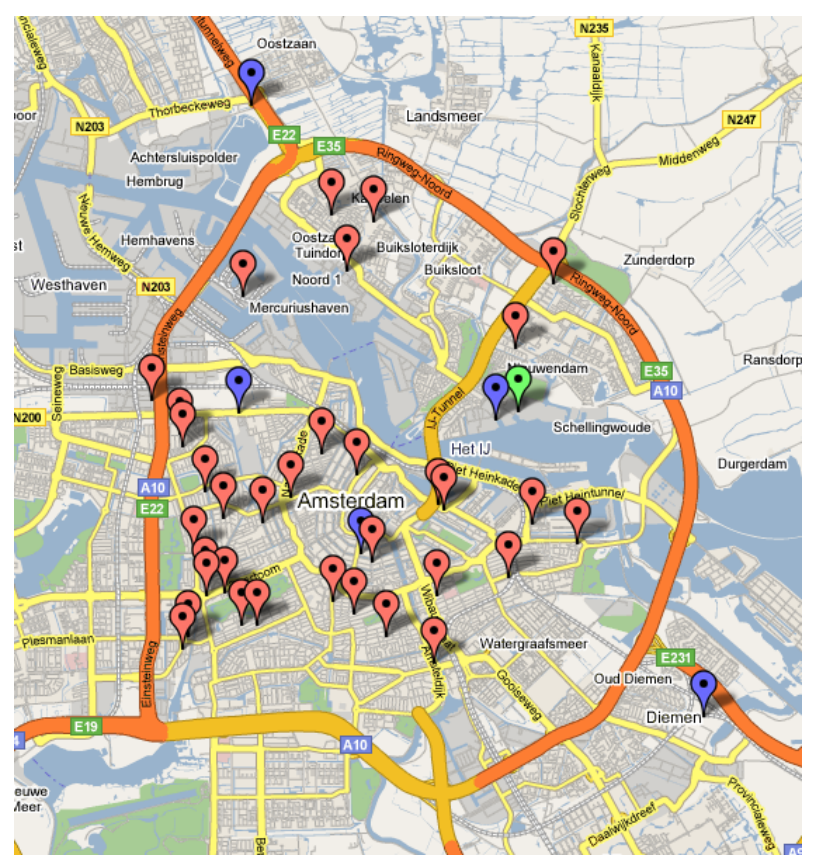

Figure 3.11: Valid indoor locations, (legend: red $=$ indoor locations, blue= transmitters of pilot network, green $=$ transmitters of Publieke Omroep) (C)Google Maps

locations. Examples of invalid locations are situations where indoor and outdoor measurements are at different height $3^{3}$ or where the outdoor measurements are in the shadow of the building, resulting in a negative average indoor penetration loss. After this purge, 34 valid indoor locations remained. These locations are given in Figure 3.11 .

\footnotetext{
${ }^{3}$ For practical reasons, it was not always possible to measure at the same height.
} 


\begin{tabular}{l|cc} 
Channel & $\sigma_{\text {place }}$ & $\sigma_{\text {time }}$ \\
\hline band III 12B & $3.8 \mathrm{~dB}$ & $0.4 \mathrm{~dB}$ \\
band III 12C & $3.6 \mathrm{~dB}$ & $0.4 \mathrm{~dB}$ \\
L-band LH & $3.4 \mathrm{~dB}$ & $0.9 \mathrm{~dB}$
\end{tabular}

Table 3.4: Standard deviation of the received signal $\sigma_{\text {time }}$ and the standard deviation of the means of all measurement points $\sigma_{\text {place }}$ for the indoor measurement points

\section{Results}

Figures 3.12 , 3.13 and 3.14 present the histogram of the indoor loss for the individual measurement point $\mathrm{s}^{4}$. As the indoor loss is defined as the average outdoor field strength minus the indoor field strength, a small portion of the distribution has an indoor gain instead of a loss.

The histogram of these point $5^{5}$ tends to have an Extreme value distribution [33], also known as the log-Weibull distribution. Applying the Jarque-Bera test ${ }^{6}$ to the indoor loss values also showed that these data cannot be considered as a log-normal distribution. This is an important conclusion as other indoor measurements reported a log-normal distribution.

Moreover, also the standard deviation of the spatial field strength variations and the variation of field strength in time were calculated for these indoor points (see Table 3.4). To calculate these values, the Statistics toolbox of Matlab was used. The histogram of the standard deviation in time tends to be a Gamma distribution [23] (Figure 2.12), while the standard deviation in place histogram tends to be a $(\log )$ normal distribution.

Figure 3.15 depicts the mean of the indoor loss for each object?. One can see that there is a relation between the losses of the three channels and

\footnotetext{
${ }^{4}$ A negative value means a loss.

${ }^{5}$ The Statistics toolbox of Matlab was used for fitting the appropriate distribution function.

${ }^{6}$ This test checks if the input data can be considered as a (log-) normal distribution.

${ }^{7}$ Only objects where all bands have valid indoor measurements are shown here.
} 


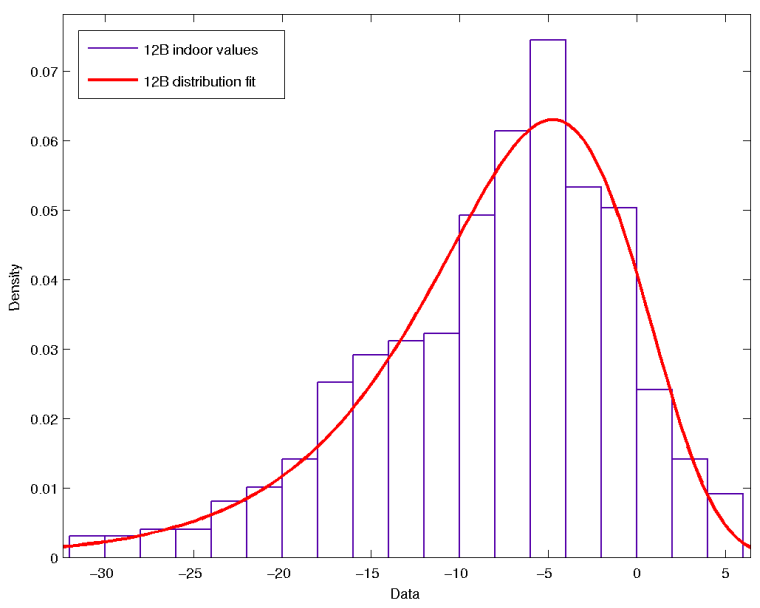

Figure 3.12: Histogram of the indoor loss for channel 12B

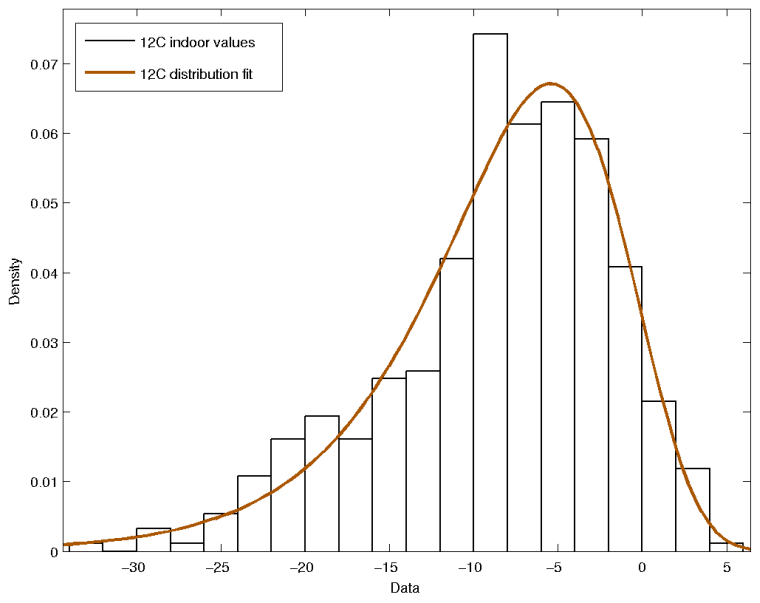

Figure 3.13: Histogram of the indoor loss for channel $12 \mathrm{C}$ 


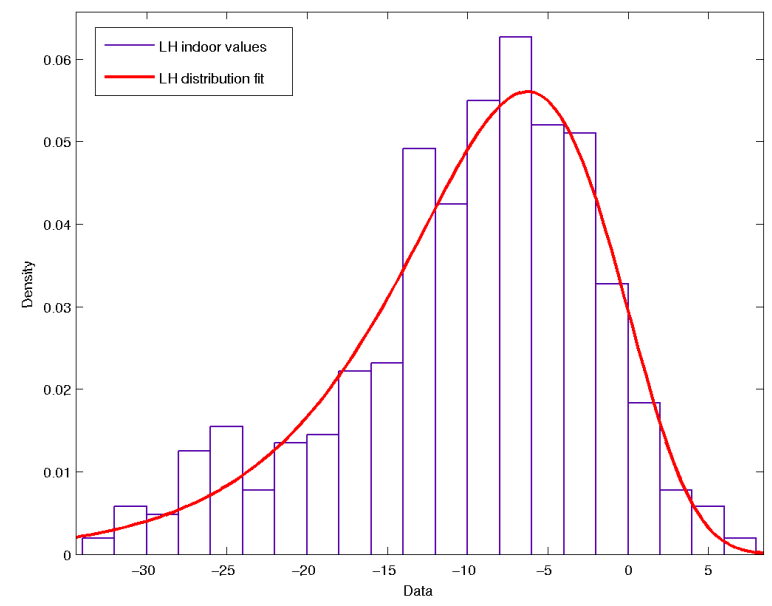

Figure 3.14: Histogram of the indoor loss for channel LH

\begin{tabular}{l|cccc} 
Channel & $\mu$ & $\sigma$ & $95 \%$ & $99 \%$ \\
\hline band III 12B & $-4.7 \mathrm{~dB}$ & $5.8 \mathrm{~dB}$ & $-22.1[ \pm 1.5] \mathrm{dB}$ & $-31.6[ \pm 2.1] \mathrm{dB}$ \\
band III 12C & $-5.4 \mathrm{~dB}$ & $5.5 \mathrm{~dB}$ & $-21.7[ \pm 1.5] \mathrm{dB}$ & $-30.7[ \pm 2.0] \mathrm{dB}$ \\
L-band LH & $-6.3 \mathrm{~dB}$ & $6.6 \mathrm{~dB}$ & $-25.8[ \pm 1.6] \mathrm{dB}$ & $-36.5[ \pm 2.3] \mathrm{dB}$
\end{tabular}

Table 3.5: Properties of the indoor loss distributions

the object.

In Table 3.5, the properties of distributions found in Figures $3.12,3.13$ and 3.14 are given. The $95 \%$ and $99 \%$ columns give the indoor loss values for which $95 \%$ or $99 \%$ of the indoor measurement points have a smaller loss. The value between brackets is the $95 \%$ confidence interval for these values. 


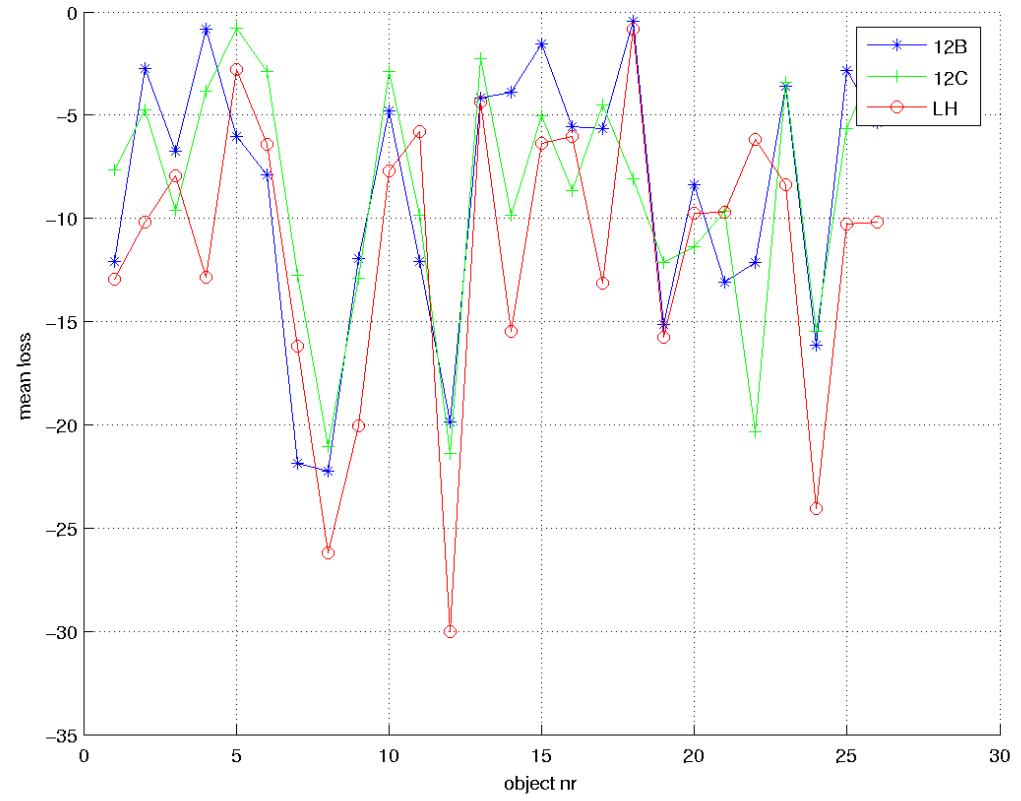

Figure 3.15: Relation between object and indoor loss for each channel 


\section{Chapter 4}

\section{Consumer receivers}

\subsection{Introduction}

This chapter describes the $\mathrm{DAB}$ receiver characteristics for consumer equipment intended for terrestrial and cable reception, operating in band III and L-band. The most interesting parts of this standard from the perspective of the T-DAB receiver experiments are the descriptions of the minimum RF performance levels and measuring methods.

There is not much previous work on the performance of T-DAB consumer receivers. Only in Canada [34] was the performance of L-band receivers investigated for an audio subchannel of $224 \mathrm{kbps}$ using protection level UEP $\beta$.

The outline of this chapter is as follows. First, the consumer receivers that have been tested are presented. This is followed by the measurement setup and an evaluation of the performance of the professional RadioScape RS-T1000b DAB monitor, which was used in the coverage measurements (Chapter 2). Finally, the results of each experiment are discussed. 

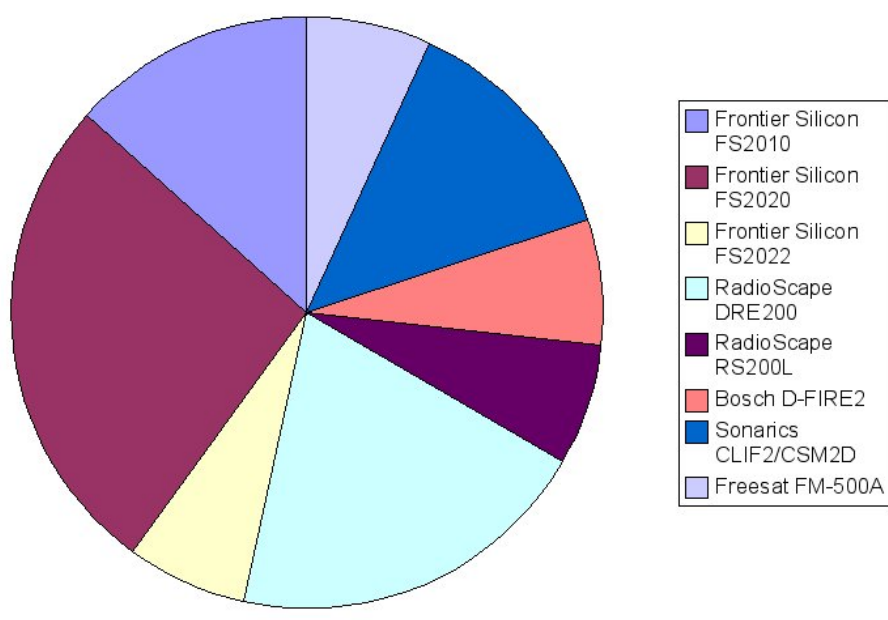

Figure 4.1: Distribution of the chipsets of the tested receivers

\subsection{Consumer receivers}

In our receiver experiments, we tested 15 consumer receivers (Table 4.1), which include different models (personal, portable and hi-fi) and chipsets (see Figure 4.1). Seven receivers also are able to receive the L-band.

This chapter discusses only the performance of the median receiver (both band III and L-band), which is compared to EN 50248 requirements. The median receiver for each experiment is defined as the receiver where $50 \%$ of the tested receivers have a better performance and $50 \%$ a worse performance.

The receivers are evaluated in four different experiments:

1. Sensitivity experiment

2. Adjacent interference experiment

3. Non-adjacent interference experiment

4. In-band interference experiment 


\begin{tabular}{c|c|c} 
Manufacturer & Model & Type \\
\hline Perstel & DR 101 & Personal \\
Pure Digital & TEMPUS-1 & Portable \\
Morphy Richards & Ordio DAB 27015 & Portable \\
FreeSky & FP-2200 & Portable \\
Rebox & R102 & Portable \\
Rebox & R105 & Personal \\
i.Tech & XFM DAB Radio & Portable \\
i.Tech & BT Aviator 10M & Portable \\
Pure Digital & EVOKE-1XT & Portable \\
Pure Digital & Elan & Portable \\
Pure Digital & DRX-702ES & Hi-Fi \\
Pure Digital & DRX-701ES & Hi-Fi \\
Blaupunkt & Nashville DAB35 & Car radio \\
Pure Digital & EVOKE-1XT Tri-Band & Portable \\
Trinloc & Inspiration & Portable
\end{tabular}

Table 4.1: Tested consumer receivers

In addition, we performed a bodyloss measurement for the two personal receivers (Perstel DR101 and Rebox R105).

\subsubsection{Audio quality}

All RF performance measuring methods in EN 50248 require BER measurements. Unfortunately a lot of consumer receivers do not have BER measurement capabilities. Therefore, we cannot use these measuring methods directly in the T-DAB receiver test. Instead of BER, we use the audio quality of the receiver as a performance measure. In order to determine the audio quality of a receiver, we apply a DAB signal mimicking a particular received $\mathrm{RF}$ signal condition to the RF (antenna) input of the receiver and record 25 seconds of the audio signal. We repeat this 15 times for the same received RF signal condition and concatenate the resulting recorded audio signals. The concatenated recorded audio signals 


\begin{tabular}{cl} 
ODG & Description of impairments \\
\hline 0 & Imperceptible \\
-1 & Perceptible but not annoying \\
-2 & Slightly annoying \\
-3 & Annoying \\
-4 & Very annoying
\end{tabular}

Table 4.2: Objective Difference Grade (ODG) scale.

are compared with a concatenated version of the original audio signal using Perceptual Evaluation of Audio Quality (PEAQ) measurement software [35]. This results in an Objective Difference Grade (ODG) indicating the perceptual difference between the recorded receiver audio signal and the original audio signal. The ODG scale ranges from 0 to -4 , see Table 4.2

In the remaining sections, the consumer receiver experiments that have been carried out are described, and further differences with the tests in EN 50248 are indicated. However, the bodyloss measurements will be discussed first.

\subsection{Bodyloss measurements}

Bodyloss is the loss of the received field strength due to bodyworn devices, i.e. the loss introduced by the human body. In this section, we discuss results from literature and compare these with the values we have measured in a simple experiment. Extensive bodyloss measurements are not within the scope of this research.

\subsubsection{Literature}

An extensive literature search using multiple source yielded only two useful articles. The first article [36] is about the bodyloss of handheld Global System for Mobile Communications (GSM telephones. The 


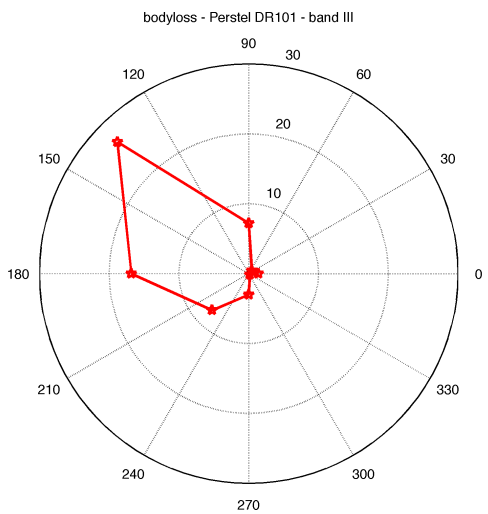

Figure 4.2: Bodyloss diagram of the Perstel DR101 receiver for band III

measured bodyloss (mean) in this article ranges from 0.9 to $16 \mathrm{~dB}$. Moreover, the bodyloss for 44 persons was determined. It was concluded that the bodyloss varies from person to person as could have been expected.

The second article [37] lists some typical bodyloss values. For a hip-mounted device the bodyloss is $17 \mathrm{~dB}$ for a signal of 150 to $170 \mathrm{MHz}$.

\subsubsection{Experimental results}

To validate the results of the literature, we performed an experiment with the two available personal DAB receivers: the Perstel DR101 and the Rebox R105. In this experiment we set up a low power DAB transmitter on an SSM site. In the far field ( $>10 \mathrm{~m})$, a person is located with the DAB receiver. This receiver was mounted in such a way that it mimics normal use.

The power of the transmitter was then reduced until audible bit-errors occurred in the selected MUSICAM subchannel. This experiment was carried out for 8 different angles ( 0 degrees is facing to the transmitter) and repeated by conducting the same experiment without any person. As 


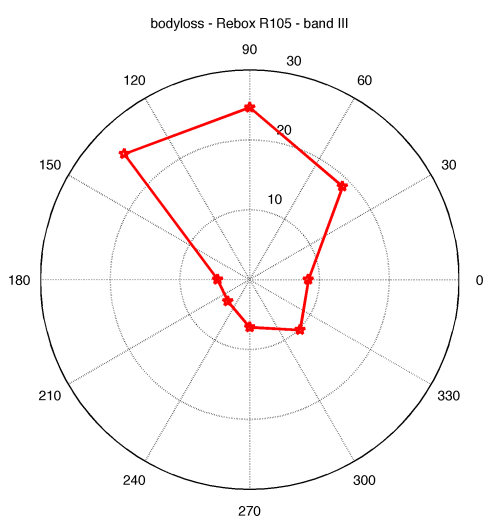

Figure 4.3: Bodyloss diagram of the Rebox R105 receiver for band III

\begin{tabular}{l|c|c|c} 
Receiver & Minimal val. & Median val. & Maximal val. \\
\hline Perstel DR101 (band III) & $-0.6 \mathrm{~dB}$ & $7.7 \mathrm{~dB}$ & $26.6 \mathrm{~dB}$ \\
Rebox R105 (band III) & $4.4 \mathrm{~dB}$ & $12.9 \mathrm{~dB}$ & $25.4 \mathrm{~dB}$ \\
Rebox R105 (L-band) & $9.4 \mathrm{~dB}$ & $17.8 \mathrm{~dB}$ & $26.4 \mathrm{~dB}$
\end{tabular}

Table 4.3: Bodyloss results

the headset is the antenna for band III, we mounted the DAB receiver including headset in the way a person would use it. The difference between the field strength in both experiments is an indication of the bodyloss. The accuracy of this experiment is about $\pm 3 \mathrm{~dB}$ (estimated). Figure 4.4 gives an impression of the test setup.

The results of the bodyloss experiments are depicted in Figures $4.2,4.3$ and 4.5 . 

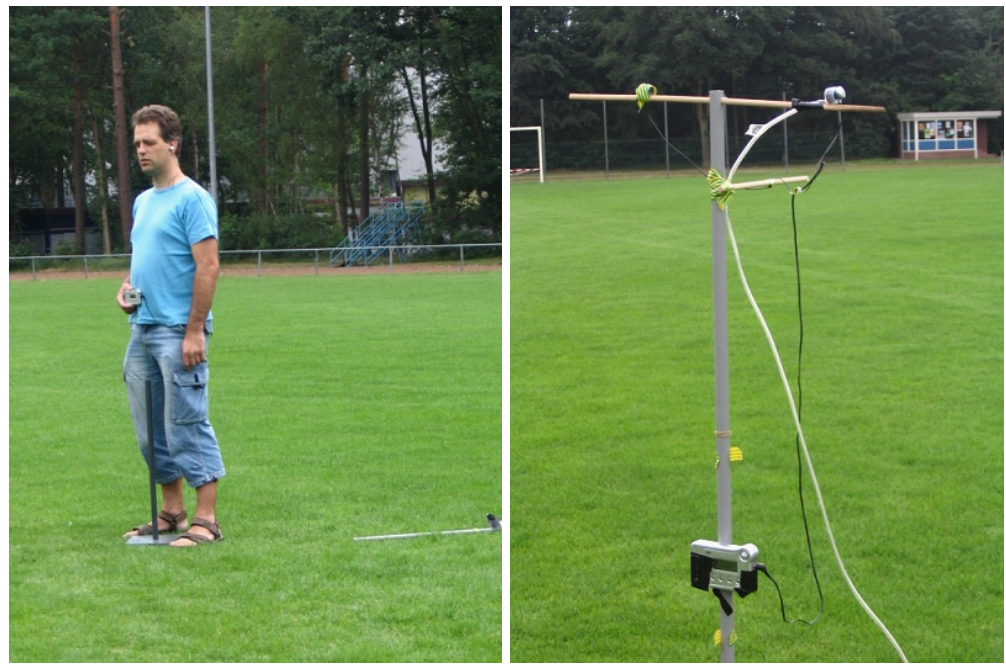

Figure 4.4: Setup of the bodyloss measurements with and without test person

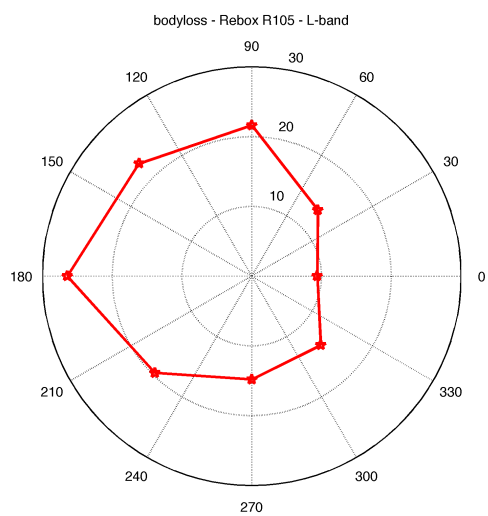

Figure 4.5: Bodyloss diagram of the Rebox R105 receiver for the L-band 
Chapter 4. Consumer receivers

\subsubsection{Discussion}

The experimental results reveal that there is a difference of $5 \mathrm{~dB}$ (mean) between the bodyloss of an earphone antenna and a normal band III antenna. In addition, there is a difference of $5 \mathrm{~dB}$ (mean) between the loss for band III and L-band. Compared with the few results from literature, it can be concluded that the measured results are in the same range. For band III the typical body loss is $10 \mathrm{~dB}$; for the L-band it is $18 \mathrm{~dB}$.

An interesting question arises whether the results derived from the bodyloss experiment mimic a realistic user scenario. In a normal environment, a person receives the radio signal from multiple directions due to reflection to objects and multiple transmitters. Therefore, actual bodyloss is expected to be lower than the measured loss. Further research is necessary to verify this assumption.

\subsection{Measurement setup}

To test the consumer receivers, we first captured the $I / Q$ output of a Plisch DAB transmitter. For the band III consumer tests, DAB mode I was captured; for the L-band, mode IV was captured. See also Figure 4.6. After file capture, the appropiate segment was cut out of the file. This segment can be converted to a file with or without channel model, or it can be converted into an interference file. The generated files are used in the setup of Figures 4.7 and 4.8 .

\subsubsection{Setup}

Figure 4.7 depicts the setup for the sensitivity and maximum input level experiment and Figure 4.8 for the (adjacent/non-adjacent) interference experiments and the in-band interference experiment. For Digital to Analog (DA) conversion, we used custom-built DA boards; for up-conversion the Agilent E4438C generator and Rhode E Schwarz SM300 were utilized. In both setups, PC3 is the master computer which controls 


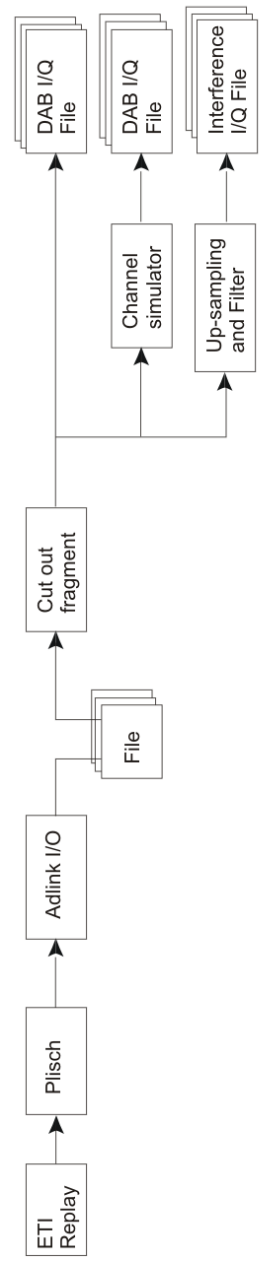

Figure 4.6: Block Scheme for file generation 
Chapter 4. Consumer receivers

all other equipment. It also captures the analog audio output of the Device Under Test (DUT) and calculates the ODG metric for each run.

\subsubsection{Calibration}

A Rhode $\mathcal{E}$ Schwarz ESPI was connected to the RF output after the analog combiner in order to calibrate the analog output of both RF generators.

\subsection{Band III results}

\subsubsection{Performance of RadioScape RS-T1000b DAB monitor}

This section discusses the performance of the RadioScape RS-T1000b DAB monitor which was used in the measurement vehicle. The goal of this section is to put the results in Chapter 2 into perspective. For the coverage measurements only the sensitivity and adjacent channel performance are relevant.

Figure 4.9 depicts the results of the sensitivity tests for the RadioScape RS-T1000b DAB monitor. More information about the sensitivity experiment can be found in Section 4.5.4. The DAB monitor is much more sensitive than the EN 50248 norm. It also has good sensitivity when a channel model is applied. The experiments with a strong adjacent interferer are shown in Figure 4.9 . Also the $\mathrm{DAB}$ monitor meets the requirements for this experiment. More information about the adjacent channel experiments can be found in Section 4.5.5.

\subsubsection{Audio quality versus BER}

In the field trial measurements, the RadioScape RS-T1000b DAB monitor was used. To establish the relation between the consumer experiments and the field trial measurements, we tested this professional receiver as well. In addition, we logged both the BER before error correction (FEC) and the $\mathrm{ODG}$ to establish the relation between the ODG and the BER before FEC 


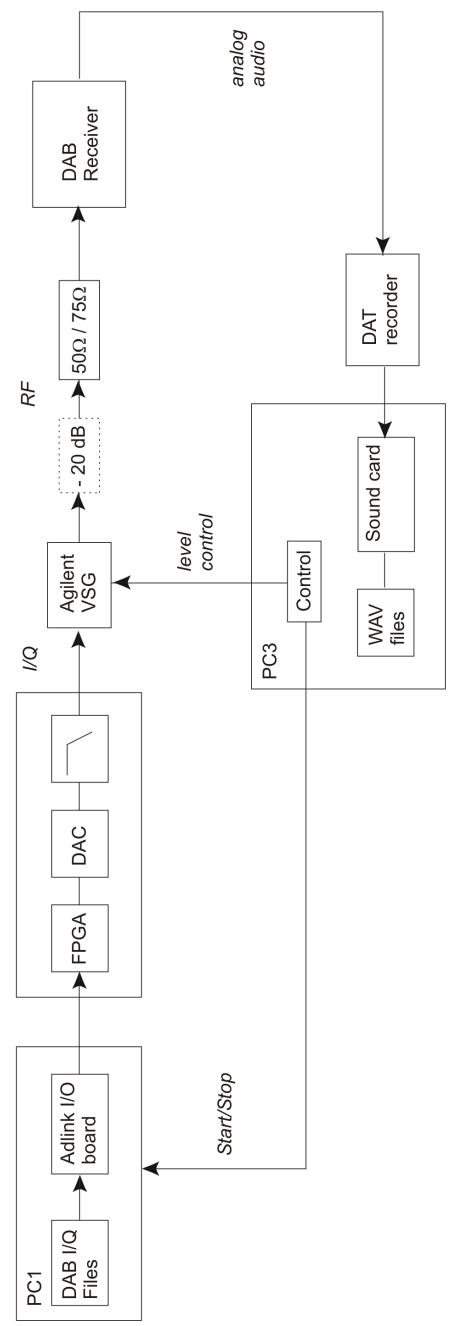

Figure 4.7: Block Scheme Sensitivity and maximum input level test 


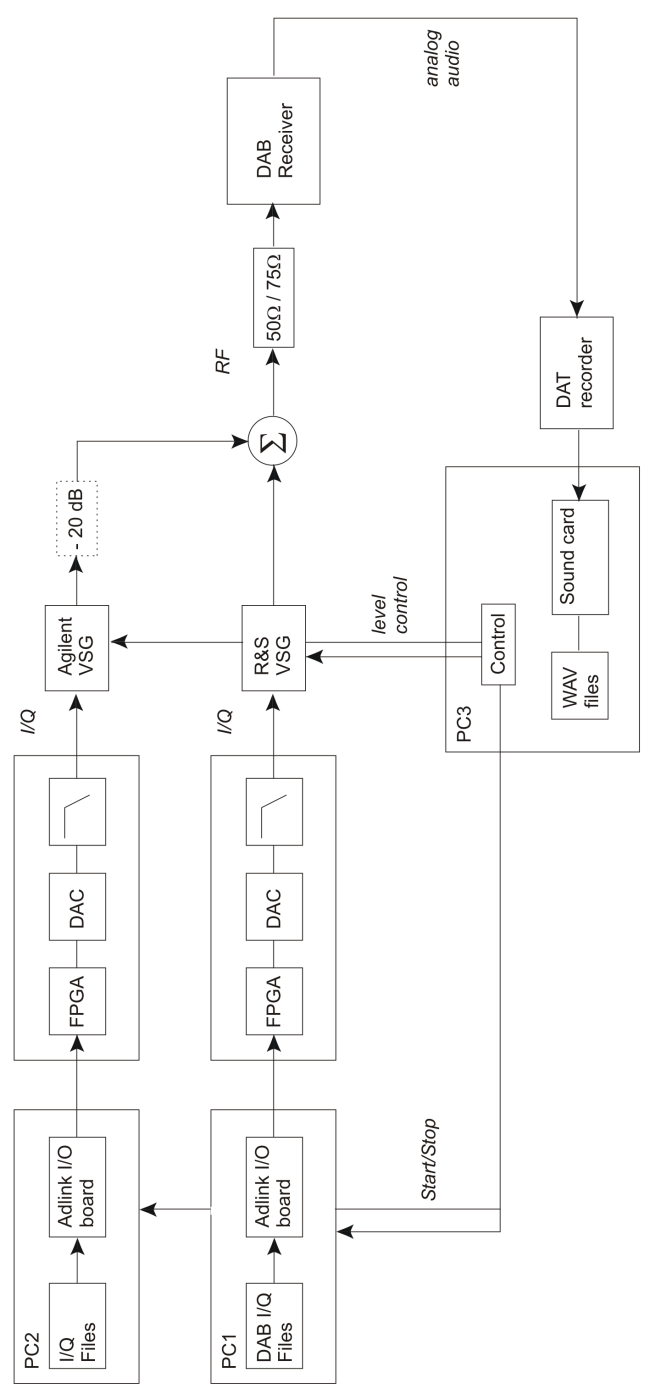

Figure 4.8: Block Scheme Interferer and in-band interference experiment 


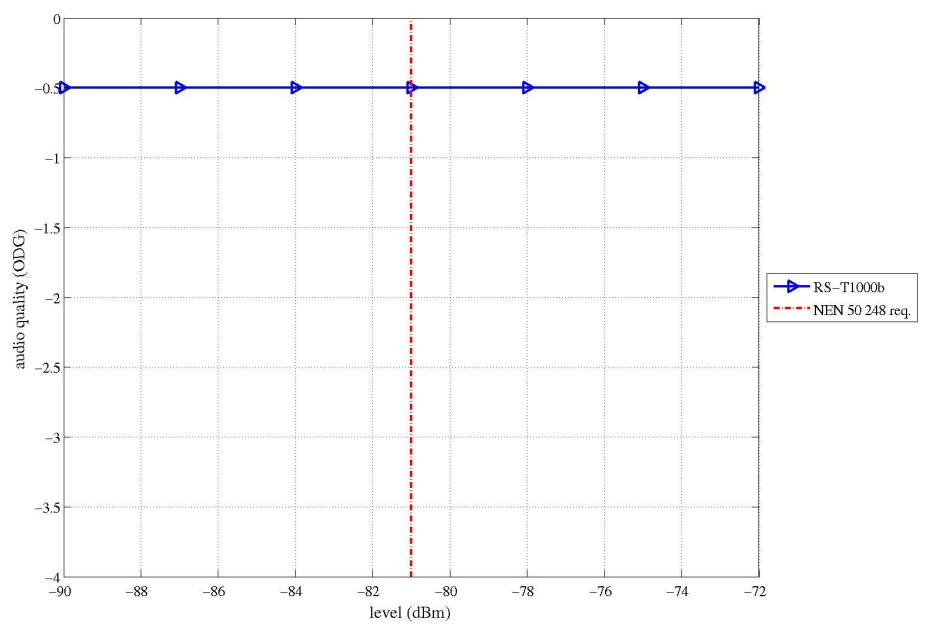

(a) Sensitivity test using no channel model

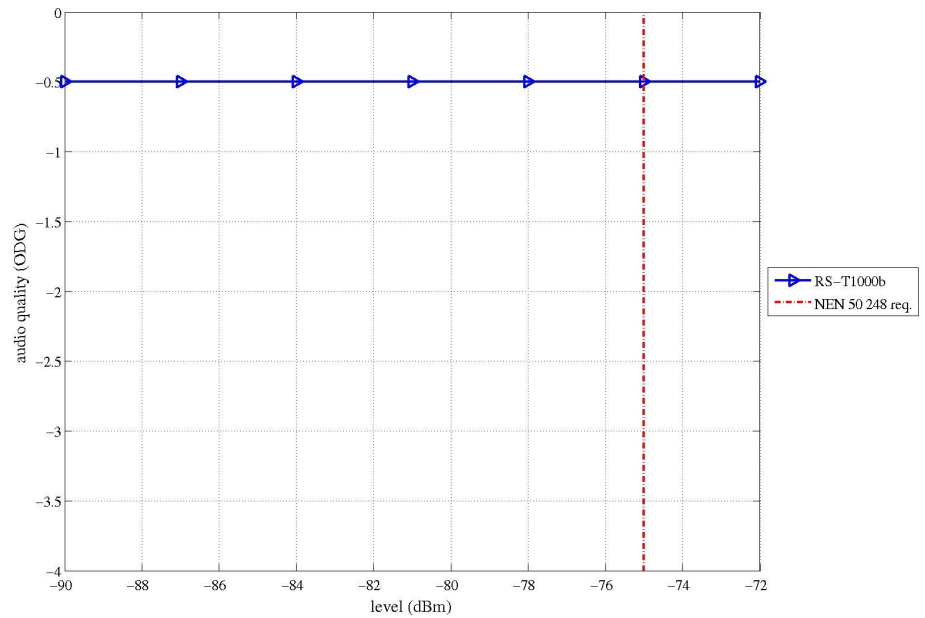

(b) Sensitivity test using COST 207 urban area channel model

Figure 4.9: Sensitivity tests of the RadioScape RS-T1000b DAB monitor for band III 


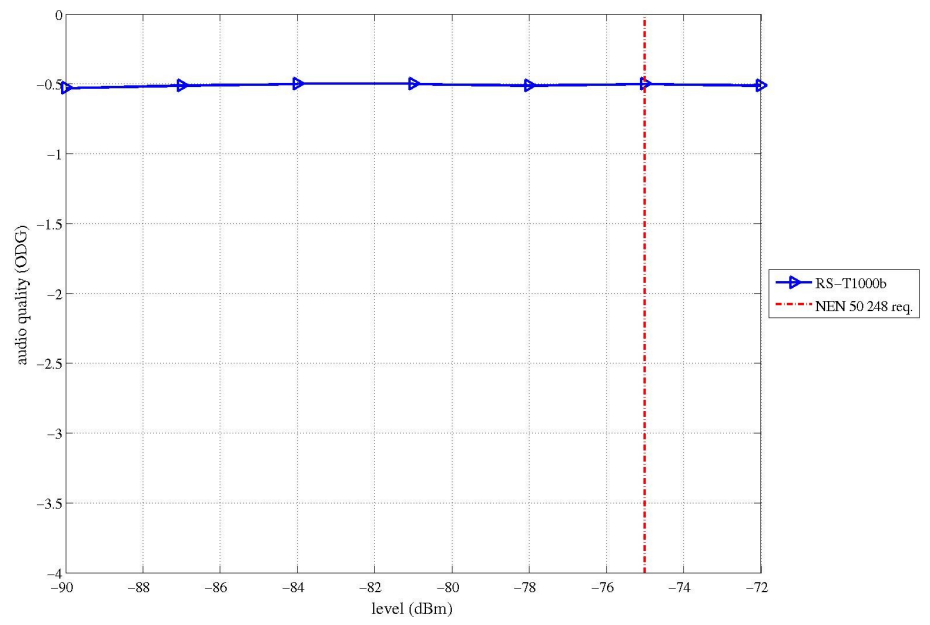

(c) Sensitivity test using COST 207 rural area channel model

Figure 4.9: Sensitivity tests of the RadioScape RS-T1000b DAB monitor for band III 


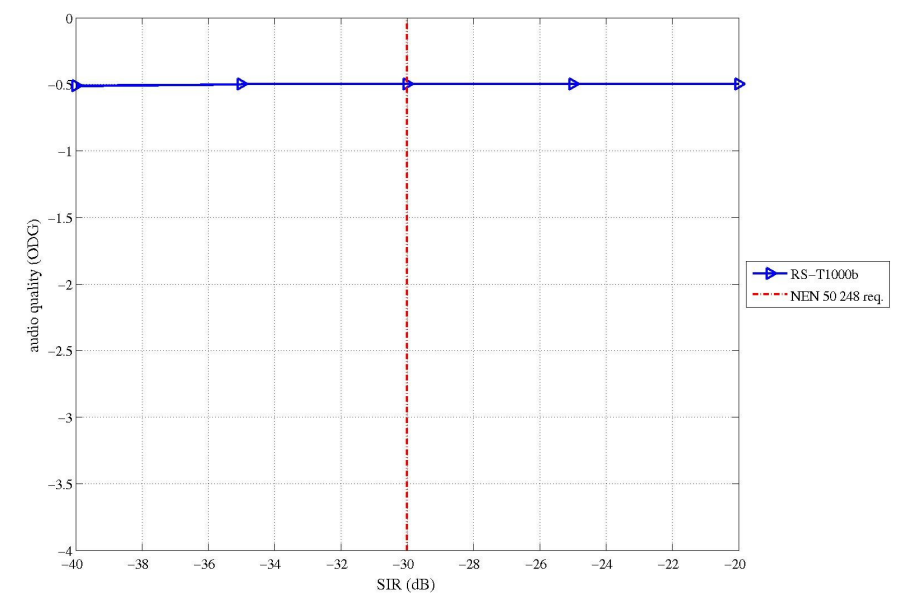

(a) Strong interferer at channel 12A using no channel model

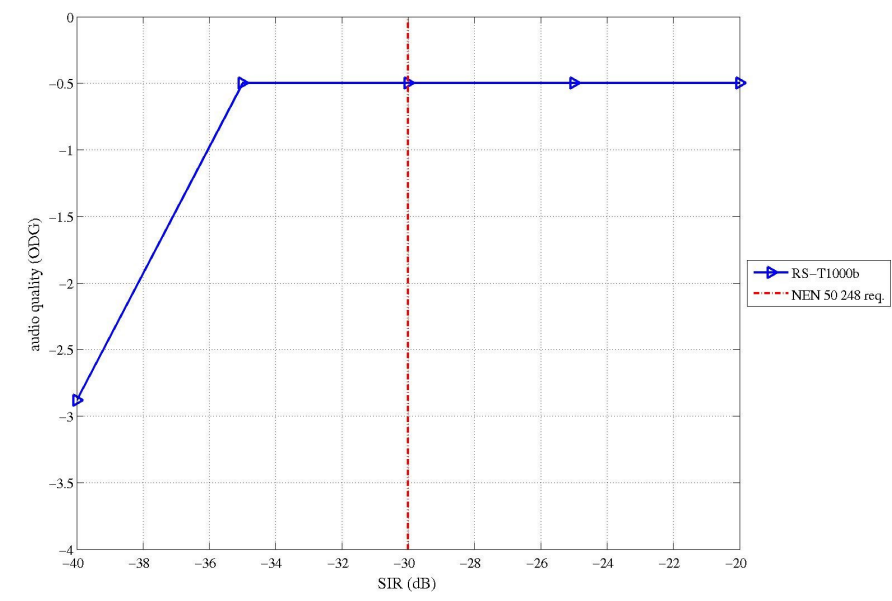

(b) Strong interferer at channel $12 \mathrm{C}$ using no channel model

Figure 4.9: Adjacent channel interference tests of the RadioScape RS-T1000b DAB monitor for band III 


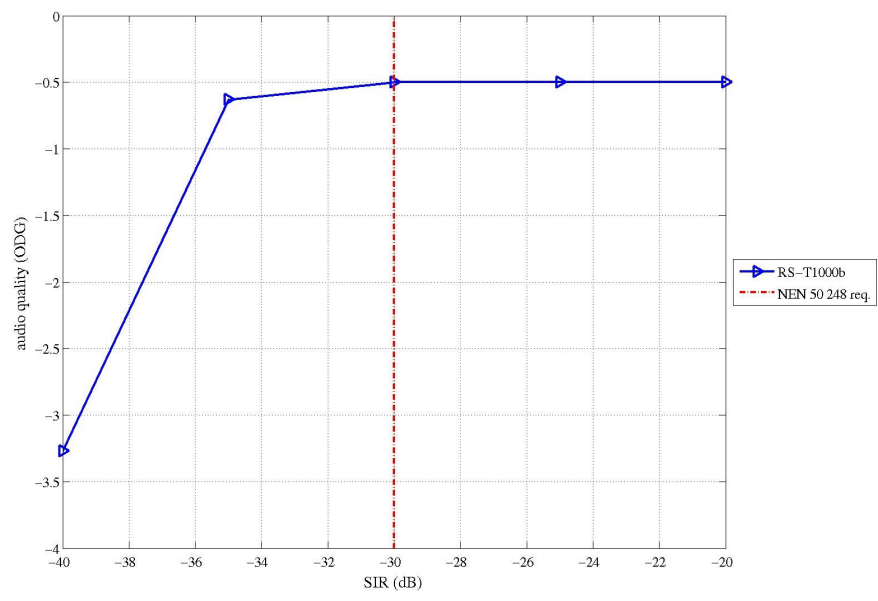

(c) Strong interferer at channel 12A using COST 207 urban area channel model

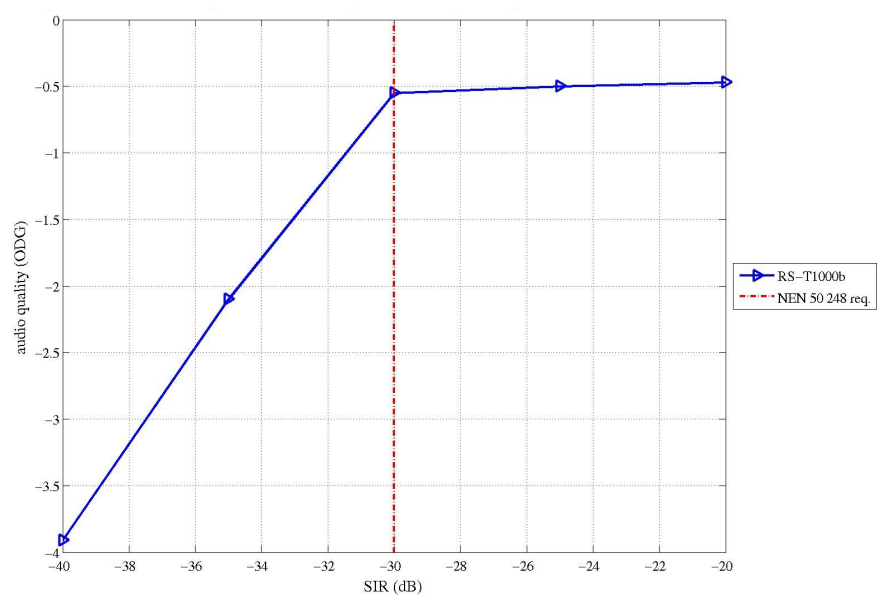

(d) Strong interferer at channel 12C using COST 207 urban area channel model

Figure 4.9: Adjacent channel interference tests of the RadioScape RS-T1000b DAB monitor for band III 


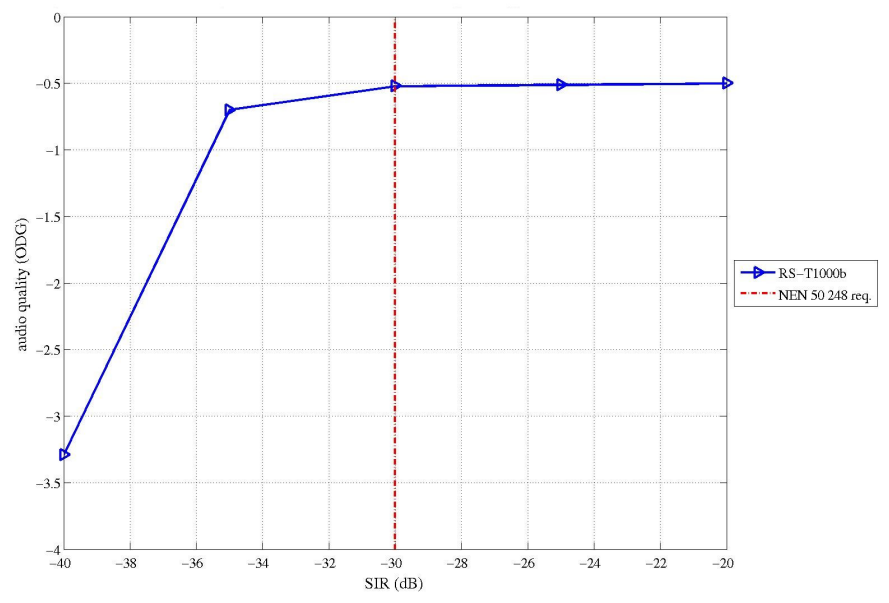

(e) Strong interferer at channel 12A using COST 207 rural area channel model

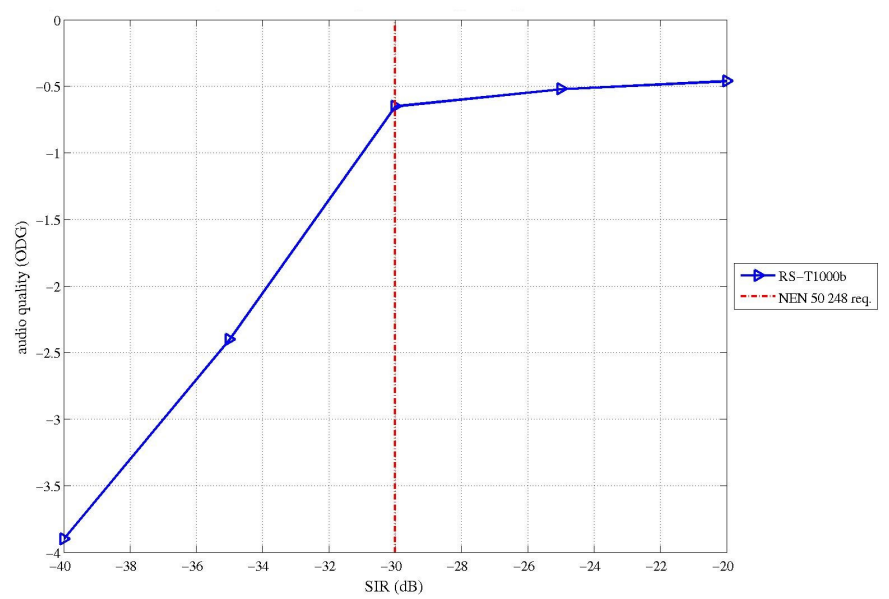

(f) Strong interferer at channel $12 \mathrm{C}$ using COST 207 rural area channel model

Figure 4.9: Adjacent channel interference tests of the RadioScape RS-T1000b DAB monitor for band III 


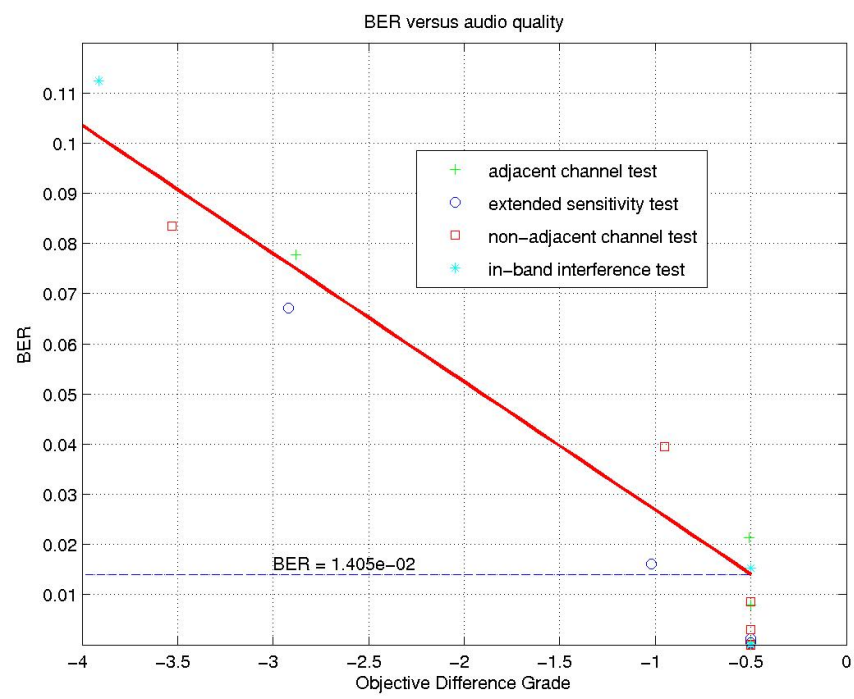

Figure 4.9: Audio quality versus sub BER before FEC for protection level UEPB

i.e. pseudo BER [38] for a subchannel with protection level [UEP3. This relation is depicted in Figure 4.9.

If the BER before FEC drops below the $1.4 \cdot 10^{-2}$ the audio is not distorted. Therefore a rule of thumb can be established for the coverage measurement results: if the BER before FEC is below $10^{-2}$, the audio quality is good for a subchannel with protection level UEP 3 .

\subsubsection{Antenna factor measurements}

At Astron, Dwingeloo we measured the Antenna Factor (AF) of consumer whip antennas for band III in an Anechoic chamber. L-band antennas are always internal antennas and could for this reason not be measured. For the measurement we used the antennas of three consumer receivers. In the chamber, a known field strength was applied, and by measuring the 


\begin{tabular}{c} 
signal power $\mathrm{dB}(\mathrm{mW})$ \\
\hline-72 \\
-75 \\
-78 \\
-81 \\
-84 \\
-87 \\
-90
\end{tabular}

Table 4.4: Signal powers for determining sensitivity.

received power the Antenna Factor (AF) could be determined. For the consumer-receiver antennas, a typical $\mathrm{AF}$ of $25 \mathrm{~dB}$ was found. This value is about $9 \mathrm{~dB}$ worse compared to the $\mathrm{AF}$ of the band III antenna of the measurement vehicle (Section 2.3.1).

More information about the Antenna Factor $\mathrm{AF}$ experiment can be found in [39].

\subsubsection{Sensitivity experiment}

The sensitivity test is used to determine the ability of a receiver to receive weak signals. EN 50248 defines a minimum sensitivity requirement of $-81 \mathrm{~dB}(\mathrm{~mW})$ in a Gaussian channel. In the sensitivity measurement procedure of EN 50248, a DAB signal is applied to the antenna input of the receiver. The power of the signal is reduced until the measured BER reaches $10^{-4}$ for a subchannel with protection level UEP 3 . The sensitivity of the receiver is then defined as the input power at which the BER reaches $10^{-4}$.

In the sensitivity test, we have determined the sensitivity of a receiver as follows: a DAB signal with a center frequency of $225.648 \mathrm{MHz}$ (channel $12 \mathrm{~B})$ and a power of $-72 \mathrm{~dB}(\mathrm{~mW})$ is applied to the RF input of the receiver. The audio signal of the receiver, which is tuned to a UEP 3 audio subchannel, is then recorded for 25 seconds. This is repeated 15 times and the resulting recorded audio signals are concatenated. The concatenated 
recorded audio signals are compared with a concatenated version of the original audio signal to determine the ODG for this signal power level. The whole procedure is repeated for the other signal power levels in Table 4.4. The sensitivity of the receiver is defined as the input power at which the ODG drops below -1 .

EN 50248 also defines a minimum sensitivity requirement of $-75 \mathrm{~dB}(\mathrm{~mW})$ in Rayleigh channels. In the Rayleigh channel sensitivity measurement procedure of EN 50248, a DAB signal is passed through a channel simulator and applied to the antenna input of the receiver. EN 50248 defines two Rayleigh channel profiles for which the Rayleigh channel sensitivity measurements have to be performed. These are a COST 207 Typical Urban channel profile at a velocity of $25 \mathrm{~km} / \mathrm{h}$ and a COST 207 Rural Area channel profile at a velocity of $120 \mathrm{~km} / \mathrm{h}$ [40].

To determine the sensitivity in Rayleigh channels, we repeat our normal sensitivity test procedure with DAB input signals, to which either the COST 207 Typically Urban or Rural Area channel profile, defined in EN 50248, is applied. For each of the 15 runs that are performed for a single RF signal condition, a different realization of the channel model is used. Because the audio quality is calculated from the concatenated recorded audio signals, this ensures that the measurement period is long enough to determine an average audio quality. The sensitivity is again the input power at which the ODG drops below -1 .

\section{Results}

Figures $4.10 \mathrm{a}, 4.10 \mathrm{p}$ and $4.10 \mathrm{k}$ depict the results of the sensitivity experiments with different channel models for the median receiver (solid black line). The audio quality [ODG] is shown along the y-axis and the signal power $[\mathrm{dBm}]$ along the $\mathrm{x}$-axis. In addition, three other lines are drawn. The vertical red line is the EN 50248 norm for this experiment, and the two dashed blue lines are the $25 \%$ and $75 \%$ border lines. For the $25 \%$ border this means that the best $25 \%$ of the tested receivers have a better performance than this line. The $75 \%$ line is defined in a similar manner.

The performance of the median consumer receiver meets the 


\begin{tabular}{c|c} 
Adjacent channel signal power $\mathrm{dB}(\mathrm{mW})$ & $\mathrm{ACS} \mathrm{dB}$ \\
\hline-50 & 20 \\
-45 & 25 \\
-40 & 30 \\
-35 & 35 \\
-30 & 40
\end{tabular}

Table 4.5: Adjacent channel signal powers and ACS

requirements and is more than $10 \mathrm{~dB}$ more sensitive than EN 50248 prescribes.

\subsubsection{Adjacent channel interference experiment}

The Adjacent Channel Selectivity (ACS) test determines the ability of a receiver to receive a signal when a strong unwanted signal occurs in the frequency band next to the frequency band of the wanted signal. EN 50248 defines a minimum ACS requirement of $\geq 30 \mathrm{~dB}$. The ACS measurement procedure of EN 50248 is defined as follows. The power level of the wanted signal at the antenna input of the $\mathrm{DAB}$ receiver is adjusted to $-70 \mathrm{~dB}(\mathrm{~mW})$. The signal power of the interfering unwanted signal at a frequency offset of $1.712 \mathrm{MHz}$ is then increased until a BER of $10^{-4}$ is reached. The ACS is then defined as:

$$
A C S=P_{\text {unwanted }}-P_{\text {wanted }}=P_{\text {unwanted }}+70[d B],
$$

where $P_{\text {unwanted }}$ is the signal power of the interfering unwanted signal at which the BER reaches $10^{-4}$.

In this experiment, the power level of the wanted signal with a center frequency of $225.648 \mathrm{MHz}$ (channel 12B) at the antenna input of the DAB receiver is also adjusted to $-70 \mathrm{~dB}(\mathrm{~mW})$. The power level of the interfering unwanted signal in the adjacent channel is adjusted according to Table 4.5 corresponding with the ACS values that are indicated in the same table. The ODG of the audio signal of the wanted signal is determined for each 


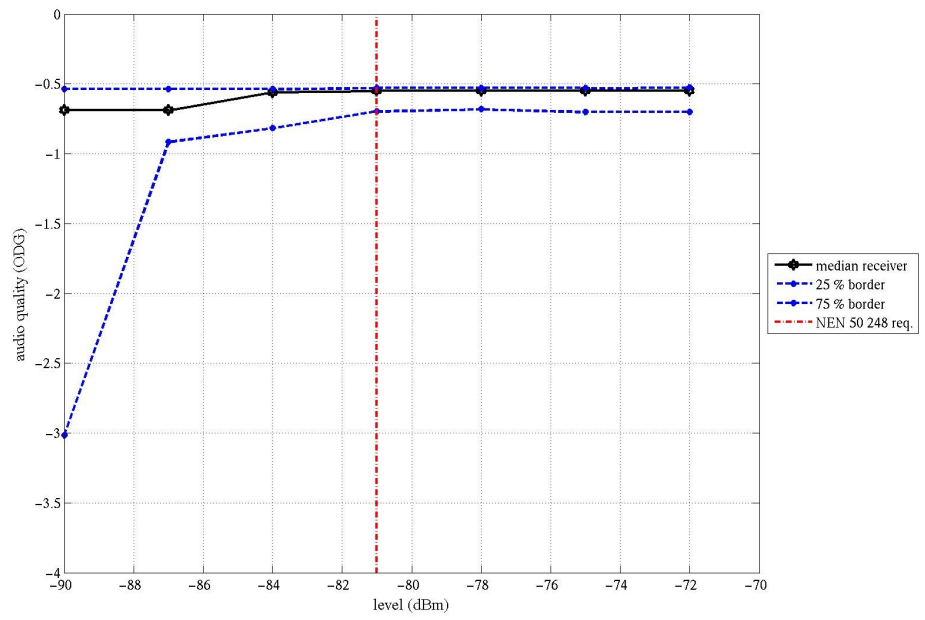

(a) Sensitivity test using no channel model

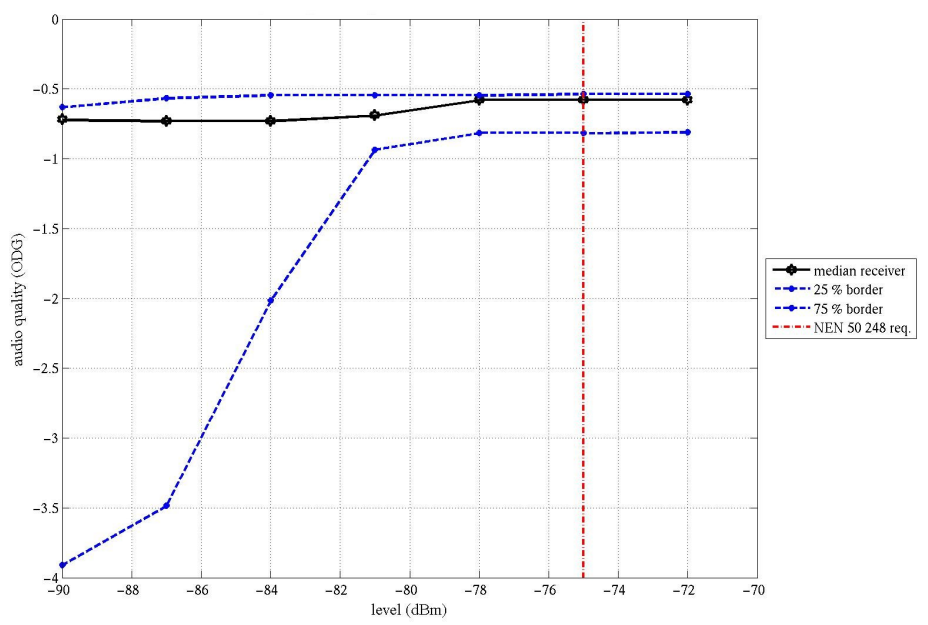

(b) Sensitivity test using COST 207 urban area channel model

Figure 4.10: Sensitivity tests of the consumer band III receivers 


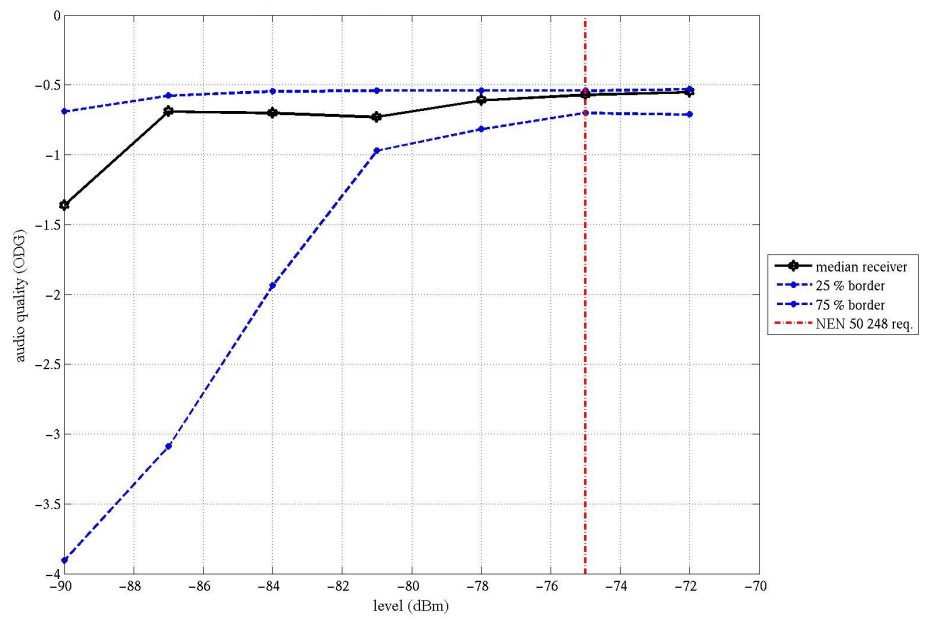

(c) Sensitivity test using COST 207 rural area channel model

Figure 4.10: Sensitivity tests of the consumer band III receivers 
of the adjacent channel power levels. The ACS is defined as the ACS value corresponding with the adjacent channel power level for which the ODG drops below -1 . The experiment is performed with an interfering unwanted signal in a channel below (offset $-1.712 \mathrm{MHz}$ ) as well as above (offset $+1.712 \mathrm{MHz}$ ) the channel of the wanted signal. The ACS test is performed without channel profile as well as for the COST 207 Typically Urban and Rural Area channel profiles, although the last two are not required by EN 50248 .

Figure 4.8 shows the setup for the (adjacent/non-adjacent) interference experiments and the in-band interference experiment.

\section{Results}

Figure 4.10 depicts the results of the adjacent channel interference experiments with the y-axis showing the audio quality [ODG] and the $x$-axis showing the power difference between both signals, the Signal-to-Interference Ratio (SIR) [dB]. In total six experiments were performed: an interfering unwanted signal in a channel below (offset $-1.712 \mathrm{MHz}$, channel 12A) as well as in a channel above (offset $+1.712 \mathrm{MHz}$, channel 12C) the channel of the wanted signal. In addition, this was tested for three channel models.

The median consumer receiver meets the EN 50248 norm for this experiment. The performance of a strong interferer higher than the wanted channel is slightly worse than that of a strong interferer lower than the wanted channel. In addition, the $25 \%$ worst performing consumer receivers do not meet the requirements for a strong interferer above the wanted channel.

\subsubsection{Non-adjacent channel interference experiment}

EN 50248 also defines a rejection of unwanted signals or far-off selectivity requirement and measurement. In the receiver tests this was replaced by a Non-Adjacent Channel Selectivity (NACS) test. The NACS test is similar to the ACS test. The only differences are that the interfering 


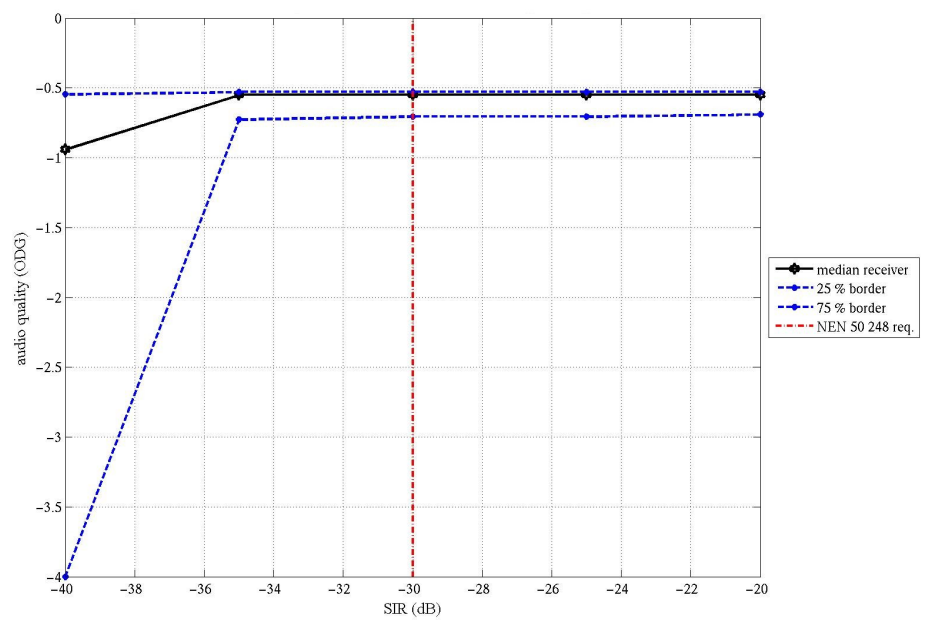

(a) Strong interferer at channel 12A using no channel model

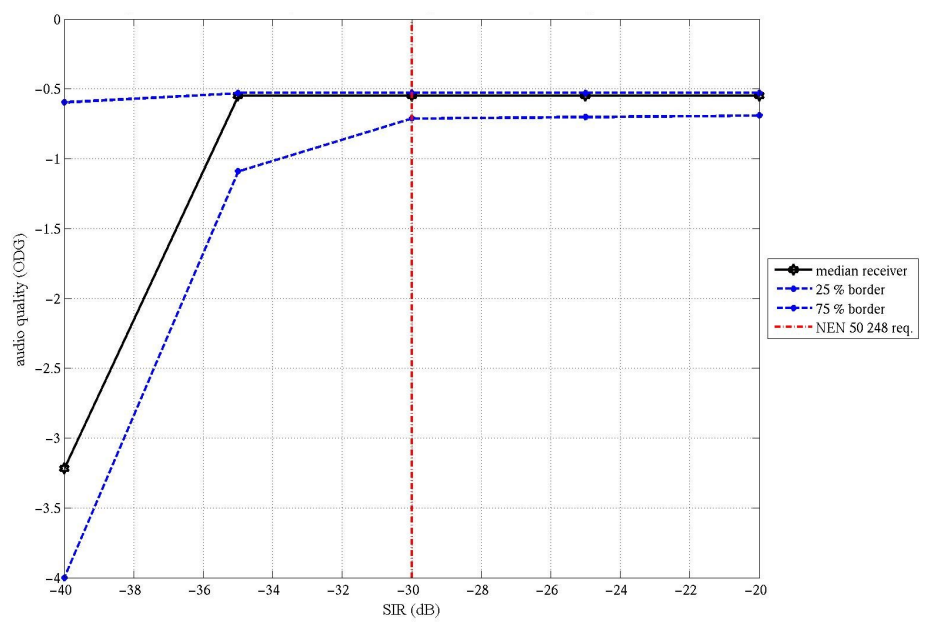

(b) Strong interferer at channel $12 \mathrm{C}$ using no channel model

Figure 4.10: Adjacent channel interference tests of consumer band III receivers 


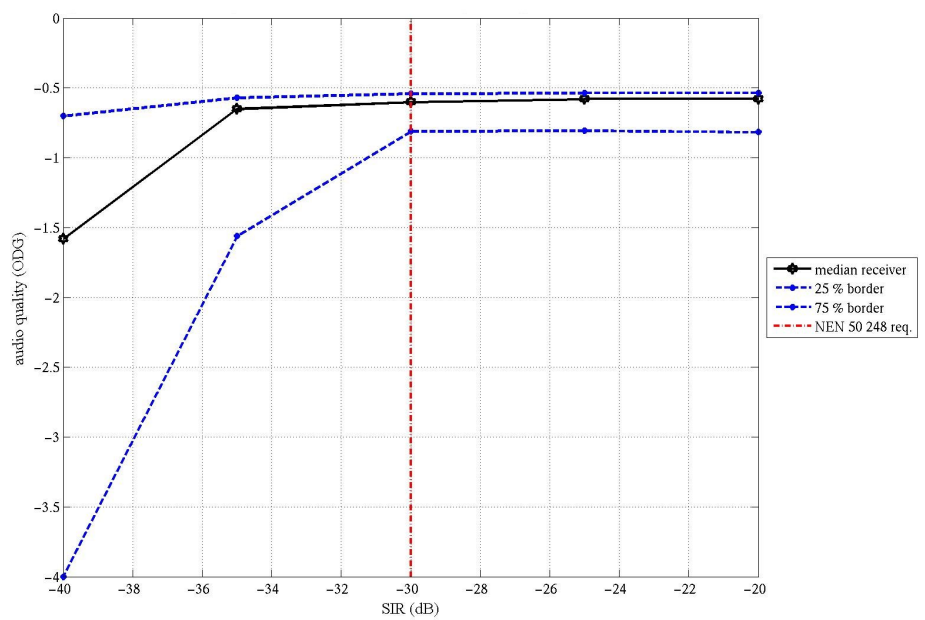

(c) Strong interferer at channel 12A using COST 207 urban area channel model

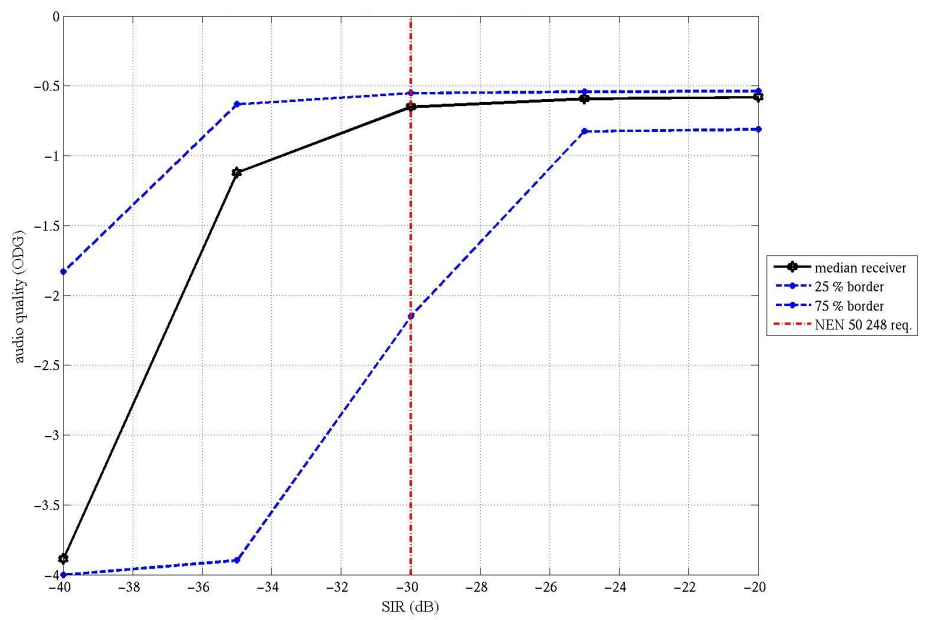

(d) Strong interferer at channel 12C using COST 207 urban area channel model

Figure 4.10: Adjacent channel interference tests of consumer band III receivers (cont) 


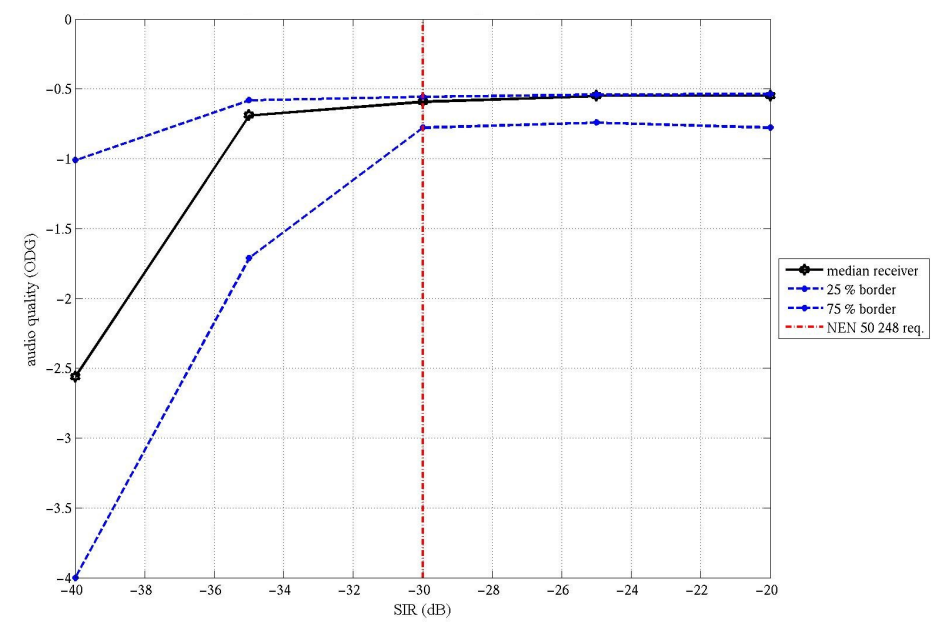

(e) Strong interferer at channel 12A using COST 207 rural area channel model

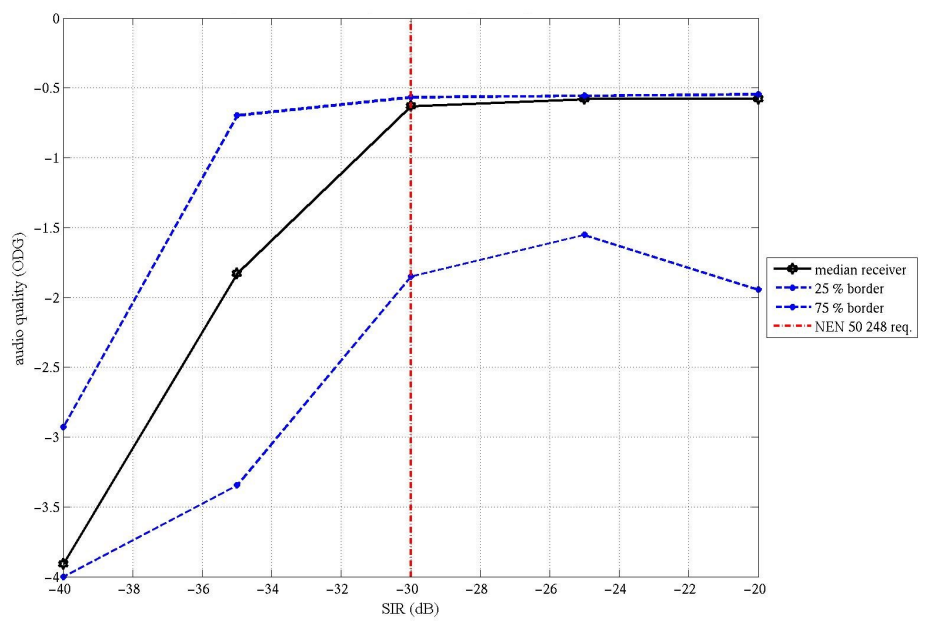

(f) Strong interferer at channel 12C using COST 207 rural area channel model

Figure 4.10: Adjacent channel interference tests of consumer band III receivers (cont) 
Chapter 4. Consumer receivers

\begin{tabular}{c|c} 
Non-adjacent channel signal power $\mathrm{dB}(\mathrm{mW})$ & NACS $\mathrm{dB}$ \\
\hline-40 & 30 \\
-35 & 35 \\
-30 & 40 \\
-25 & 45 \\
-20 & 50
\end{tabular}

Table 4.6: Non-adjacent channel signal powers and NACS

unwanted signal is in the first non-adjacent channel (at a frequency offset of $3.424 \mathrm{MHz}$ ) and that the power levels of the interfering signals are higher (see Table 4.6). This means that the corresponding NACS requirements are higher as well. The NACS is defined as the NACS value corresponding with the non-adjacent channel power level for which the ODG drops below -1 . The NACS test is performed without channel profile as well as for the COST 207 Typically Urban and Rural Area channel profiles.

\section{Results}

Figure 4.10 depicts the results of the non-adjacent channel interference experiments with the y-axis showing the audio quality [ODG] and the $x$-axis showing the power difference between both signals, the SIR [dB]. In total six experiments were conducted: a strong non-adjacent interfering unwanted signal in a channel below (offset $-3.424 \mathrm{MHz}$, channel 11D) as well as in a channel above (offset $+3.424 \mathrm{MHz}$, channel 12D) that of the wanted signal. In addition, this was tested for three channel models.

For a strong non-adjacent interferer below the wanted channel, the median receiver just meets the requirements. For a strong interferer with a frequency higher than that of the wanted channel, the median receiver has up to $10 \mathrm{~dB}$ (for the urban channel model) worse performance than required. Also one can see that the $25 \%$ worst performing consumer receivers have difficulties with all non-adjacent interferer experiments. Only the $25 \%$ best performing receivers meet the 


\begin{tabular}{c|c} 
In-band noise signal power $\mathrm{dB}(\mathrm{mW})$ & SNR $\mathrm{dB}$ \\
\hline-100 & 30 \\
-95 & 25 \\
-90 & 20 \\
-85 & 15 \\
-90 & 10 \\
-75 & 5
\end{tabular}

Table 4.7: In-band noise signal powers and SNR

non-adjacent requirements set by EN 50248 .

\subsubsection{In-band interference experiment}

In addition to the experiments based on EN 50248, we also defined an in-band interference experiment. This experiment determines the ability of a receiver to receive a signal with a low signal-to-noise ratio. It therefore gives an indication of the ability of a receiver to deal with in-band interference.

In the required SNR experiment the power level of the wanted signal, with a center frequency of $225.648 \mathrm{MHz}$ (channel 12B) at the antenna input of the $\mathrm{DAB}$ receiver, is adjusted to $-70 \mathrm{~dB}(\mathrm{~mW})$. The power level of an in-band white Gaussian noise signal is adjusted according to Table 4.7 corresponding with the SNR values that are indicated in the same table. The ODG of the audio signal of the wanted signal is determined for each of the in-band noise power levels. The required SNR is defined as the SNR value corresponding with the in-band power level for which the ODG drops below -1 . The required SNR experiment is performed without channel profile as well as for the COST 207 Typically Urban and Rural Area channel profiles. 


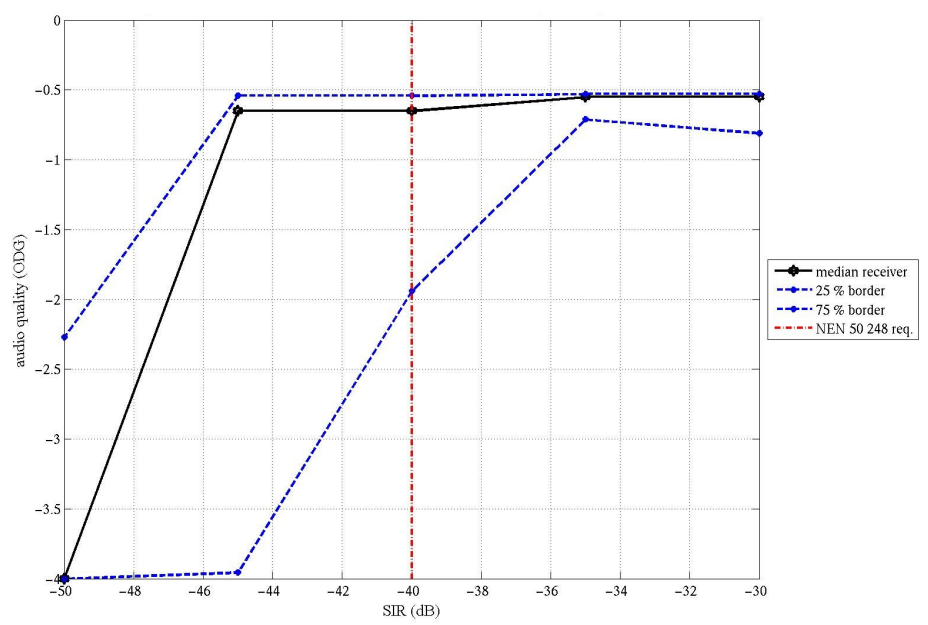

(a) Strong interferer at channel 11D using no channel model

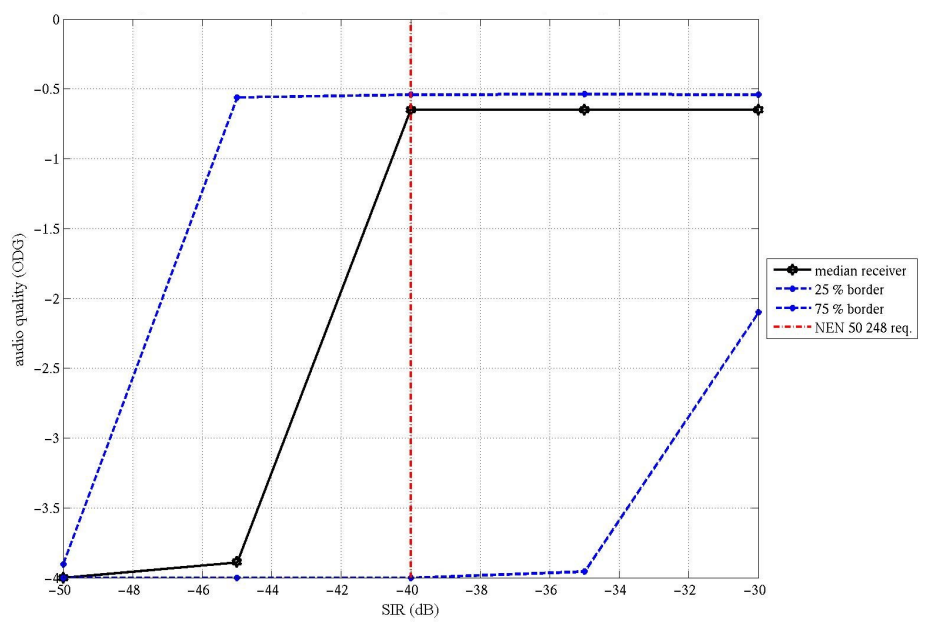

(b) Strong interferer at channel 12D using no channel model

Figure 4.10: Non-adjacent channel interference tests of consumer band III receivers 


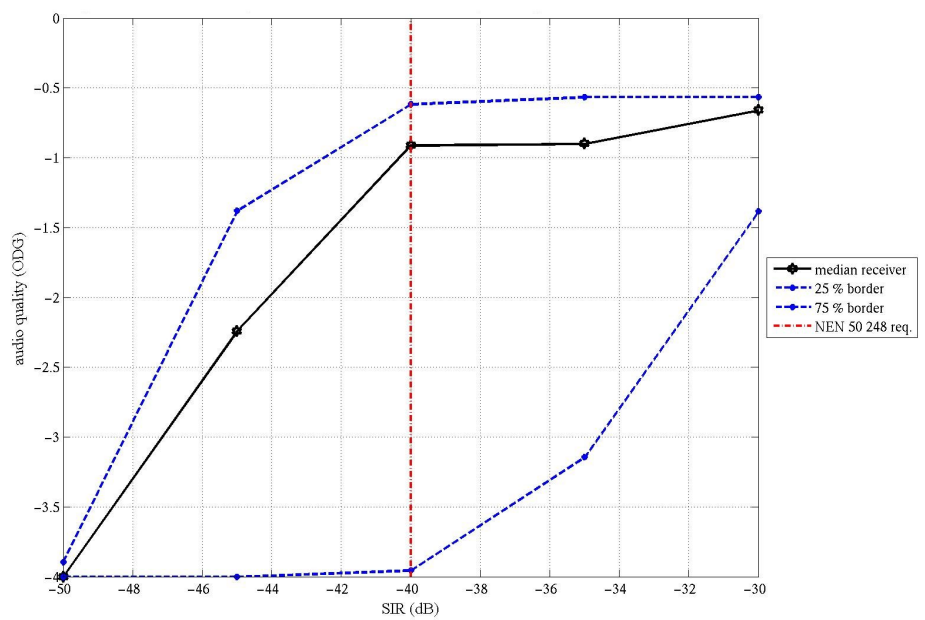

(c) Strong interferer at channel 11D using COST 207 urban area channel model

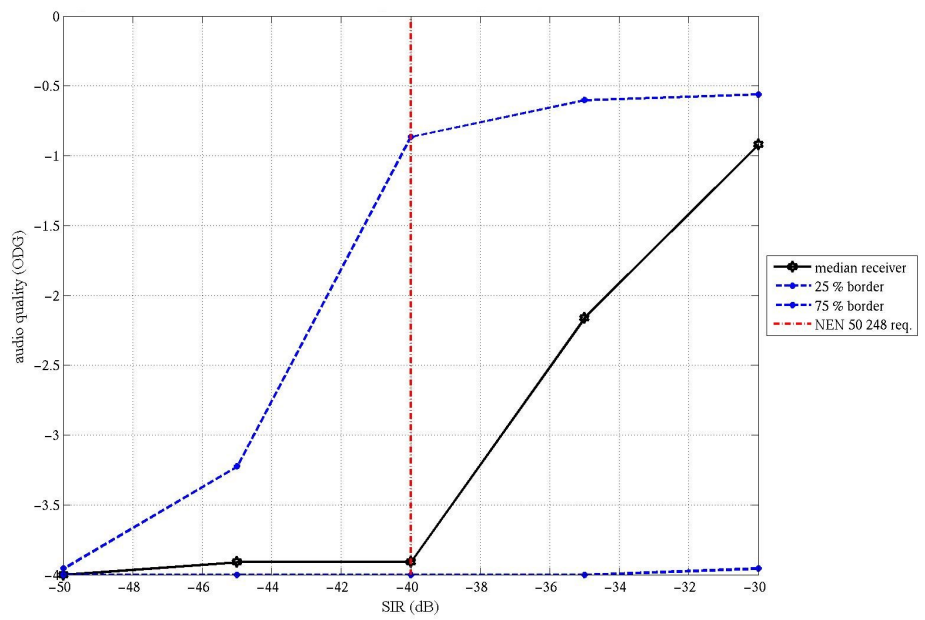

(d) Strong interferer at channel 12D using COST 207 urban area channel model

Figure 4.10: Non-adjacent channel interference tests of consumer band III receivers (cont) 


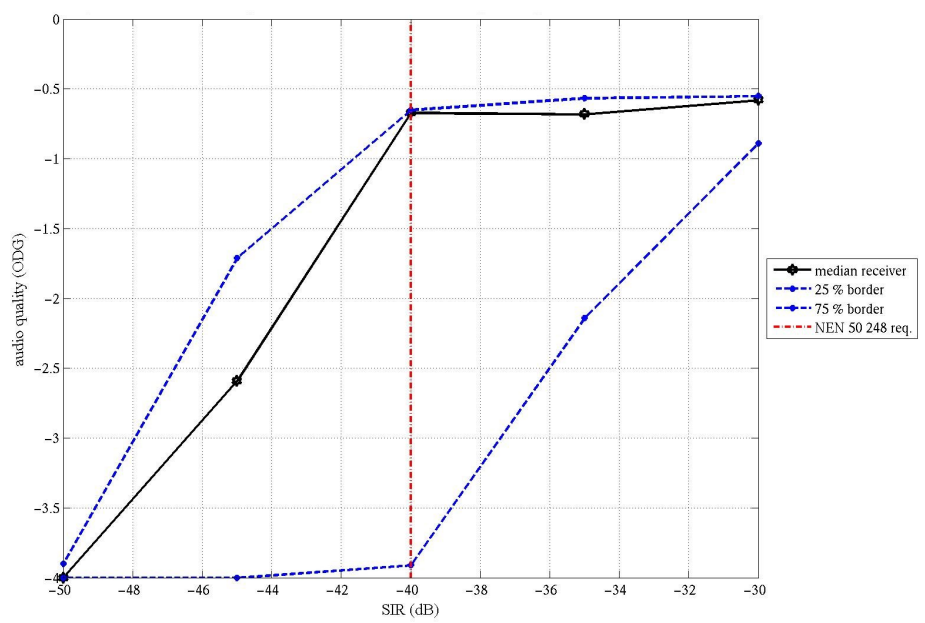

(e) Strong interferer at channel 11D using COST 207 rural area channel model

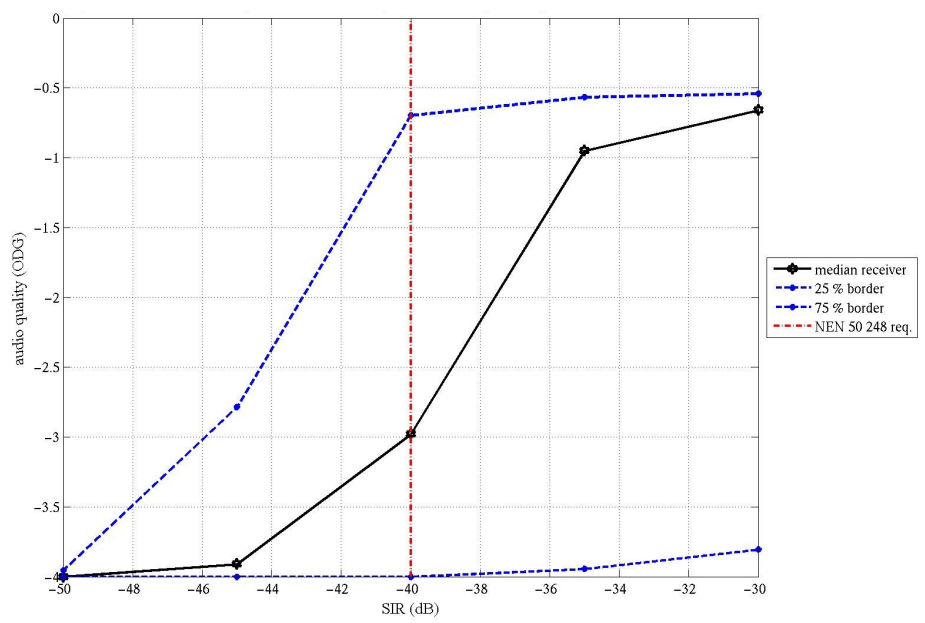

(f) Strong interferer at channel 12D using COST 207 rural area channel model

Figure 4.10: Non-adjacent channel interference tests of consumer band III receivers (cont) 


\section{Results}

Figure 4.10 depicts the results of the in-band interference experiment, with the $y$-axis showing the audio quality [ODG] and the x-axis showing the power difference between both signals, the SIR [dB].

The median receiver requires an SNR of about $15 \mathrm{~dB}$. This value is slightly higher than the value found in [41].

\subsection{L-band results}

Only the FreeSky FP-2200, Rebox R102, Rebox R1051] Pure Digital DRX-702ES, Blaupunkt Nashville DAB35, Pure Digital EVOKE-1XT Tri-Band and Trinloc Inspiration are capable of receiving the L-band. The L-band receiver were tested in a similar manner as the band III receivers. The only differences were the channel used (channel LH) and the mode (mode IV).

Both mode II and mode IV are suitable for the L-band, but the latter allows a larger distance between transmitters [18]. For a commercial service, it is likely that mode II will be used instead of mode IV as the latter is only useable for speeds up to $80 \mathrm{~km} / \mathrm{h}$. (The field strength measurements in this report revealed that the maximum speed for mode IV is $50 \mathrm{~km} / \mathrm{h}$ and not $80 \mathrm{~km} / \mathrm{h}$.) According to [34], the performance of a consumer receiver depends on the mode used. For that reason, the results shown in this section should be used with care.

\subsubsection{Performance of RadioScape RS-T1000b DAB monitor}

This section discusses the performance of the RadioScape RS-T1000b DAB monitor which was used in the measurement vehicle. The goal of this section is to put the results in Chapter 2 into perspective. For the coverage measurements in the L-band, only the sensitivity performance is important.

\footnotetext{
${ }^{1}$ Due to synchronization problems, this receiver was tested.
} 


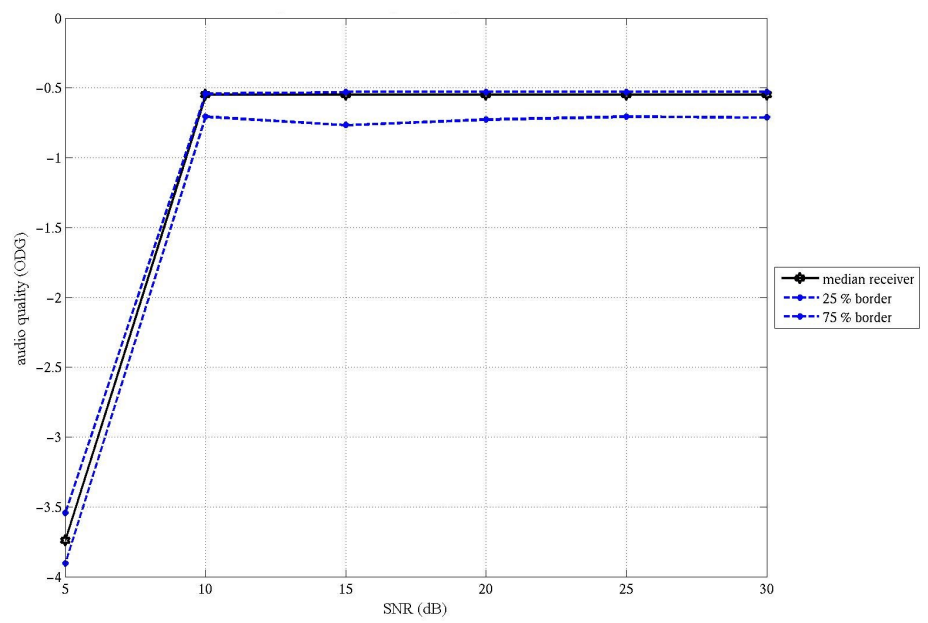

(a) In-band interference using no channel model

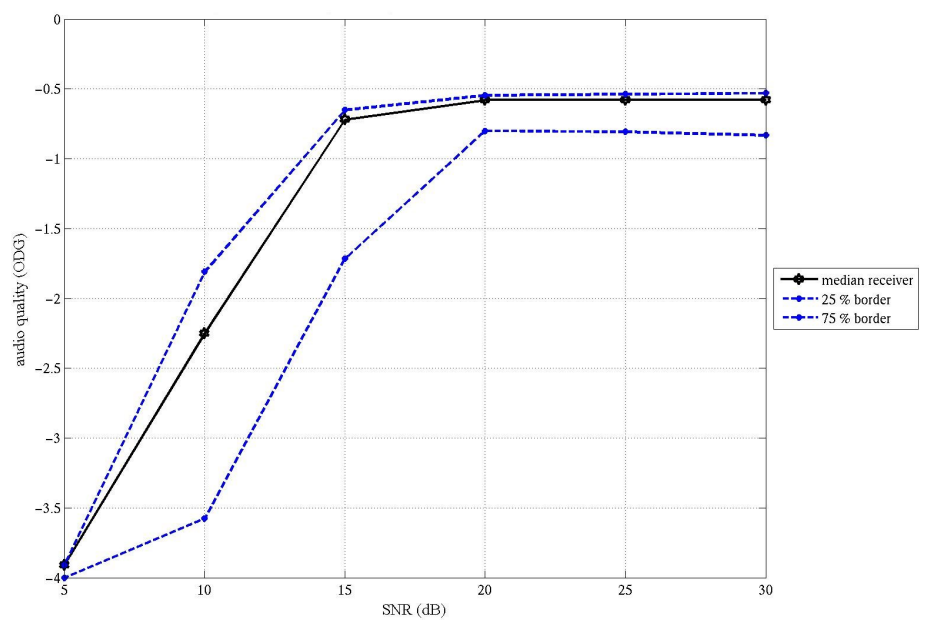

(b) In-band interference using COST 207 urban area channel model

Figure 4.10: In-band interference tests of consumer band III receivers 


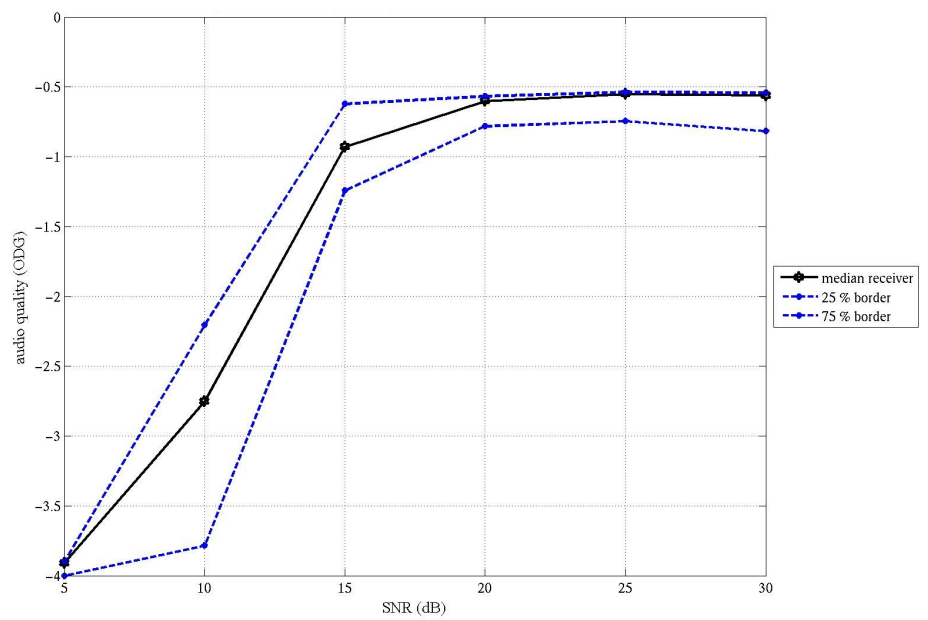

(c) In-band interference using COST 207 rural area channel model

Figure 4.10: In-band interference tests of consumer band III receivers (cont) 
Chapter 4. Consumer receivers

Figure 4.10 depicts the results of the sensitivity tests for the RadioScape RS-T1000b DAB monitor.

The sensitivity of the DAB monitor meets the requirements of the EN 50248 norm if no channel model or the urban channel model is applied. However, for the rural channel model, the $\mathrm{DAB}$ monitor receiver cannot decode the signal at all. Listening to the audio signal of the DAB monitor reveals that the audio signal is good at the start of a run, but that it degrades very quickly. For that reason, the BER results of the coverage measurements should be used with care.

\subsubsection{Sensitivity experiment}

Figures 4.10a, 4.10 $\mathrm{p}$ and $4.10 \mathrm{k}$ depict the results of the sensitivity experiments with different channel models for the median receiver (solid black line). The y-axis shows the audio quality [ODG], and the x-axis shows the signal power [dBm]. In addition, three other lines are drawn. The vertical red line is the EN 50248 norm for this experiment, and the two dashed blue lines are the $25 \%$ and $75 \%$ border lines. For the $25 \%$ border line this means that the best $25 \%$ of the tested receivers have a better performance than this line. The $75 \%$ line is defined in a similar manner.

The performance of the median consumer receiver meets the requirements for the no-channel model and the urban area channel. For the rural area channel, the audio quality of the median receiver is too low for good reception.

The coherence time for the COST $207 \mathrm{~L}-$ band urban channel is $8.9 \mathrm{~ms}$ and for the rural model $4.6 \mathrm{~ms}$. (For band III, the values are $73.7 \mathrm{~ms}$ for the urban channel model and $12.5 \mathrm{~ms}$ for the rural channel model.) The coherence time is the time that the channel can be considered as constant. For differential detection, such as Differential Quadrature Phase-Shift Keying (DQPSK) that is used in DAB, the channel has to be constant over two symbols for proper demodulation. The duration of an Orthogonal Frequency Division Multiplexing (OFDM) symbol for mode IV is $0.623 \mathrm{~ms}$ [42], so a properly designed DAB receiver should be capable of decoding 


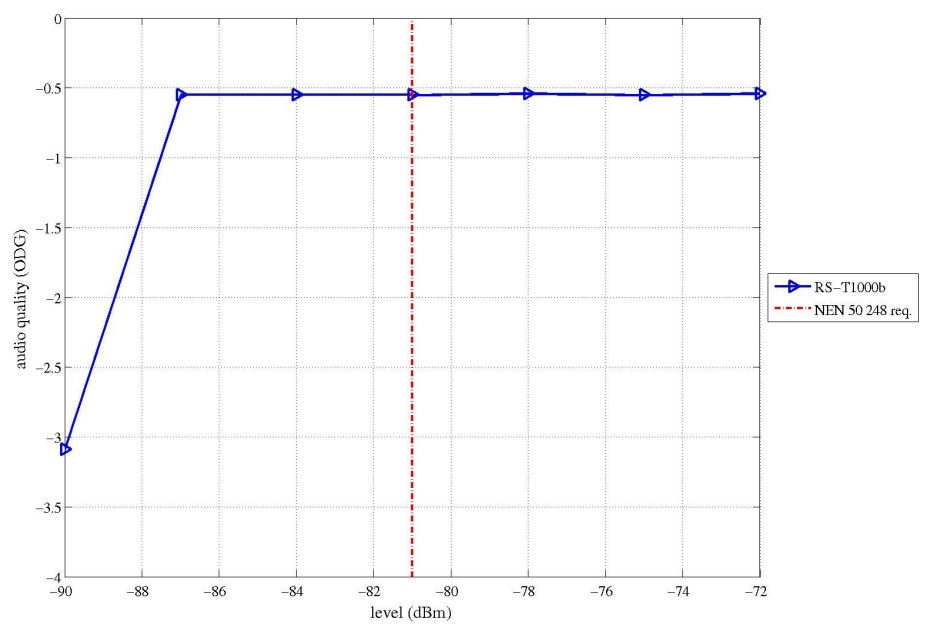

(a) Sensitivity test using no channel model

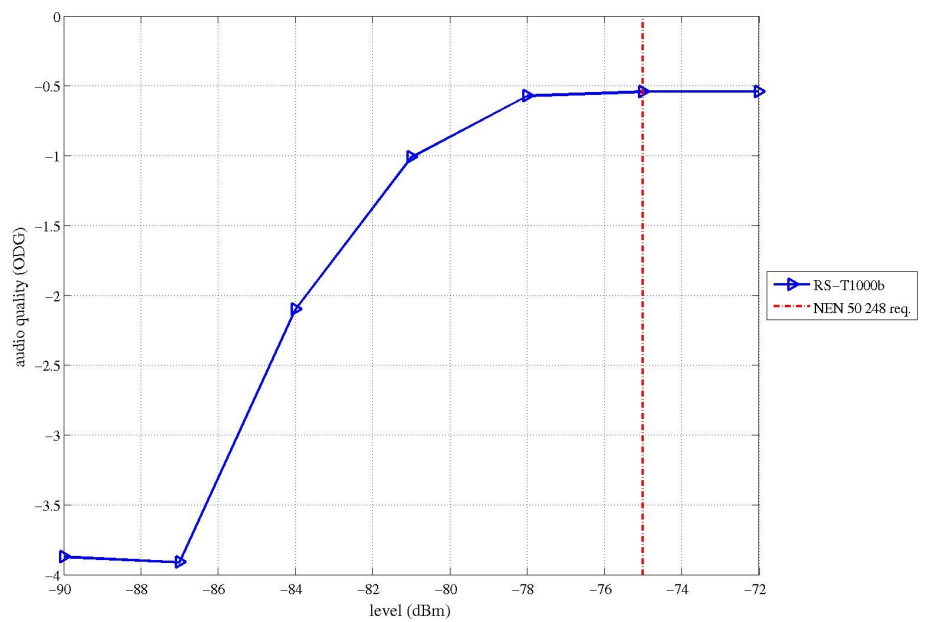

(b) Sensitivity test using COST 207 urban area channel model

Figure 4.10: Sensitivity tests of the RadioScape RS-T1000b DAB monitor for L-band 


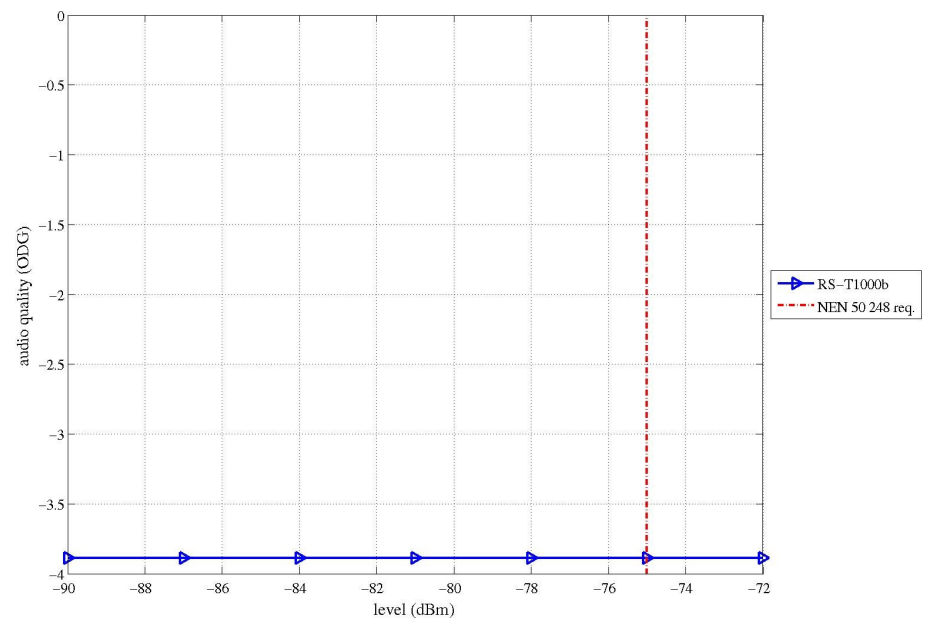

(c) Sensitivity test using COST 207 rural area channel model

Figure 4.10: Sensitivity tests of the RadioScape RS-T1000b DAB monitor for L-band 
the signal for a rural channel model. It is expected that the receivers will have a better performance for mode II in the L-band as the OFDM symbol time is smaller $(0.312 \mathrm{~ms}$ [42]).

In Canada [34] (2004), the performance of L-band receivers was also investigated for mode II. This paper reached similar conclusions. Only one out of six receivers was capable of decoding the signal with the rural area channel model, and three were able to decode the urban area signal. So, compared to this paper, the performance of the receivers has improved.

In addition, the university has carried out a small experiment for a subchannel with protection level UEP 3 and mode II. In this experiment, the audio quality of a RF signal level at $-70 \mathrm{dBm}$ has been manually evaluated for a short period. In these experiments no audible audio artefects were noticed for all L-band receivers. Analysis of the COST 207 channel models support these results.

So, to obtain good audio quality in the L-band there are two options:

- Use mode II instead of mode IV, but this also affects the network topology: for mode IV the maximum distance is $37 \mathrm{~km}$ and for mode II it is $18 \mathrm{~km}[18]$.

- Add more protection to a subchannel (i.e. use protection level 1 or 2). However this also decreases the available capacity up to $30 \%$ compared with protection level UEP 3 . Additional research is required to verify this.

It should be noted that for in-house use, the L-band consumer receivers will work properly as the channel conditions are less severe compared to the rural channel model. Only T-DAB car receivers would be able to decode the signal for the rural channel model.

\subsubsection{In-band interference experiment}

Figure 4.10 depicts the results of the in-band interference experiment with the $y$-axis showing the audio quality [ODG] and the x-axis showing the power difference between the two signals, the SIR [dB]. 


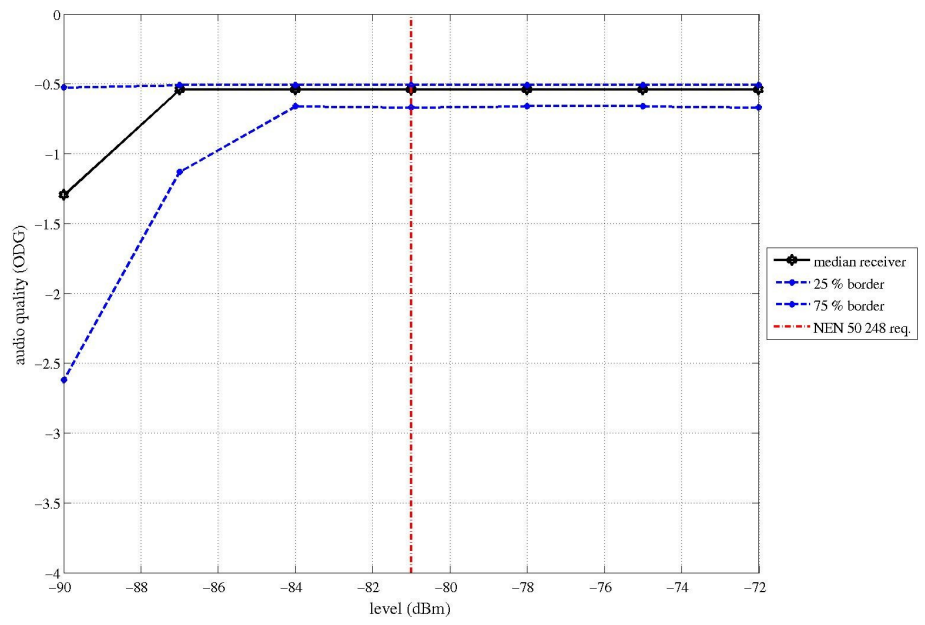

(a) Sensitivity test using no channel model

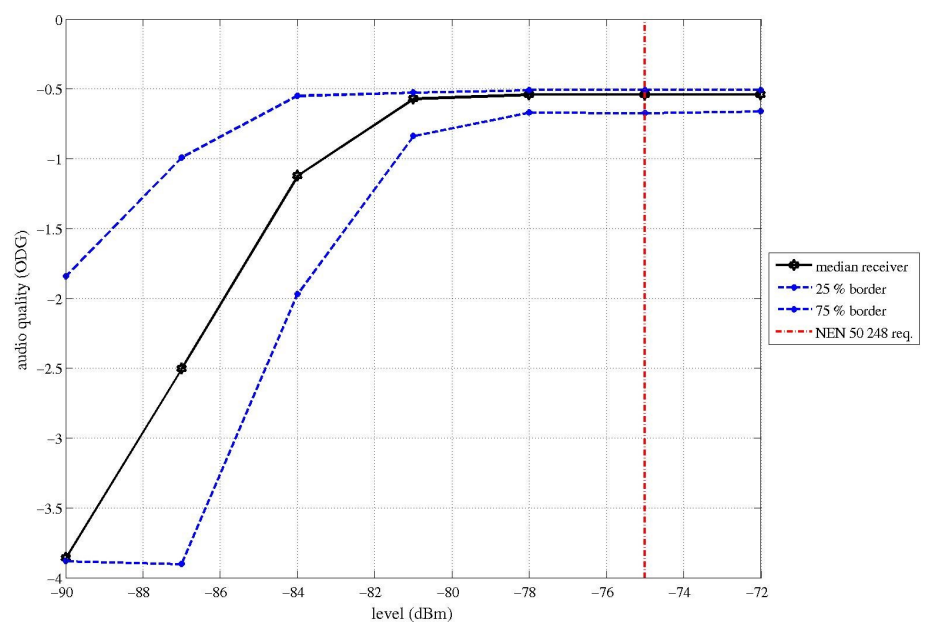

(b) Sensitivity test using COST 207 urban area channel model

Figure 4.10: Sensitivity tests of consumer L-band receivers 


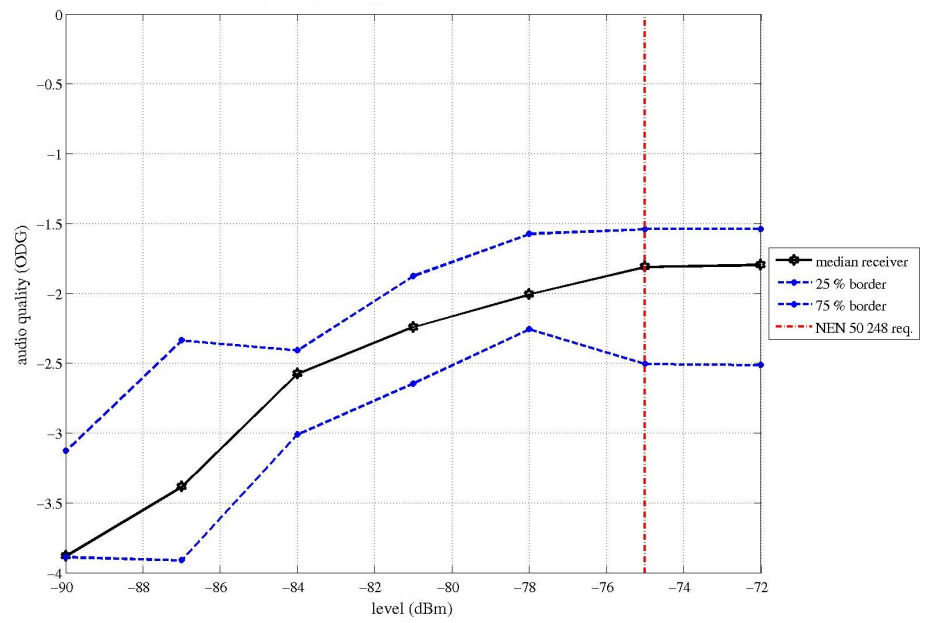

(c) Sensitivity test using COST 207 rural area channel model

Figure 4.10: Sensitivity tests of consumer L-band receivers (cont) 
The median receiver requires an SNR of about $15 \mathrm{~dB}$ for the urban channel model. This value is less than the SNR value of $18 \mathrm{~dB}$ found in [41].

\subsection{Typical sensitivity of a T-DAB consumer receiver}

Another interesting question is whether the minimum sensitivity set by the Wiesbaden agreement can be achieved by a consumer receiver. In this section, the typical achievable sensitivity of a T-DAB receiver will be derived.

The sensitivity of a receiver is mainly determined by the combination of three factors:

1. Thermal noise (in semiconductor devices)

2. Noise figure of the analog RF front-end

3. The required Signal-to-Noise (SNR) ratio

\section{Thermal noise}

Every semiconductor device has a noise floor caused by thermal noise [43, 44]:

$$
P=k_{B} T \Delta f
$$

with

$k_{B}$ The Boltzmann's constant: $1.38 \cdot 10^{-23}$ Joules per Kelvin

$T$ The temperature in Kelvin (room temperature is $295 \mathrm{~K}$ )

$\Delta f$ The signal bandwidth in Hertz

In $\mathrm{dBm}$-scale this equation becomes for room temperature:

$$
P=-174+10 \log (\Delta f)
$$




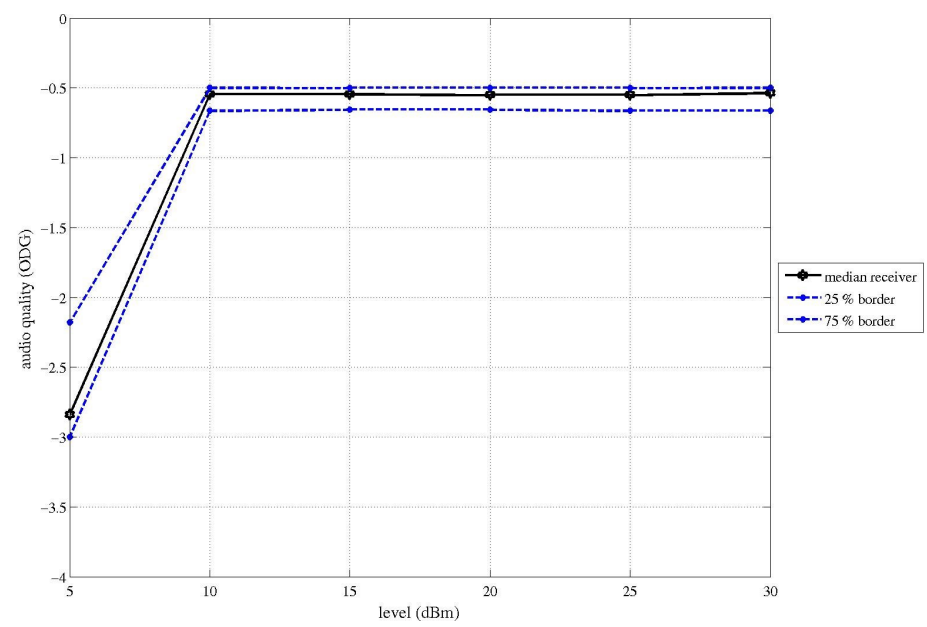

(a) In-band interference using no channel model

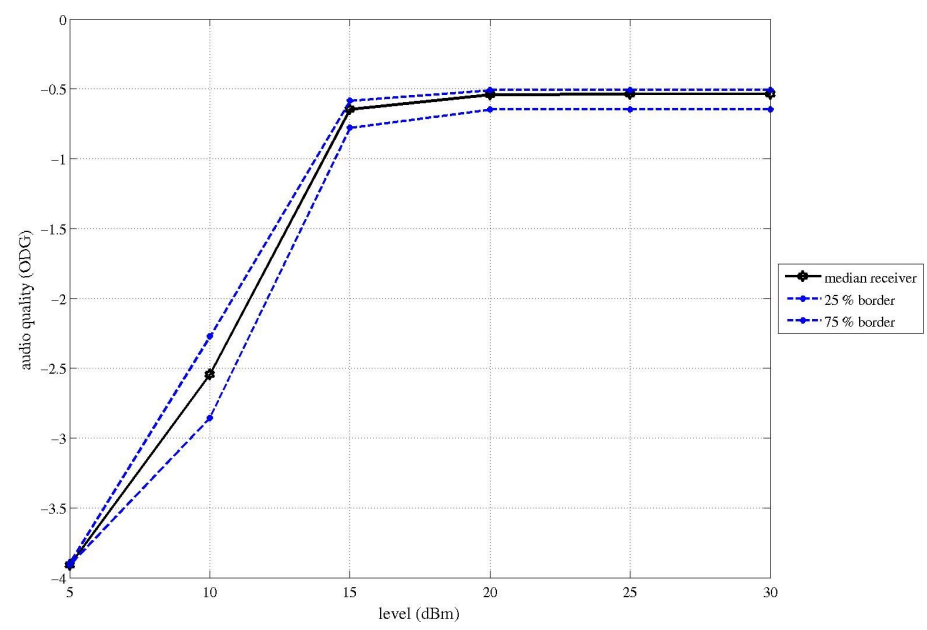

(b) In-band interference using COST 207 urban area channel model

Figure 4.10: In-band interference tests of consumer L-band receivers 


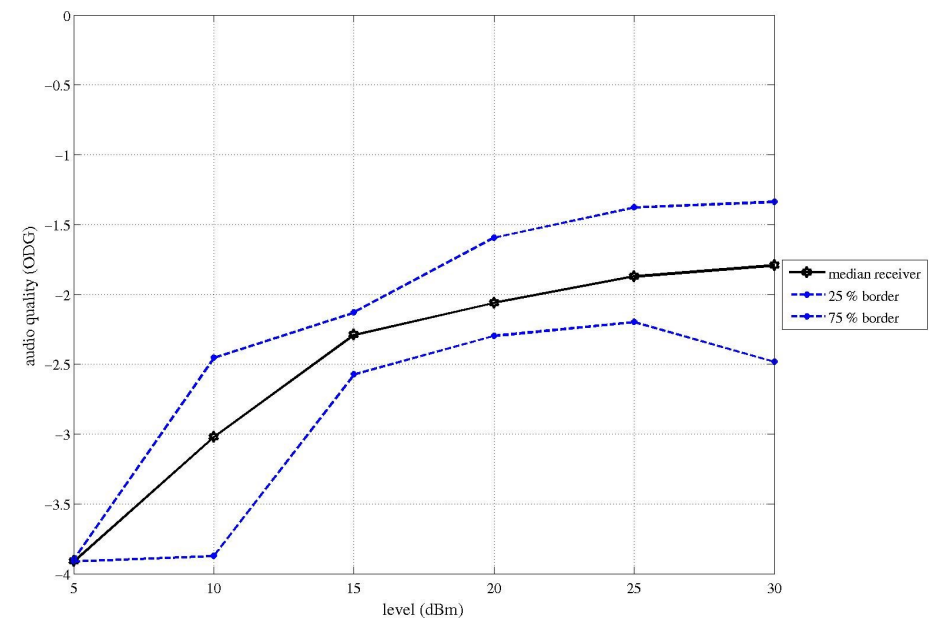

(c) In-band interference using COST 207 rural area channel model

Figure 4.10: In-band interference tests of consumer L-band receivers (cont) 
In case of $\mathrm{DAB}$, the signal bandwidth is $1.5 \mathrm{MHz}$ and the noise floor becomes $P=-174+10 \log \left(1.5 \cdot 10^{6}\right)=-112 \mathrm{dBm}$.

Noise figure

Each $\mathrm{DAB}$ receiver contains an analog $\mathrm{RF}$ front-end. This front-end introduces extra noise in the wanted DAB channel; this is called the Noise Figure (NF). A typical noise figure for a $\mathrm{DAB}$ front-end in band III and L-band is $6 \mathrm{~dB}$ [45]. This means that the noise floor in a receiver is increased by $6 \mathrm{~dB}$.

Required Signal-to-Noise ratio

After the analog $\mathrm{RF}$ front-end, the SNR should be high enough to have a BER below $10^{-4}$. A BER below $10^{-4}$ means good reception [24]. In [45], a relation between SNR and BER is given, see Figure 4.10 for band III (mode I) and Figure 4.11 for L-band (mode 2). From this figure, one can conclude that the minimal $S N R$ for band III is $15 \mathrm{~dB}$ for code rate $\frac{1}{2}$ (i.e. protection level UEP 3 ; for the L-band it is $17 \mathrm{~dB}$.

\subsubsection{Typical sensitivity}

The minimal sensitivity that a T-DAB receiver can have in band III is the sum of thermal noise, noise figure and required SNR $-112+6+15=$ $-91 \mathrm{dBm}$. For L-band the minimal sensitivity is: $-112+6+17=$ $-89 \mathrm{dBm}$. (This is a worst case scenario of a rural area channel model with a speed of $130 \mathrm{~km} / \mathrm{h}$.)

Converted to field strength, these values are:

- band III: $41 \mathrm{~dB} \mu \mathrm{V} / \mathrm{m}$ ( $-91 \mathrm{dBm}$ (sensitivity for a rural channel model) +122 (conversion to $\mathrm{dB} \mu \mathrm{V} / \mathrm{m}$ ) +10 (Antenna Factor with regards to a dipole antenna))

- L-band: $56 \mathrm{~dB} \mu \mathrm{V} / \mathrm{m}$ ( $-89 \mathrm{dBm}$ (sensitivity for a rural channel model) +138.5 (conversion to $\mathrm{dB} \mu \mathrm{V} / \mathrm{m}$ ) +6 [45] (Antenna Factor with regards to a dipole antenna))

\footnotetext{
${ }^{2}$ After error correction, i.e. the MPEG audio stream.

${ }^{3}$ We used protection level UEP 3 in our receiver tests. See also [24].
} 


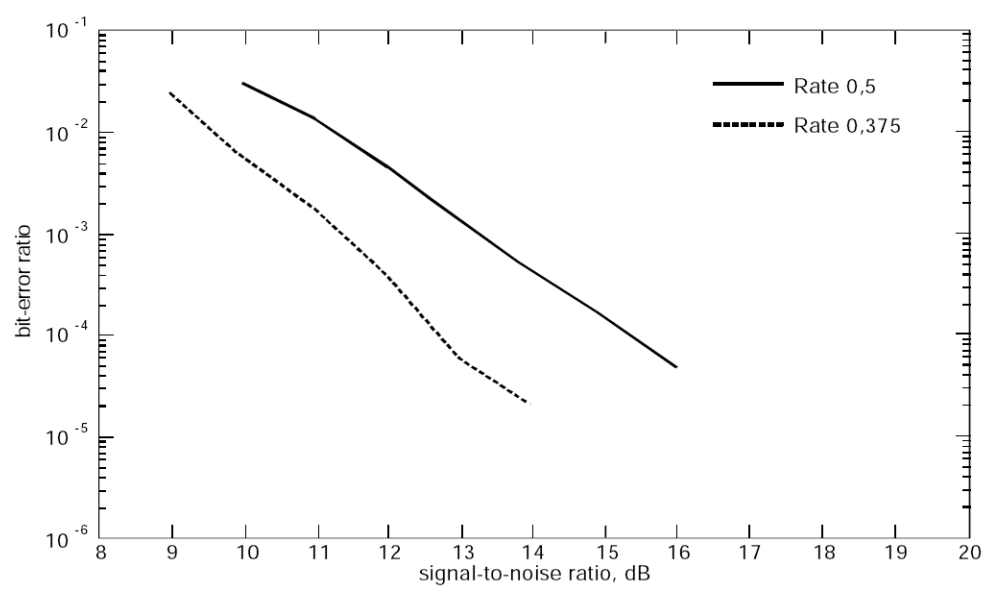

Figure 4.10: The performance of DAB in a simulated Raleigh Channel, Mode 1, Rural environment, $130 \mathrm{~km} / \mathrm{h}$ speed, Band III, taken from [45]

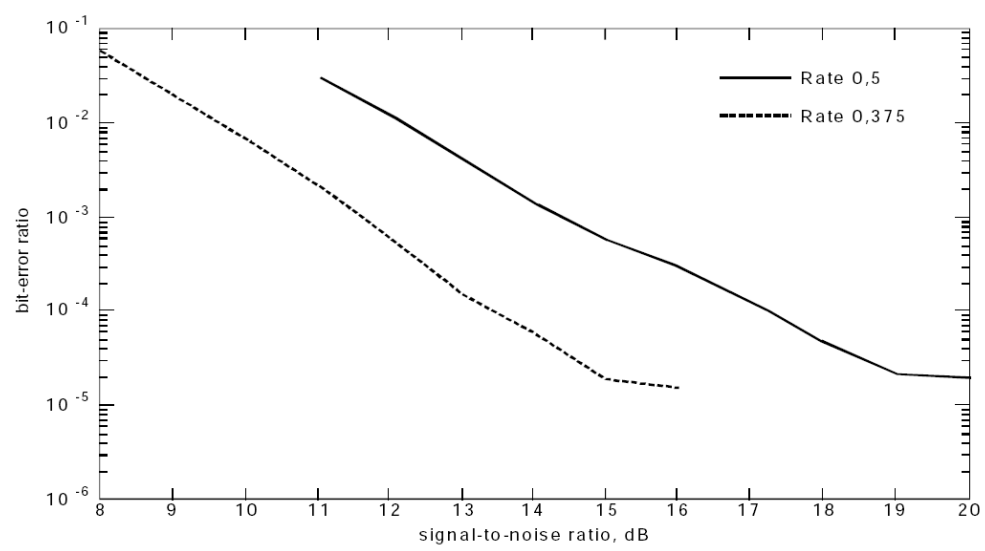

Figure 4.11: The performance of DAB in a simulated Raleigh Channel, Mode 2, Rural environment, $130 \mathrm{~km} / \mathrm{h}$ speed, L-Band, taken from [45] 
Thus, for band III, the minimal sensitivity is $6 \mathrm{~dB}$ less than the value set by the Wiesbaden agreement; for L-band the difference is $10 \mathrm{~dB}$. The sensitivity of consumer receivers will be better for another channel model (urban: band III $2 \mathrm{~dB}$ and for L-band: $5 \mathrm{~dB}$ ). Also a better (e.g. active) antenna will close the gap. The consumer receiver experiments showed that, for band III, the median receiver has a similar performance as the sensitivity derived in this section. For the L-band, however, the performance of the median receiver is, even for the urban channel model, $6.5 \mathrm{~dB}$ less than the performance of the rural channel model that is used in this section.

\section{Summary}

For a kitchen radio and assuming an urban channel model and a passive (whipe) antenna, the typically achievable sensitivity will be $39 \mathrm{~dB} \mu \mathrm{V} / \mathrm{m}$ for band III and $51 \mathrm{~dB} \mu \mathrm{V} / \mathrm{m}$ for the L-band. 



\section{Chapter 5}

\section{Summary}

With the results presented in the previous chapters, the research questions in the introduction can now be answered. For purpose of convenience, each question and related answer are located in a separate section below.

Can a T-DAB network consisting of low-power transmitters with antennas mounted at relatively low positions (i.e. the pilot network) coexist with the existing T-DAB network consisting of high-power transmitters mounted at relatively high positions (i.e. Publieke Omroep network)?

In this report, a worst case scenario was investigated involving a high-mast and high-power T-DAB network of the Publieke Omroep at channel $12 \mathrm{C}$ and the low-mast and low-power pilot network at channel 12B. In Amsterdam, the IJ-mast of the Publieke Omroep radiates its main power in a south easterly direction with $2 \mathrm{~kW}$ ERP. The transmitters of the pilot network use an omnidirectional antenna with $200 \mathrm{WERP}$.

In this setup, there is an interference area around the pilot transmitters where the strong signal of channel 12B will prevent reception of the multiplex at 12C. Due to the near vicinity of the Aambeeldstraat pilot location, there is no interference area for the pilot network around the IJ-mast. One of the solutions to suppress the interference areas is to use 
a gap filler at channel $12 \mathrm{C}$ at the pilot transmitter sites. Other possible solutions such as a smaller vertical opening angle of the antenna system were not investigated.

If no gap fillers are used, the holes in the service area of the Publieke Omroep are a circle with a radius of $\pm 800 \mathrm{~m}$ for transmitter site Diemen, $\pm 1000 \mathrm{~m}$ for Vredehof and \pm 1650 for Oostzaan. As the field strength of the Publieke Omroep is the lowest near Oostzaan, the hole in this service area is the largest. A gap filler of $880 \mathrm{~mW}$ which is $24 \mathrm{~dB}$ lower than the radiated power of the pilot transmitter, will be enough to neutralize the holes in the service area of the Publieke Omroep. The interference area around a high-power mast was not investigated, but it is expected that this interference area will be significantly larger. The T-DAB pilot network was mounted on masts of the C2000 TETRA network. The interference of the T-DAB signal on the TETRA communication system was investigated by the C2000 organization.

\section{What is the performance of consumer T-DAB receivers currently on the market compared to the reference Wiesbaden receiver?}

For band III, the median T-DAB consumer receiver has a better or equal performance than the reference receiver (using mode I) specified by the EN 50248 norm. Only for strong adjacent interferers does the median receiver have a performance up to $10 \mathrm{~dB}$ worse than required. Only the $25 \%$ best performing receivers meet the non-adjacent requirements set by EN 50248.

As the L-band is expected to be issued to one multiplex operator, the adjacent and non-adjacent interference will be caused by the same operator. For that reason, the adjacent and non-adjacent performance have no relevance for the L-band licenses. The median T-DAB L-band receiver has a better or equal performance compared to the EN 50248 norm (using mode IV), except for the rural channel model. The rural channel model mimics a rural environment at a velocity of $120 \mathrm{~km} / \mathrm{h}$. Using mode II instead of mode IV is likely to increase the performance of the receivers for this situation. This is supported by the results of a short experiment using 


\begin{tabular}{l|ccc} 
Band & $\mu$ & $\sigma$ & $95 \%$ \\
\hline band III & $-5.1 \mathrm{~dB}$ & $5.7 \mathrm{~dB}$ & $-21.9[ \pm 1.5] \mathrm{dB}$ \\
L-band LH & $-6.3 \mathrm{~dB}$ & $6.6 \mathrm{~dB}$ & $-25.8[ \pm 1.6] \mathrm{dB}$
\end{tabular}

Table 5.1: Properties of the indoor loss distributions

mode II. For in-house use, the L-band consumer receivers are expected to work properly as the channel conditions are less severe than for the rural channel model. The rural channel model is important for T-DAB car receivers. Another option is to use a lower protection level, but this also decreases the available capacity up to $30 \%$ compared with protection level UEPB.

For a kitchen radio and assuming an urban channel model and a passive (whipe) antenna, the typical achievable sensitivity will be 39 $\mathrm{dB} \mu \mathrm{V} / \mathrm{m}$ for band III (which is $4 \mathrm{~dB}$ higher than the minimum sensitivity specified in the Wiesbaden agreement); for the L-band it is $51 \mathrm{~dB} \mu \mathrm{V} / \mathrm{m}(5$ $\mathrm{dB}$ higher). The median T-DAB consumer receiver achieves the typically achievable band III sensitivity. However, for the L-band, the sensitivity of the median T-DAB consumer receiver is $6.5 \mathrm{~dB}$ less the typically achievable L-band sensitivity.

\section{What is the indoor penetration loss for both band III and the L-band?}

The indoor penetration loss depends on the percentage of the buildings that have to be covered. For good indoor coverage, it is assumed that $95 \%$ of the buildings have to be covered. Using this value, the loss for band III is $21.9 \mathrm{~dB}$ and for L-band $25.8 \mathrm{~dB}$. See also Table 5.1. (A negative value means a loss.) In this table, the values between brackets are the $95 \%$ confidence intervals. The indoor penetration loss values are slightly higher than than the values found in literature (see Chapter 3 ).

In the Final Acts of the RRC06 conference [46], an indoor penetration loss of $16 \mathrm{~dB}$ was used for band III, which is $6 \mathrm{~dB}$ less than the value derived in this report. 
Chapter 5. Summary

\begin{tabular}{c|c|c|} 
& $\begin{array}{c}\text { band III } \\
\text { outdoor }\end{array}$ & $\begin{array}{c}\text { band III } \\
\text { indoor }\end{array}$ \\
\hline $\begin{array}{c}\text { Sensitivity } \\
\text { Indoor loss (95\%) }\end{array}$ & $39 \mathrm{~dB} \mu \mathrm{V} / \mathrm{m}$ & $39 \mathrm{~dB} \mu \mathrm{V} / \mathrm{m}$ \\
99\% to $50 \%$ place & $7.0 \mathrm{~dB}(13 \mathrm{~dB})$ & $21.9 \mathrm{~dB}$ \\
\hline $\begin{array}{c}\text { Req. outdoor } \\
\text { field strength }\end{array}$ & $46.0 \mathrm{~dB} \mu \mathrm{V} / \mathrm{m}(52.0)$ & $67.9 \mathrm{~dB}(13 \mathrm{~dB})$ \\
\hline
\end{tabular}

Table 5.2: Link budget for band III

Which network architecture can provide indoor coverage that meets the current Wiesbaden agreement [2]?

A link budget has to be constructed to answer this question. For each band, two link budgets will be calculated: outdoor and indoor coverage with a portable radio (without the influence of the human body).

For band III, a consumer receiver with a whipe antenna can have a minimum field strength of $39 \mathrm{~dB} \mu \mathrm{V} / \mathrm{m}$. For the L-band this value is $51 \mathrm{~dB} \mu \mathrm{V} / \mathrm{m}$. For outdoor coverage the value is converted to $50 \%$ of the locations. The same settings were also used in the coverage measurements. Indoor coverage is calculated in a similar way, but now indoor penetration loss is added. The results are shown in Tables 5.2 and 5.3 .

For conversion from $99 \%$ to $50 \%$ of the locations (i.e. $2.33 \cdot \sigma_{\text {place }}$ ), we used values from the indoor and coverage measurements. The values between brackets are those according to the Wiesbaden agreement. Apparantly, an SFN network reduces the spatial standard deviation. The field trial yielded a spatial standard deviation of 2.2 to $2.8 \mathrm{~dB}$ (outdoor) instead of $5.5 \mathrm{~dB}$ according to Wiesbaden [2].

In the UK [29] a minimum outdoor field strength for indoor coverage of $71 \mathrm{~dB} \mu \mathrm{V} / \mathrm{m}$ was found. This value is $3 \mathrm{~dB}$ higher than the required field strength found in this report. In the Final Acts of the RRC06 conference [46] a value of $66 \mathrm{~dB} \mu \mathrm{V} / \mathrm{m}$ was derived for indoor coverage in $95 \%$ of the indoor locations. 


\begin{tabular}{c|c|c|} 
& $\begin{array}{c}\text { L-band } \\
\text { outdoor }\end{array}$ & $\begin{array}{c}\text { L-band } \\
\text { indoor }\end{array}$ \\
\hline $\begin{array}{c}\text { Sensitivity } \\
\text { Indoor loss (95\%) }\end{array}$ & $51 \mathrm{~dB} \mu \mathrm{V} / \mathrm{m}$ & $51 \mathrm{~dB} \mu \mathrm{V} / \mathrm{m}$ \\
99\% to 50\% place & $5.1 \mathrm{~dB}(13 \mathrm{~dB})$ & $5.1 \mathrm{~dB}(13 \mathrm{~dB})$ \\
\hline $\begin{array}{c}\text { Req. outdoor } \\
\text { field strength }\end{array}$ & $56.1 \mathrm{~dB} \mu \mathrm{V} / \mathrm{m}(64.0)$ & $81.9 \mathrm{~dB} \mu \mathrm{V} / \mathrm{m}(89.8)$
\end{tabular}

Table 5.3: Link budget for the L-band

For indoor coverage the outdoor field strength for band III has to be $67.9 \mathrm{~dB} \mu \mathrm{V} / \mathrm{m}$ and for L-band $81.9 \mathrm{~dB} \mu \mathrm{V} / \mathrm{m}$, for $50 \%$ of the locations and $50 \%$ of the time at an antenna height of $1.5 \mathrm{~m}$. This value can be used in coverage planning software. For bodyworn devices (mobile telephones, personal radios) these values should be increased by $10 \mathrm{~dB}$ for band III and $18 \mathrm{~dB}$ for the L-band. In received power values $[\mathrm{dBm}]$ the difference between these values is $14.0 \mathrm{~dB}$ whereas the difference in Antenna Factor (AF) is $16.5 \mathrm{~dB}$. So, the field strength requirements of the L-band network are $2.5 \mathrm{~dB}$ less than for band III.

On the other hand, this value can only be achieved if the sensitivity performance of the L-band consumer is improved. Current L-band T-DAB consumer receivers are $6.5 \mathrm{~dB}$ less sensitive than the typically achievable L-band sensitivity. Band III receivers on the other hand have a sensitivity equal to the typically achievable band III sensitivity.

Figure 5.1.5.2 and 5.3 present the current indoor reception for the three networks using the values derived in this section. In Figure 5.2 there is indoor coverage around every pilot site, because the gap fillers were switched on. With the current network configuration, there is no good indoor coverage for both band III and L-band in Amsterdam.

Good indoor coverage can be obtained by increasing the power level or using more transmitter locations. In Figures 5.4, 5.5 and 5.6, the expected indoor reception is shown when the output power of each transmitter location is increased by $10 \mathrm{~dB}$. For both band III networks this results in 
good indoor coverage. Another option is of course to use more transmitter locations. For the L-band, more transmitters as well as more output power are required for good indoor reception in Amsterdam.

However, current international regulations are based on outdoor coverage and it was decided at the RRC06 conference [46] that the interference level at the Dutch border may increase by $3 \mathrm{~dB}$ and it in particular cases by $6 \mathrm{~dB}$ to achieve indoor coverage. So, both the high-mast and low-mast topologies require more transmitter locations to obtain indoor coverage and to be in line with the RRC06 agreement. 


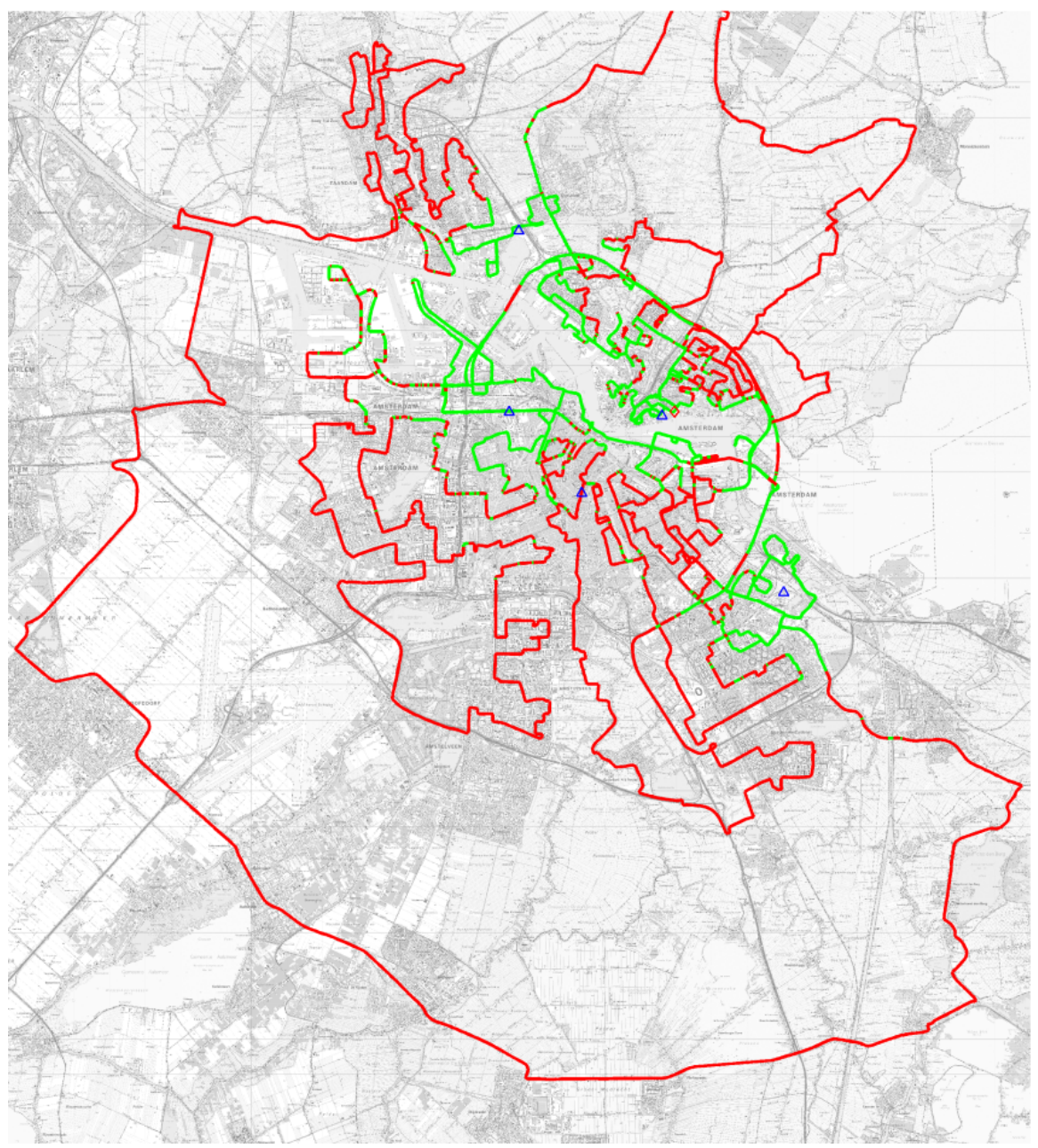

Figure 5.1: Indoor reception of channel 12B with the current pilot network configuration (green is indoor reception, red no indoor reception) 


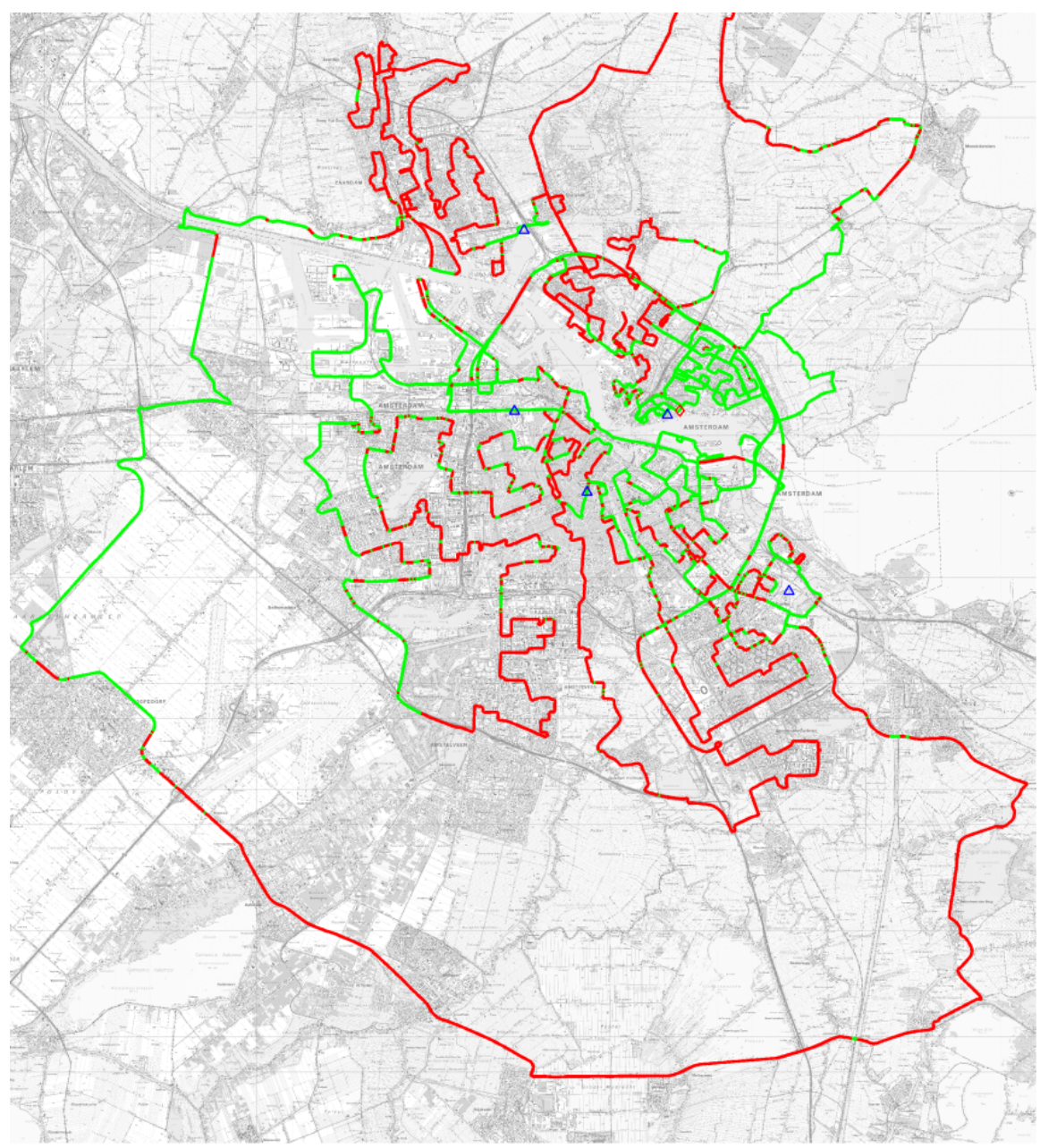

Figure 5.2: Indoor reception of channel $12 \mathrm{C}$ with the current Publieke Omroep network configuration (green is indoor reception, red no indoor reception) 


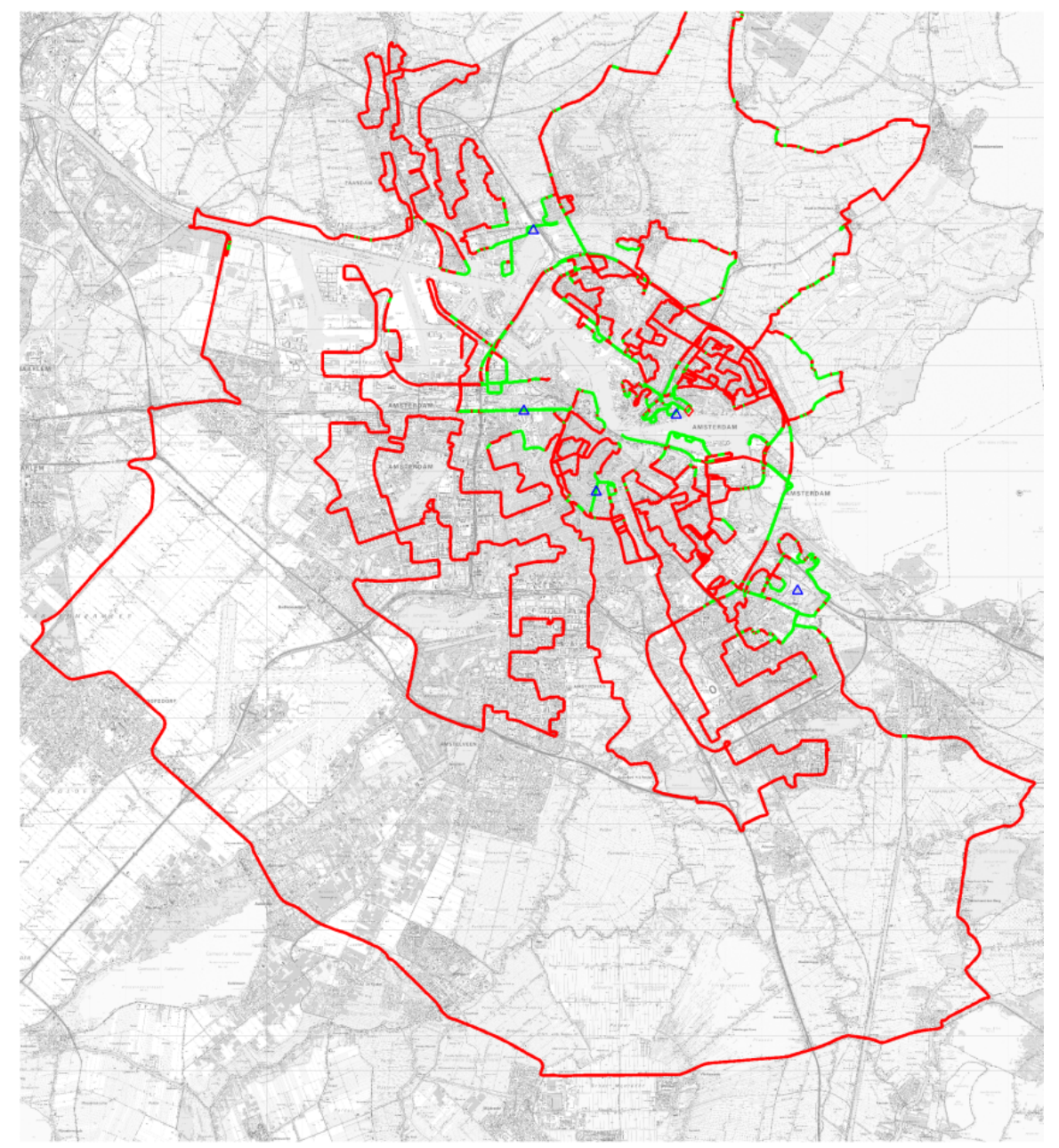

Figure 5.3: Indoor reception of channel LH with the current pilot network configuration (green is indoor reception, red no indoor reception) 


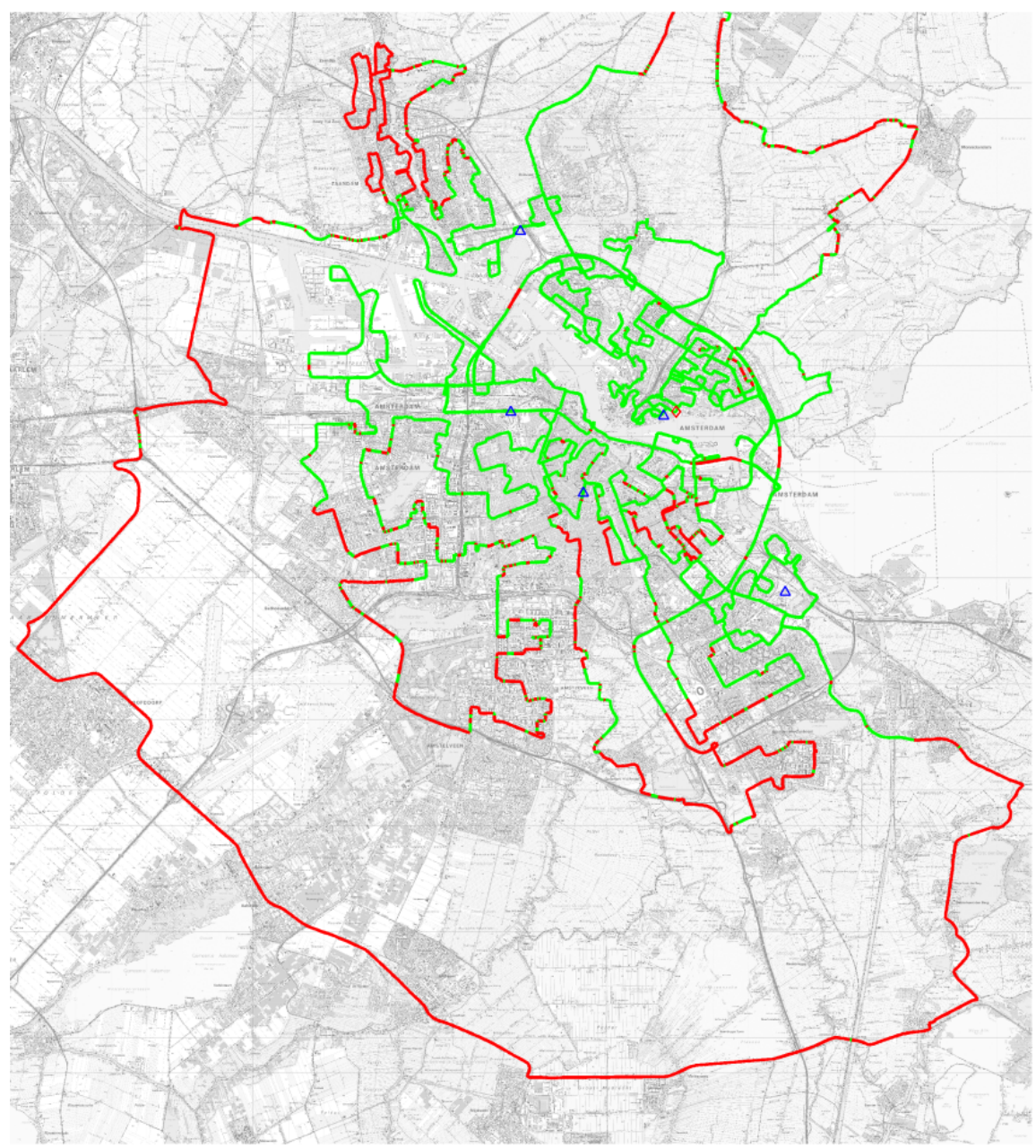

Figure 5.4: Expected indoor reception of channel 12B with the current pilot network configuration with $10 \mathrm{~dB}$ extra transmit power at each location (green is indoor reception, red no indoor reception) 


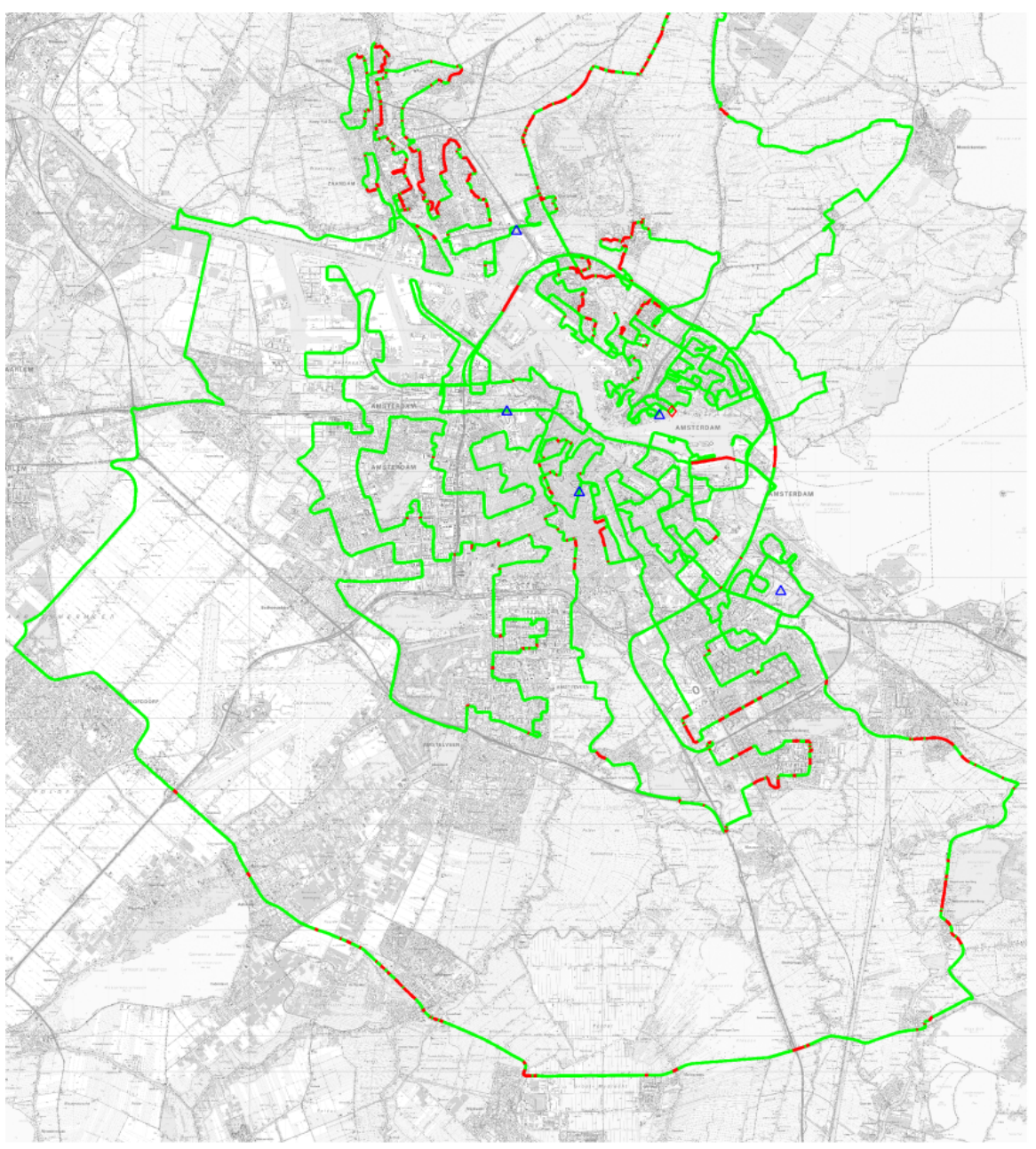

Figure 5.5: Expected indoor reception of channel 12C with the current Publieke Omroep network configuration with $10 \mathrm{~dB}$ extra transmit power at each location (green is indoor reception, red no indoor reception) 
Chapter 5. Summary

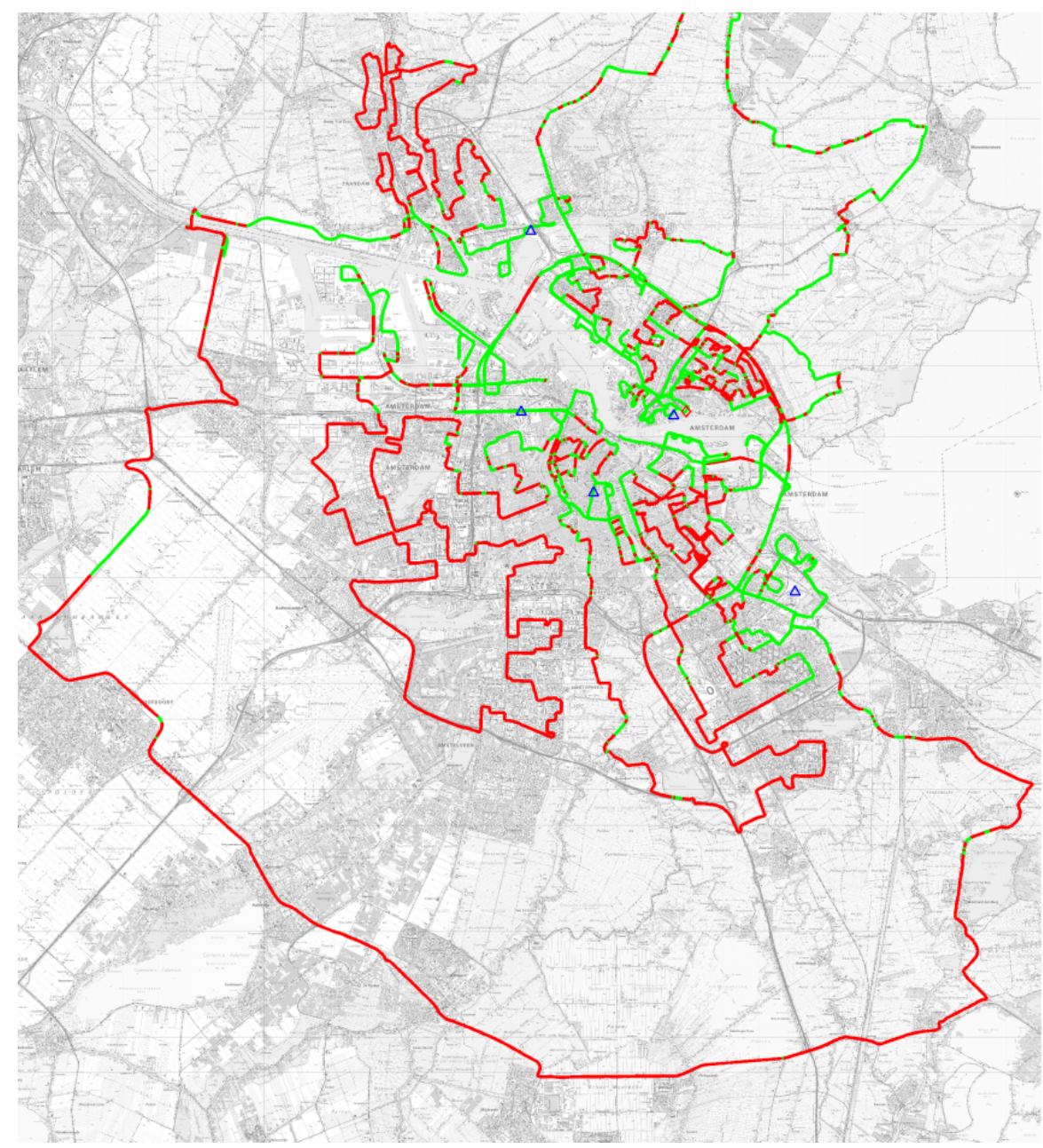

Figure 5.6: Expected indoor reception of channel LH with the current pilot network configuration with $10 \mathrm{~dB}$ extra transmit power at each location (green is indoor reception, red no indoor reception) 


\section{References}

[1] EZ. TP/OT 4051169: offerte aanvraag voor wetenschappelijk onderzoek betreffende $T D A B, 2004$.

[2] CEPT. FINAL ACTS of the CEPT T-DAB Planning meeting (3). Maastricht, 2002.

[3] J. Bach Andersen, T.S. Rappaport, and S. Yoshida. Propagation Measurements and Models for Wireless Communications Channels. IEEE Communications Magazine, January 1995.

[4] M.C.D. Maddocks, I.R. Pullen, and J.A. Green. Digital Audio Broadcasting: Measuring techniques and coverage performance for a medium power VHF single frequency network. BBC research, (2), 1995.

[5] J.A. Green. Building penetration loss measurements for DAB signals at 211MHz. BBC research, (14), 1992.

[6] M.C.D. Maddocks, I.R. Pullen, and J.A. Green. Field trials with a high-power VHF single frequency network for DAB: Measurement techniques and network performance. EBU Technical Review, (Autumn), 1994.

[7] V. Erikkilä and M. Jokisalo. DAB field trials in Finland. EBU Technical Review, (Autumn), 1994. 
References

[8] A. Lau, M. Pausch, and W. Wütschner. First results of field tests with the DAB single frequency network in Bavaria. EBU Technical Review, (Autumn), 1994.

[9] G. Chouinard, F. Conway, W.A. Stacey, and J.R. Trenholm. Digital Radio Broadcasting in Canada: A strategic approach to DRB implementation. EBU Technical Review, (Winter), 1994.

[10] ITU-R. Recommendation ITU-R P.1546-1: Method for point-to-area predictions for terrestrial services in the frequency range $30 \mathrm{MHz}$ to 3000 MHz. 2003.

[11] European Radiocommunications Committee (ERC). Field strength measurements along a route with geographical coordinate registrations, ERC/REC/(00)08. Technical report, 2003.

[12] W.C.Y. Lee. Estimate of local average power of a mobile radio signal. IEEE Transactions on Vehicular Technology, 34(1):22 - 27, February 1985.

[13] http: // www. mathworks. com.

[14] db Europe BV. Bill of Materials DAB pilot. Technical report, 2005.

[15] http: // www. plisch. de/?\&id=162\&id_ $l c=25 \&$ mo de $=i d \xi i d_{-} g o=$ 162 .

[16] http://www. anik. ca/satellites/transmissions/ delay-response-times. htm

[17] C.J. Bovy, H.T. Mertodimedjo, G. Hooghiemstra, H. Uijterwaal, and P. van Mieghem. Analysis of end-to-end delay measurements in Internet. PAM, 2002.

[18] W. Hoeg and T. Lauterbach, editors. Digital Audio Broadcasting: Principles and applications of Digital Radio. Wiley, second edition, 2003.

[19] A.A. Smith. Radio Frequency Principles and Applications. The Generation, Propagation, and Reception of Signals and Noise. IEEE Press, 1998. 
[20] ANSI. C63.5: American National Standard for Electromagnetic Compatibility - Radiated Emission Measurements in Electromagnetic Interference (EMI) Control - Calibration of Antennas (9 kHz to $40 \mathrm{GHz}$ ). 1998.

[21] A.A. Smith. Standard-Site Method for Determining Antenna Factors. IEEE Transactions on Electromagnetic Compatibility, 24(3):316-322, 1982.

[22] CEPT. FINAL ACTS of the CEPT T-DAB Planning meeting (4). Maastricht, 2002.

[23] http: //mathworld.wolfram. com/GammaDistribution. html

[24] CENELEC. Characteristics of DAB Receivers. EN 50248, 1999.

[25] ITU-R. Recommendation ITU-R P.370-7: VHF and UHF propagation curves for the frequency range from $30 \mathrm{MHz}$ to $1000 \mathrm{MHz} .1995$.

[26] B. Breton, R. Voyer, and D. Jacques. Coverage design aspects of L-band $D A B$ with transmission modes II and IV. International Broadcasting Conference (IBC), September 1997.

[27] N. Yarkoni and N. Blaunstein. Prediction of Propagation Characteristics in Indoor Radio Communication Environments. Progress in Electromagnetic Research, PIER-59, 2006.

[28] A.A. Smith. Attenuation of Electric and Magnetic Fields by Buildings. IEEE Transactions on Electromagnetic Compatibility, 20(3), 1978.

[29] S. Mason. Indoor reception of DAB - consequences for planning and implementation. EBU Technical Review, July 2004.

[30] O. Michler and M. Strey. DAB-Indoor-Versorgung im L-band. SLM, 1998.

[31] W. Dickson. T-DAB Sydney Trial: Building penetration loss Survey for band III and L-band TDAB. October 2005. 
[32] M.M. Velez, P. Angueira, D. de la Vega, and A. Arrinda J.L Ordiales. L-band DAB Eureka 147 Field Trials and Coverage Measurements in Urban Areas. IEEE Transactions on Broadcasting, 48(2), June 2002.

[33] http: // mathworld.wolfram. com/ExtremeValueDistribution. html.

[34] A. Carr and B. McLarnon. DAB-T receiver performance characterisation. International Broadcasting Conference (IBC), September 2004.

[35] M. Kahrs and K. Brandenburg, editors. Applications of Digital Signal Processing to Audio and Acoustics, chapter 1. Audio quality determination based on perceptual measurement techniques. Kluwer Academic Publishers, 1998.

[36] G.F. Pedersen, K. Olesen, and S.L. Larsen. Bodyloss for Handheld Phones. In Proceedings of the 49th Vehicular Technology Conference, volume 2, pages 1580-1584, Houston, Texas, USA, May 1999.

[37] General Electric Company. Two-way Personal Radio System Design. http://www. softwright.com/faq/engineering/Building\% 20and\%20Body\%20Loss\%20Values.html.

[38] R. Schramm. Pseudo channel BER - an objective quantity for assessing $D A B$ coverage. EBU Technical Review, Winter 1997.

[39] M.J. Norden (Astron). T-DAB field strength measurements. January 2006.

[40] M. Pätzold. Mobile Fading Channels. John Wiley \& Sons, 2002.

[41] Y.H Jeong, S.R. Park, and S.I. Lee. Evaluation of Protection Ratios on COFDM for In-band adjacent-channel Digital Audio Broadcasting. Proceedings of IEEE Region 10 International Conference on Electrical and Electronic Technology, 2001.

[42] ETSI. Radio Broadcasting Systems; Digital Audio Broadcasting (DAB) to mobile, portable and fixed receivers. ETSI EN 300 401, 2001. 
[43] Wikipedia. Johnson-Nyquist noise. http://en.wikipedia.org/wiki/ Thermal_noise.

[44] P.Z. Peebles. Probability, random variables and random signal principles. McGraw-Hill, third edition, 1993.

[45] ETSI. Digital Audio Broadcasting (DAB); Signal strengths and receiver parameters; Targets for typical operation. ETSI EN 101 758, 2001.

[46] Final Acts of the Regional Radiocommunication Conference 2006 (RRC-06). http://www.itu.int/ITU-R/conferences/rrc/rrc-06/index.asp. 



\section{Acronyms}

ACS Adjacent Channel Selectivity

AF Antenna Factor

BER Bit Error Rate

CDF Cumulative probability Density Function

CEPT European Conference of Postal and Telecommunications Adminstrations

CIR Channel Impulse Response

DA Digital to Analog

DAB Digital Audio Broadcasting

DIQ Digital baseband In-phase and Quadrature

DQPSK Differential Quadrature Phase-Shift Keying

DUT Device Under Test

ERP Effective Radiated Power

ETI Ensemble Transport Interface

FEC Forward Error Correction 
GPS Global Positioning System

GSM Global System for Mobile Communications

I/Q Inphase/Quadrature

MUSICAM Masking pattern adapted Universal Subband Integrated Coding And Multiplexing

NACS Non-Adjacent Channel Selectivity

NF Noise Figure

ODG Objective Difference Grade

OFDM Orthogonal Frequency Division Multiplexing

PC Personal Computer

PEAQ Perceptual Evaluation of Audio Quality

PRBS Pseudo Random Bit Sequence

RF Radio Frequency

SFN Single Frequency Network

SIR Signal-to-Interference Ratio

SNR Signal-to-Noise Ratio

T-DAB Terrestrial Digital Audio Broadcasting

TII Transmitter Identification Information

UEP Unequal Error Protection

SSM Standard Site Method 